\title{
PATHWAYS FROM CHILD MALTREATMENT TO JUVENILE OFFENDING
}

\author{
Dr Anna Stewart \\ Dr Susan Dennison \\ Ms Elissa Waterson \\ School of Criminology and Criminal Justice \\ Griffith University
}

This project is supported by a Grant from the Criminology Research Council. The views expressed are the responsibility of the author and are not necessarily those of the Council. 


\section{CONTENTS}

Page

List of Tables $\quad$ V

List of Figures $\quad$ vii

Acknowledgements $\quad$ viii

CHAPTER $1 \quad$ INTRODUCTION AND CONCEPTUAL ISSUES

1.1 Introduction and aims 1

1.2 Definitions and maltreatment 5

$\begin{array}{lll}\text { 1.3 Definitions and delinquency } & 7\end{array}$

$\begin{array}{lll}1.4 & \text { Methodological issues } & 9\end{array}$

$\begin{array}{lll}1.5 & \text { Summary } & 12\end{array}$

CHAPTER $2 \quad$ REVIEW OF THE RESEARCH 13

2.1 Maltreatment and common demographic characteristics 13

2.2 The relationship between maltreatment and delinquency 16

2.3 Types of maltreatment and delinquency 22

2.4 Severity of maltreatment and delinquency 25

2.5 Parenting and delinquency 26

2.6 Timing of maltreatment and delinquency 30

2.7 Severing the link: Evidence from demonstration projects 33

$\begin{array}{lll}2.8 & \text { Summary } & 39\end{array}$ 


\section{MALTREATMENT-DELINQUENCY LINK}

$\begin{array}{lll}3.1 & \text { Psychological perspectives } & 41\end{array}$

3.2 Criminological perspectives 43

3.3 Developmental criminology: Integrated perspectives 45

$\begin{array}{lll}3.4 & \text { Summary } & 50\end{array}$

CHAPTER $4 \quad$ AIMS, HYPOTHESES AND METHOD 52

4.1 Aims and Hypotheses $\quad 52$

4.2 Method 53

4.2.1 Birth cohort 53

4.2.2 Child protection system $\quad 54$

4.2.3 Child protection data $\quad 56$

$\begin{array}{ll}\text { 4.2.4 Juvenile justice system } & 59\end{array}$

$\begin{array}{ll}\text { 4.2.5 Juvenile justice data } & 61\end{array}$

$\begin{array}{lll}\text { CHAPTER } 5 & \text { RESULTS } & 66\end{array}$

5.1 Children with a child protection notification 67

5.1.1 Substantiated and unsubstantiated notifications $\quad 67$

5.1.2 Biographical details: Sex, indigenous status, and age at $\quad 69$ first and final maltreatment incident

5.1.3 Type and frequency of maltreatment incidents 73

5.1.4 Outcomes of maltreatment: Out of home placement 83

5.2 Children with a finalised juvenile justice appearance 84

5.2.1 Biographical details: Sex, indigenous status, and age at $\quad 84$ 
first offence

5.2.2 Repeat offending $\quad 86$

5.2.3 Type of offending: Most serious finalised offence $\quad 88$

5.2.4 Outcome of offending: Most serious finalised outcome $\quad 91$

5.3 The links between child protection and juvenile justice 94

5.3.1 Prospective designs 95

5.3.2 Retrospective question 99

5.4 The pathways from child maltreatment to offending 101

$\begin{array}{lll}\text { CHAPTER } 6 & \text { DISCUSSION } & 103\end{array}$

6.1 Experiences of maltreatment 103

6.1.1 Single versus repeat victimization $\quad 104$

$\begin{array}{ll}\text { 6.1.2 Indigenous status } & 105\end{array}$

6.1.3 Type of maltreatment 106

6.1.4 Out of home placements 107

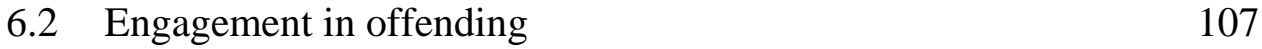

6.2.1 Frequency and outcomes of offending 108

$\begin{array}{ll}\text { 6.2.2 Offence types } & 109\end{array}$

6.3 Links between maltreatment and offending 110

6.4 Pathways from maltreatment to offending 114

$\begin{array}{lll}6.5 & \text { Limitations and further research } & 114\end{array}$

$\begin{array}{lll}6.6 & \text { Conclusions } & 117\end{array}$ 


\section{LIST OF TABLES}

Table 4.1 Police response to juvenile offending (1999-2000) 60

Table 4.2 Number of finalised appearances for an offence by most serious $\quad 64$ offence

Table 4.3 Number of finalised appearances for an offence by most serious $\quad 64$ outcome

Table $5.1 \quad$ Distinct children (1983 birth cohort) by number of notifications and 68 number of substantiated maltreatment episodes

Table 5.2 Individual children's experience with notifications by number of substantiated and unsubstantiated notifications

Table 5.3 Mean age of children at first and final maltreatment incident by sex and indigenous status

Table 5.4 Timing of maltreatment by sex and indigenous status 72

Table 5.5 Mean age at the first maltreatment incident and at the final maltreatment incident by maltreatment experience

Table 5.6 Children's experience of maltreatment by timing of maltreatment 75

Table 5.7 Children only substantiated for one type of maltreatment by 76 maltreatment type

Table 5.8 Children with multiple types of abuse by number of children and total number of maltreatment incidents

Table 5.9 Type of maltreatment (Cicchetti and Rogosh, 1997) classification 78 by number of substantiated notifications

Table 5.10 Maltreated children's experience of each type of maltreatment 79

Table 5.11 Children's timing of maltreatment by type of maltreatment 83 experienced

Table 5.12 Young offenders by sex and indigenous status 85

Table 5.13 Multiple finalised appearances where an order was made by number $\quad 87$ of children

Table 5.14 Mean number of finalised appearances by age of first offence, indigenous status and sex

Table 5.15 Children with only one type of finalised offence by most serious finalised offence 
Table 5.16 Offence type by number of offences by appearance number 90

Table 5.17 Most serious outcome from the court by court appearance number 91

Table 5.18 Most serious outcome for a child by mean number of finalised 92 appearances

Table 5.19 Most serious outcome for a child by indigenous status 92

Table 5.20 Most serious outcome for a child by sex 93

Table 5.21 Most serious order the child received by age of child at first 93 appearance

Table 5.22 Children in the 1983 birth cohort with a child protection notification 94 and/or a finalised juvenile justice appearance for an offence

Table 5.23 Number of children notified by outcome of notification and juvenile 95 justice appearance

Table 5.24 Logistic regression analysis of offending status as a function of child protection notifications

Table 5.25 Logistic regression analysis of child protection status as a function of offending appearances

Table 5.26 Children who offended and had a child protection history by sex and indigenous status. 


\section{LIST OF FIGURES}

Figure 4.1 Number of children who were subject to notifications in Queensland $(1983-2000)$

Figure 4.2 Child protection records: Age of the birth cohort at notification of maltreatment

Figure 4.3 Number of juvenile appearances for an offence matter in Queensland (1993 - 2000)

Figure 4.4 Finalised appearances for the birth cohort by age of the child 63

Figure 5.1 Age of child at first maltreatment incident and final maltreatment incident

Figure 5.2 Maltreatment experience by indigenous status 73

Figure 5.3 Children's experience of maltreatment (Cicchetti \& Rogosh, 1997) by sex

Figure 5.4 Children's experience of maltreatment (Cicchetti \& Rogosh, 1997) by indigenous status

Figure 5.5 Children's experience of maltreatment (Cicchetti \& Rogosh, 1997) by mean age of the first and final maltreatment incident

Figure 5.6 Age of children at first finalised appearance 


\section{Acknowledgements}

The authors thank the staff at the Department of Families who generously gave their time to provide us with the data for this study. In particular, we would like to extend our thanks to Rob Spencer and Julie Pesch who spent countless hours making sure we had the data that we needed.

We would also like to thank the Criminological Research Council for their support of this project. 


\section{CHAPTER 1: INTRODUCTION AND CONCEPTUAL ISSUES}

\subsection{Introduction and Aims}

In recent years the life course or developmental criminology perspective has begun looking at criminal behaviour in terms of criminal careers. This position simply suggests that offending begins at one point in time and ends at another and will vary according to the frequency and seriousness of juvenile offending, depending on the individual and their circumstances. Thus the emerging field of developmental criminology has focused researcher's and policy maker's attention on the differential impact of criminogenic life experiences at different points in the developmental timeline (Loeber \& Stouthamer-Loeber, 1996). Central to these inquiries are the factors that lead to the onset and desistance of criminal behaviour. The Developmental Crime Prevention Consortium (1999) argues "to uncover significant risk factors that are the facilitating conditions for entry into a criminal career requires a life course perspective that views each potential young offender as someone who is developing over the life course and in specific social settings” (p. 4).

It is not merely the presence of risk factors early in life that produces pathways to offending. Rather developmental criminology emphasises the interrelationships of both risk and protective factors and the life transitions that children and young people move through. These children's trajectories or paths are not fixed or determined, instead they are based on a range of factors with some outcomes becoming more probable and other outcomes becoming less probable (Kazdin, 1997). Developmental crime prevention refers to interventions aiming to reduce risk factors and promote protective factors (Tremblay \& Craig, 1995). To demonstrate this perspective, the first instance of child abuse or neglect, or the first contact with police or 
the justice system, are transition points in the child's life. At these crucial times a child or youth may travel down one pathway or another, with one potentially leading to criminal behaviour. These transition points are times at which intervention in the child's life might be most effective, as intervention may buffer the child from proceeding down a negative pathway through providing protective mechanisms such as support, advice, safety or opportunities.

Relevant to the criminal careers and life course perspective is the suggestion that there are two types of offenders: the life-course persistent type, who start engaging in delinquent behaviour and offending early in life and offend for a long period of time; and the adolescent limited type, who offend for a short period of time mainly during adolescence (Moffitt, 1993). It is thought that early neuropsychological problems, personality characteristics and other negative childhood experiences may contribute to an individual being a persistent offender over the life-course. Although not specifically identified by Moffitt (1993), maltreatment is one negative experience that may have a profound impact on children's developmental paths. A number of both cross-sectional and longitudinal studies had reported that adolescents who experience maltreatment as children, whether it is abuse or neglect, have a greater likelihood of becoming juvenile offenders (e.g., Alfaro, 1981; Bolton, Reich \& Gutierres, 1977; Brown, 1984; McCord, 1983; Smith \& Thornberry, 1995; Weatherburn \& Lind, 1997; Widom, 1989).

However, as not all abused and neglected children proceed to later offending, it is important to identify those factors associated with the maltreatment specifically, and in the child's social setting more generally, that may influence the pathways of children. What happens at each transition point also depends on earlier life experiences and whether the person is 
equipped to deal with challenges. The type of past experiences can produce either cumulative risk or protective factors, and can affect future transition points. For example, a child who has been maltreated may have low self-esteem, poor family support and advice, which may eventually lead to weak bonds with school and other community services, and therefore possess multiple risk factors for criminality (Developmental Crime Prevention Consortium, 1999). Early intervention in the form of an introduction of protective factors for children exposed to abuse and neglect may have immediate effects as well as long-term benefits by reducing what could potentially have been an accumulation of risk factors.

The purpose of this research is to examine in detail the risk factor of child maltreatment and the effect maltreatment has on engagement in juvenile offending. Understanding the relationship between child maltreatment and juvenile offending has important implications for understanding the manifestation of criminal behaviour as well as implications for child protection initiatives and crime prevention strategies. While the link between child maltreatment and juvenile offending has been supported by various studies, there is less known about the impact of the maltreatment on the nature and duration of the offending. Concerted attention also needs to be directed towards establishing causal influences. Much of the research on trajectories from maltreatment to juvenile offending is correlational and what is often not clear is the causal evidence that risk factors, such as maltreatment, produce delinquent outcomes. Even those studies that are longitudinal are restricted to measures at Time 1, Time 2 and so on, which do not produce a dynamic account of risk factors as they accumulate and interact.

As a way to move forward our understanding of outcomes of maltreatment and trajectories to offending this research examines the relationship between the accumulation of maltreatment 
and the onset and nature of juvenile offending. The focus of the study is the first 17 years of life of a birth cohort with data including every notification of neglect or abuse, and/or appearance in court as a juvenile. The study has three aims. The first aim is to examine the nature and frequency of individual children's experiences with the child protection and juvenile justice systems. Of particular interest is the extent of repeat victimisation and repeat offending. The second aim is to look at the relationship between child maltreatment and juvenile offending. A prospective focus examines whether children who have been maltreated are more likely to offend in adolescence than children for whom there is no evidence of maltreatment. A retrospective focus compares offending behaviour of children who had been maltreated with children who were not maltreated. The third aim is to examine pathways from child maltreatment to juvenile offending. Specifically, we will focus on the timing, frequency and type of maltreatment and subsequent outcomes for children. Of interest is whether clusters of children with similar maltreatment experiences follow the same trajectories into adolescence.

Chapter 1 reviews the methodological and conceptual issues related to research in the area of maltreatment and delinquency. This chapter sets the context for the present research by addressing definitional and measurement issues. Chapter 2 examines the empirical evidence for a link between child maltreatment and juvenile offending by reviewing correlational, longitudinal and intervention research. Chapter 3 reviews existing theoretical explanations for a progression from maltreatment to subsequent offending and outlines how the present research fits within and contributes to the developmental criminology framework. Chapter 4 describes how the current study was conducted, while Chapter 5 reports the findings of the research. A discussion of how the findings tie in with past research and the trajectories model 
of juvenile offending is contained in Chapter 6, alongside recommendations for future research and intervention approaches with maltreated children.

\subsection{Definitions and maltreatment}

When reviewing the literature in this area, it is important to keep in mind the various methodological limitations and variations that plague such research. Such methodological considerations are both specific and general. The application of questionable research methods may apply to certain, specific studies, while the problem of defining maltreatment and delinquency across jurisdictions and across studies is a limitation regarding the generalisability and comparability of all studies in the area, including those with otherwise sound methodologies.

The more broad definitional constraint of maltreatment will be considered first. In regard to maltreatment, research has employed and focused upon varying subtypes. Early studies in particular focused on abuse, including physical, emotional, and sexual abuse as well as neglect under the one blanket term (see Garbarino \& Plantz (1986) for a review). Many studies during the last 20 years have differentiated maltreatment into either two categories: physical abuse and neglect, or three categories: physical abuse, neglect or sexual abuse. This type of categorisation largely reflects the definitions and categories that have been adopted by government agencies processing cases of maltreatment. It has been pointed out however, that reliance on such official data and the respective categories can cause further problems in comparability (Leiter, Myers \& Zingraff, 1994). This is largely because the requirements for classification as one type or another may differ across jurisdictions so that, in effect, categories with the same label are not necessarily referring to the same maltreatment 
problems. Furthermore, agency-processing practices may also effect such categorisation. For example, Crouch \& Milner (1993) claim that there is some evidence of agencies classifying a child as neglected when it is actually suspected that they are abused but physical evidence of such abuse is lacking. However, it should not be assumed that the lack of comparable definitions only applies to official data. In self-report studies utilising interview or questionnaires, the measures used to ascertain maltreatment status are varying and often study specific (Crouch \& Milner, 1993).

More specific categories of maltreatment have also been identified. In the early 1990s, Cicchetti, Barnett and associates developed a classification system for maltreatment including seven different types of maltreatment: physical abuse, sexual abuse, emotional maltreatment, moral/legal maltreatment, educational maltreatment, physical neglect, and lack of supervision (Barnett, Manly \& Cicchetti, 1993). Attention has also been directed towards specific forms of neglect. Conceptually overlapping with Cicchetti and Barnett's classification system, Zuravin and Taylor (1987, cited in Crouch \& Milner, 1993) identified eight different types of neglect: physical health care, lack of medical health care, inadequate supervision, child abandonment, shelter hazards, lack of household sanitation, lack of hygiene, and lack of nutrition. Other commonly identified forms of neglect include educational neglect and emotional neglect. Use of such specific categorisations somewhat restricts methodological options. Self-report appears to be the most suitable form of data collection however, again, problems of different conceptualisations and measurement techniques arise. In order to capture many of the specific categories of maltreatment or neglect using official data, this would require access to very detailed case histories and, again, would be determined by the judgement and information available to the researcher involved. 
As a final comment regarding the conceptualisation of maltreatment, it is interesting to note that the dimensions of severity, frequency, duration and number of different types of maltreatment have also been considered in more recent studies. In the Cicchetti and Barnett classification system, exemplars of five different levels of severity are provided in order to score individual incidents of maltreatment. According to such a specific classification system (in combination with types of maltreatment), several sub-types of maltreatment would be derived. This leads to methodological problems in itself in that a very large sample would be required to make any comparison meaningful. Furthermore, access to such large numbers of detailed case histories (if official data were to be used) would again make any such study somewhat cumbersome and subject to some degree of coder judgement. Finally the problem arises of what to do with those cases that fit into more than one category. Previous research has adopted one of four options: to delete the case from analysis, to place the case in the 'most serious' category to which it applies, to categories the case according to the earliest incidence of maltreatment, or to count the case in all applicable categories. Clearly there are limitations with whichever classification system is used, with the optimal system probably dependent on the richness of the information available. However, conceptual and definitional difficulties do not only arise in regard to maltreatment.

\subsection{Definitions and delinquency}

Delinquency and offending behaviour have also been conceptualised and measured differently across studies (Garbarino \& Plantz, 1986). Definitions are often reliant on the point at which data is collected during the juvenile justice process. Some studies measure how many official police contacts an individual has had, others look at court appearances while others look at the number of convictions an individual has had (see, for example, 
Weatherburn and Lind, 1997; Zingraff, Leiter, Johnsen and Myers, 1994). This difference in measurement of the dependent variable means that many studies are not comparable and have produced vastly different estimates of both delinquency and the relationship of maltreatment to delinquency (Garbarino \& Plantz (1986). A similar difference arises when self-report data is used as opposed to official data.

The measurement of delinquency also varies depending upon what types of behaviour are included in the researchers' definition of delinquency (Garbarino \& Plantz, 1986). Some researchers do not include status offences or traffic offences in their analysis as these are not always considered to be serious offending behaviour (Farrington, 1995), while other studies include all types of offending for analysis (Barnes \& Farrell, 1992; Brown, 1984). Furthermore, while some studies only report on one general 'offending behaviour' variable (Zingraff et al, 1994; Leiter et al, 1994), others are more specific, reporting on various categories of offences such as personal or violent offences and property offences (Weatherburn \& Lind, 1997; Smith \& Thornberry, 1995; Widom, 1989). While more specific categories are generally agreed to be more appropriate, the division of offences into types presents methodological difficulties similar to those outlined for the division of maltreatment, namely the size of the data set, coder agreement and arriving at meaningful interpretations of the data. Further difficulties with classification arise when multiple charges and offence types are evident for one individual.

The above-mentioned difficulties, while not necessarily representing flaws in individual studies, highlight more general methodological concerns in the area that make comparability of findings difficult as well as establishing a consensus or status-quo as to the nature of the 
relationship between maltreatment and delinquency. There are however, other methodological concerns that are specific to the strategies employed in various studies.

\subsection{Methodological Issues}

Many of the early studies exploring the relationship between maltreatment and offending behaviour were retrospective studies consisting of small sample groups, such as case studies of clinical samples and interviewing samples of incarcerated offenders (Kratcoski, 1982; Post, 1982; Duncan \& Duncan, 1971; all cited in Garbarino \& Plantz, 1986). This methodology rendered very high associations between the two variables and, while drawing attention to the importance of further study in this area, such studies have since been considered methodologically unsound (Crouch \& Milner, 1993; Smith \& Thornberry, 1995; Widom, 1994; Zingraff, Leiter, Myers \& Johnsen, 1993). One of the reasons for this is that when retrospective studies are conducted using a sample group such as incarcerated offenders, the estimated strength of the relationship appears higher than it actually is. In a recent study by Weeks and Widom (1998) 68\% of a sample of 301 incarcerated adult male offenders reported some form of childhood victimisation. However, while many offenders may have a history of maltreatment, it is not true that most maltreated children will later offend (Widom, 1994). Thus, in estimating the magnitude of the relationship between maltreatment and delinquency, and in identifying protective and risk factors, prospective studies have been judged to be far more appropriate.

Further difficulties inherent in some retrospective studies include the utilisation of self-report methods. This is because events may be forgotten or reframed to accord more with current life circumstances and perceptions (Widom, 1989). It has also been suggested that groups 
such as those who are incarcerated may also present their past in the most favourable light (Widom, 1989). For example, they may report maltreatment when none existed in order to provide an excuse for their current behaviour. Thus, in a retrospective, self-report study there are many potential confounds, although whether these will result in under or over reporting of maltreatment instances is not always clear.

Self-report data can be problematic whether it is retrospective in nature or not. First, selfreport represents the perceptions and interpretations of one person, which may not provide a valid representation of the whole picture. Second, the effect of social desirability may impact on reporting, particularly in such condemned and potentially shameful situations as maltreatment and delinquency. Researchers using self-reports of delinquency have claimed that this method of data collection may be more accurate than official records for identifying minor offences. However, it is thought that self-report measures are less accurate when it comes to serious offences (Widom \& Ames, 1994). At the same time, official data also has its strengths and weaknesses. First, those cases that are brought to the attention of authorities and then processed through official agencies are likely to represent more serious cases of both maltreatment and delinquency (Widom, 1989) and may only represent a fraction of actual incidences. This means that those studies utilising official data will not accurately represent rates of occurrence in the general population. Some have suggested that this may lead to under-representation of the relationship between maltreatment and delinquency (Leiter at al, 1994). Second, it has been suggested that official data over-represents those with a low socioeconomic status because of bias in agency activity (Brown, 1984).

Another limitation of many studies is that they are correlational in nature and lack the use of inferential statistics from which cause may be derived (Garbarino \& Plantz, 1986). 
Correlational data also tends to be drawn from one point in time rather than over time as in longitudinal studies (Widom \& Ames, 1994). As such, it contains temporal ambiguity, where it is not known whether instances of maltreatment preceded instances of delinquency. Thus while many hold the view that maltreatment leads to delinquency, such studies cannot answer critics who are proponents of the perspective that some forms of delinquent behaviour may actually cause (directly or indirectly) incidents of maltreatment to occur. Utilising data from the Pittsburgh Youth Study, Stouthamer-Loeber and associates found that while most Child Youth Service contact tended to precede or co-occur with the onset of overt and covert problem behaviours, in about half of the cases contact with the Child Youth Service was preceded by behaviours demonstrating authority conflict (Stouthamer-Loeber, Loeber, Homish \& Wei, 2001). Establishing temporal order is therefore an important issue in study design, which has been addressed by some researchers by restricting the age range for maltreatment and delinquency incidents so that one precedes the other respectively (Smith \& Thornberry, 1995; Widom, 1989).

A further consideration in methodological design is that variables associated with delinquency extend beyond measures of maltreatment. Additional variables include age, race, sex, socio-economic status and family structure. This highlights the need for appropriate control groups to be used in studies to ensure that these variables are taken into account and controlled for. The lack of matched cohorts or other appropriate control groups is a common criticism of research into the association between maltreatment and delinquency (Crouch \& Milner, 1993; Garbarino \& Plantz, 1986). A similar problem revolves around the fact that many participants who have been maltreated and/or delinquent come from multi-problem families (Widom, 1994). Isolating the effect of one factor can be difficult. As such, many 
studies have been criticised by reviewers for being too simplistic and not considering or controlling for possibly intervening or confounding variables.

\subsection{Summary}

Whether reviewing the literature on maltreatment and delinquency or designing a study aimed at examining this link in a way that moves knowledge in the area forward, definitional constraints and methodological limitations need to be identified. In short, prospective studies are preferred to retrospective studies, as they tend to more accurately reflect the proportion of children who are maltreated and later offend. Studies that measure the incidence and type of maltreatment and offending at various points throughout the youth's life are preferred to correlational studies which take a snapshot of a person's life, as they provide indicators of the causal influences of delinquency and offending. Numerous methods exist by which to categories the type and severity of maltreatment. While a more extensive categorisation system may be more informative in terms of discerning the effect of types of maltreatment on later offending, this categorisation system should also be guided by the sample size and the ability to statistically analyse and interpret outcomes. The methodology of the present research is guided by, and acknowledges, the methodological limitations of maltreatment and delinquency research. 


\section{CHAPTER 2: REVIEW OF THE RESEARCH}

\subsection{Maltreatment and common demographic characteristics}

Before addressing the link between maltreatment and delinquency, it is important to consider the background characteristics common among those who have been maltreated. An identification of similarities between maltreated children is relevant in considering how risk factors accumulate and affect children's trajectories into adolescence.

In his investigation of the link between maltreatment and delinquency, Alfaro (1981) found that children reported as abused or neglected and children reported as delinquent or ungovernable come from similar families. Such families are also significantly different from the general population in that they are larger, have a greater percentage of illegitimate children, and a greater percentage of one-parent households. Minority groups were also overrepresented. Similarly, in their investigation of the relationship between maltreatment and delinquency, Smith and Thornberry (1995) found significant differences demographically between those children who were maltreated and those who were not. Such differences occurred according to underclass status (19.5\% maltreated compared to $8.2 \%)$ and family structure $(18.6 \%$ maltreated in families that were not intact compared to $3.2 \%$ for intact families). In their review of the literature, Weatherburn and Lind (1997) point out that aggregate level studies almost universally show a strong positive association between measures of economic stress and reported rates of child maltreatment. According to Vondra (1990), increased irritability, arbitrary discipline, conflict and physical punishment appear to be common parental responses to economic stressors. Vondra (1986) goes so far to say that child maltreatment can be thought of as "a symptom of stressors resulting from adverse socio-economic conditions” (p. 193). 
Thus it appears that a high stress environment characterises the familial background of those who have been maltreated. Garbarino and Guttman (1986) found that high risk families were larger, had more remarriages, may be chronically enmeshed, have higher discipline and parental conflict and a greater number of life changes. Stressors may be both economic and social as geographic mobility and social support have also been identified as predictors of rates of maltreatment. According to research conducted by Garbarino (1976), the amount of social support available influences rates of maltreatment in a community. Social support systems for the parenting function were examined across 58 New York State counties. The degree to which mothers in a particular county are subject to socio-economic stress without adequate support systems accounted for a substantial proportion (36\%) of the variance in rates of child abuse/maltreatment across counties while economic conditions more generally affecting the family accounted for $16 \%$ of the variance.

From the above findings it appears that the presence or absence of support systems is an important variable in identifying high-risk families. This conclusion is echoed by Weatherburn and Lind (2001) who, following a review of previous research, suggested that "poverty and unemployment are probably less likely to lead to child maltreatment in families which have strong social supports but more likely to lead to maltreatment among parents or caregivers whose parenting is already weakened...” (p. 42).

Other factors have also been investigated in relation to maltreatment. Schellenbach and Krejci (1986) report that abusive families tend to interact less frequently and are more negative in their interactions. In particular, physical abuse tends to occur in families described as verbally impoverished and with highly negative patterns of interactions. 
Differences in abuse and neglect have also been examined according to family functioning and characteristics. In a review of 29 studies regarding the fertility outcomes of maltreating families, Zuravin and Taylor (1987, cited in Widom, 1994) found that neglecting parents tended to have more children and began having children earlier than abusive parents. As an overall pattern, both abusive and neglecting families were found to have children at a younger age, had children closer together, and the children were more likely to have different fathers.

Despite the aforementioned findings, it is important to emphasise that most families who are 'high risk' by definition do not maltreat their children. Further, although the common background characteristics of those who have been maltreated and those who become delinquent are similar, the majority of those who are maltreated do not become delinquent (Widom, 1994). Although this does not necessarily mean that children who do not go on to offend have gone on to lead happy, healthy and productive lives. For example, in a longitudinal study McCord (1983) reported that approximately half of the abused and neglected boys had been convicted for serious crimes, become alcoholics or mentally ill, or had died when unusually young. So we must be careful not to assume the outcomes for children who did not become juvenile offenders.

It is also worth noting that families in which only adolescent abuse occurs differ both in demographic characteristics and in the type of maltreatment from families in which younger children are abused. Children who experience abuse only in adolescence are more likely to have married parents (or step-parent), and parents with higher levels of education, employment and income. It is also the case that for sexual abuse (particularly for girls), perpetrating fathers tend to have different demographic characteristics compared to those 
who commit other types of abuse. This may account for some of the differences between adolescent versus child abuse (Vondra, 1986).

\subsection{The relationship between maltreatment and delinquency}

In one of the earliest large prospective studies in the area, Bolton, Reich \& Gutierres (1977) identified a sample of 5,392 children reported for maltreatment in Arizona. A comparison group of 900 non-maltreated siblings were also identified. In regard to later offending, it was found that $16 \%$ of the maltreated group had juvenile court records for delinquency compared to $8 \%$ of the non-maltreated group. This research design has strengths in that the use of siblings controls for the confounding effect of many demographic variables. However, whether such siblings provide a valid control group is questionable.

Later, Alfaro (1981) investigated the relationship between child abuse and neglect and subsequent socially deviant behaviour. Data was collected from the child protection and court systems in eight New York counties in two different samples. The first sample involved 3,637 children from 1,423 families who had been reported to child protection in the 1950s. Court histories were then checked for these individuals. The second sample consisted of 1,963 children who had been reported as delinquent or nongovernable in the 1970s. The histories of these individuals were then checked to see if there were any reports of neglect or abuse. Authorities knew approximately 19\% of the 1950s follow-up group (with differences across location and gender). As many as $50 \%$ of the families reported for child abuse or neglect had at least one child who was later taken to court as delinquent or ungovernable. In the 1970s delinquent sample, it was found that a significant percentage had previously been reported as abused or neglected. 
In a study of 110 ninth graders, Brown (1984) examined the links between emotional abuse, physical abuse, neglect and self-reported delinquency. Both neglect and emotional abuse were positively correlated with all forms of delinquent behaviour examined. While physical abuse was not appreciatively correlated with any of the forms of delinquency, the relationships between neglect, emotional abuse and delinquency held even when social class was controlled. In a study conducted by Weatherburn and Lind (1997), it was similarly found that neglect was more strongly related to later deviance than the experience of physical abuse on an aggregate level. Thus there is some evidence that child abuse is not as strong a predictor of offending behaviour as child neglect. However, as Weatherburn and Lind point out, it should be remembered that those children who are abused are nonetheless at increased risk of engaging in criminal activity.

In 1989, Widom reported the results from a prospective study based on a large sample $(\mathrm{N}=$ 908) of substantiated and validated cases of physical and sexual abuse and neglect from the years 1967 to 1971 . Official criminal histories were collected for this group and for a control group of 667 individuals matched according to age, sex, and race. Criminal records included those for both juvenile and adult offending while maltreatment records were only utilised for cases that occurred before age 11 to establish temporal order. Findings indicated that the number of individuals with an adult criminal record was significantly higher for the maltreated sample compared to the control group. The number of arrests was also significantly higher for the maltreated group.

A logit analysis revealed that the odds of having an adult criminal record were 1.72 times higher for the abused/neglected group than the control group. Findings also indicated that the group at highest risk for criminality was older, black, abused or neglected males. Greater risk 
for maltreated children was found in relation to offending behaviour as an adolescent as well as when an adult. Results indicated that early childhood victimisation significantly increased the risk for an arrest during adolescence by more than 50\% (26\% vs $17 \%$ ). Maltreated children also began offending activity almost one year earlier than the control subjects at 16.5 and 17.3 years respectively. The maltreated group also had approximately two times the number of arrests compared to the control group. The overall pattern of maltreated children being at greater risk for arrest as a juvenile was evident across genders. The risk of juvenile arrest for females increased from 11\% (controls) to 19\% (maltreated group), which represents an increase of $73 \%$. The risk of juvenile arrest for males increased from $22 \%$ (controls) to $33 \%$ (maltreated group) which represents a 55\% increase in risk. Arrest data was again gathered for this group in 1994 when less than 1\% of the sample had not yet turned 25 years (the end of the peak offending period). Analysis of this data revealed that being abused or neglected as a child increased the likelihood of arrest as a juvenile by $59 \%$, as an adult by $28 \%$, and for a violent crime by $30 \%$. It is interesting to note however, that roughly the same proportion of abused and neglected children and controls that had juvenile arrests also had arrests as adults (71\% and 66\% respectively) (Widom \& Maxfield, 2001). While Widom’s (1989) study utilised a sample of validated and substantiated maltreatment cases, providing a valid sample, it should also be reiterated that many cases of maltreatment are never reported or do not proceed to the courts even when they are reported. Therefore Widom's sample may represent more severe or repeated cases of maltreatment. The severity of maltreatment may be associated with an increased risk of offending.

Smith and Thornberry (1995) reported on a study that examined the impact of childhood maltreatment on delinquency while addressing several methodological weaknesses in previous studies. One such weakness is the lack of prospective, as opposed to retrospective, 
self-report studies. As such, Smith and Thornberry (1995) examined the proposed relationship between maltreatment and delinquency using both official and self-report data. Data was sourced from the Rochester Youth Development Study, a study that employed a representative sample not preselected on the basis of maltreatment or delinquency. There was a significant bivariate relationship between maltreatment and the likelihood of official delinquency. Forty-five percent of maltreated participants had a contact record compared with 32\% of non-maltreated participants. This relationship was significant even when control variables of race, sex, underclass status, and family structure were held constant. Similarly, there was a significant relationship between maltreatment and self-reported delinquency. However, when control variables were held constant, only two of the self-report scales remained significant, these were moderate and violent delinquency. There was a maltreatment effect on the frequency of contact with the justice system. Maltreated participants had an average of 1.4 contacts with the justice system while non-maltreated participants had an average of 0.8 , a significant difference that was maintained with control variables.

In terms of the pathway from child maltreatment to juvenile offending, this is generally not considered to be a direct one. As noted previously, economic and familial stresses often form the backdrop to children who have been mistreated. Weatherburn and Lind (1997) explored the pathway from socio-economic status to delinquency in an investigation of whether this relationship is mediated by abuse or neglect (rather than by general parenting skills). This study was conducted at an aggregate level and as it utilised data from New South Wales, is probably the most relevant to the current investigation of those studies reviewed. The basis of this study is that low socio-economic status increases the risk of child neglect and other forms of harsh parenting (because of strain and the 
tendency for single parent families and a larger number of children). These types of parenting are known to increase the risk of juvenile crime. The question arises as to how much of the effect of socio-economic status on delinquency can be explained by the effect of socio-economic status on child neglect and abuse?

Official data was used to test this question on an aggregate level. All notifications of abuse or neglect, whether substantiated or not were recorded, from notifications to the New South Wales Department of Community Services between July 1986 and June 1991. Involvement in crime was measured according to a record of appearances for all court cases finalised from July 1990 to June 1995. Socio-economic data was sourced from the "Community Profile" which is part of the Australian Bureau of Statistics census data collected in 1991.

Juvenile participation in crime was positively correlated with the socio-economic stress measures of poverty, unemployment, single parent families, residential stability, and crowded dwellings. Rates of reported child abuse and neglect were also positively correlated with these measures of social and economic stress. Further, juvenile participation in crime was positively correlated with rates of reported neglect and abuse. Postcodes with high levels of socio-economic stress also tend to have high rates of child maltreatment and high rates of juvenile criminal behaviour.

Regression analysis was used to identify explanatory variables for several different relationships. Poverty, single parent families and crowded dwellings were found to be the best socio-economic explanatory variables for juvenile participation in crime. Together these three measures accounted for $56 \%$ of the variation across postcodes in the level of juvenile participation in crime. In regard to maltreatment, the rate of child neglect on its own, was 
found to explain $57 \%$ of the variation in juvenile participation in crime across postcodes. Considering property and violent crime separately, neglect accounted for $58 \%$ of the variation across postcodes in the rate of juvenile participation in property crime. For participation in violent crime, neglect accounted for $49 \%$ of the variation across postcodes. In a regression model, which included neglect as a joint predictor with poverty, single parent families and crowded dwellings, neglect was found to account for most of the explained variation in juvenile participation in crime. A similar result is found when neglect is replaced with abuse, however Weatherburn and Lind (1997) point out that this is probably due to the high correlation between abuse and neglect.

Finally, a path analysis was conducted including the social and economic stress variables of poverty, single parent families and crowded dwellings, the mediator variables of abuse and neglect and the outcome variable of juvenile participation in crime. This analysis showed that neglect was the most important causal influence on juvenile participation in crime (path coefficient of 0.50). The conclusion reached from these findings is that poverty, single parent families and crowded dwellings affect the level of juvenile participation in crime mainly by increasing the rate of child neglect. The relationships found in rural areas were largely the same as those in urban areas however most of the relationships were weaker. A deeply concerning finding was “...assuming other factors remain unchanged, an increase of 1,000 additional neglected children would result in an additional 256 juveniles involved in crime. Alternatively, and again assuming other factors remain unchanged, an increase of 1,000 additional poor families would result in an additional 141 juveniles involved in crime” (Weatherburn and Lind, 1997, p. viii). 
There is strong evidence for an association between maltreatment and delinquency. Regardless of whether cases of maltreatment and delinquency have been based on self-reports or official cases, or a combination of both, children who have been maltreated are more likely to engage in delinquency and juvenile offending than children for whom there is no evidence of maltreatment. While these findings suggest that maltreatment is a significant risk factor for later criminal behaviour, they do not speak as to whether specific forms of maltreatment are related to particular offending outcomes. This is important, as successful interventions may be dependent upon the nature of the maltreatment.

\subsection{Types of maltreatment and delinquency}

More recently, researchers have begun to investigate the differential effects of various types of maltreatment. In 1994, utilising the data from Widom's 1989 study, Widom and Ames assessed the long-term criminal consequences of sexual abuse. There are several general beliefs regarding the impact of childhood sexual abuse and its link to problem behaviours such as delinquency and sexualised behaviour. In their retrospective study utilising selfreports of childhood victimisation of incarcerated offenders, Weeks \& Widom (1998) found that on an overall index of childhood sexual abuse, sex offenders reported higher rates of childhood sexual abuse than other offenders (26.3\% vs $12.5 \%)$. However, much of the evidence for such assertions comes from early, retrospective and methodologically flawed studies, while more current research is not definitive (Widom \& Ames, 1994; Widom, 1994). Therefore Widom and Ames (1994) addressed whether sexually abused children were at greater risk for delinquency compared to other maltreatment and control groups, and whether they were at greater risk for committing sex crimes such as prostitution and rape. Findings indicated that there was an increased risk of arrest for the maltreated group as a whole 
compared to the control group. This occurred both as juveniles and as adults. The sexually abused group was not at any more risk for arrest than the abused or neglected groups. Across different types of offences there were no significant differences between the physically abused, sexually abused, and neglected groups except for arrests for running away. The sexually abused group was significantly more likely to have been arrested for running away compared to the other two maltreated groups.

Arrests for sex crimes occur relatively infrequently and have fairly low base rates of occurrence, a factor that should be kept in mind in interpreting these results. In an analysis of sex crimes as a whole, the sexually abused group was no more likely than the neglected group to be arrested for a sex crime. Both of these groups were less likely than the physically abused group to be arrested for sex crimes. Analysis of individual types of sex crimes revealed that no one in the sample had been arrested for incest, child molestation or public indecency. As such, remaining analyses were carried out in regard to prostitution and violent sex offences (rape and sodomy). Sexually abused participants were significantly more likely to be arrested for prostitution than the neglected, physically abused, and control groups. For violent sex offences, the physically abused group tended toward higher risk, however the difference was not significant. To control for variance caused by race, age, and sex, logistic regression was carried out with adult criminal record as the response variable and race, sex, age, and type of abuse as the explanatory variables. Holding constant these other variables, those in the sexually abused group had 4.7 times higher odds than the control group for being arrested for any sex crime. The odds for being arrested for prostitution were 27.7 times higher for this same group. The physically abused group had 7.6 times higher odds of being arrested for a violent sex offence while the neglected group showed odds 10.2 times higher than the control group of being arrested for prostitution. Thus sexually abused children were more 
likely to be arrested for prostitution than a violent sex offence. So while there appears to be a link between sex abuse and later sexualised behaviour, it seems more likely to take form in a self-deprecating manner rather than a violent one.

In an investigation of the 'cycle of violence' hypothesis, utilising data from the same study, it was found that abused and neglected children did not have significantly higher rates of arrest for violent crimes as juveniles than controls (Widom, 1994). However, it is interesting to note that physically abused females had the highest rates of arrest for violent crimes as compared to controls and neglected females while neglected males had the highest risk of arrest for violent crimes compared to controls and physically abused males. Analysis of the 1994 data presented by Widom and Maxfield (2001) showed that physically abused and neglected children (as opposed to sexually abused) were the most likely to be arrested for a violent crime. Thus it would appear that it might not only be violence that begets violence, but also some aspect/s of neglect. In fact, in their retrospective study Weeks and Widom (1998) found that violent offenders reported significantly more childhood neglect than non-violent offenders but not more physical abuse. Alfaro (1981) found that those delinquents who had been victims of abuse or neglect were far more likely than their non-abused delinquent counterparts to have engaged in violent delinquent acts. He cautions however, that such results should be used with caution in prediction of behaviour, as it is still the case that the majority of maltreated children do not engage in violent, criminal behaviour.

In an interesting study Weiler and Widom (1996) investigated psychopathy and violent behaviour in abused and neglected young adults. Using Hare's Psychopathy Checklist (PCLR) and assessment of violence based on both official arrest records and self-report information it was found that victims of childhood abuse and/or neglect had significantly 
higher PCL-R scores than a matched control group. This effect held despite controls for demographic characteristics and criminal history. The PCL-R scores predicted both official and self-reported violence and while childhood victimisation was a significant predictor of violence, it was no longer significant when PCL-R scores were introduced. Therefore Weiler and Widom suggest that the relationship between victimisation and violence in some individuals may be mediated through psychopathy.

\subsection{Severity of maltreatment and delinquency}

Along with examination of the effects of different types of maltreatment, recent studies have begun to examine other dimensions of maltreatment such as severity, frequency and duration. In the Smith and Thornberry (1995) study previously mentioned, a measure of the severity of maltreatment was employed based on a classification system developed by Cicchetti and Barnett (see, for example, Smith \& Thornberry, 1995; Barnett, Manly \& Cicchetti, 1993). This classification produces a severity 'score' based on information such as the frequency and duration of maltreatment as well as how many different types of maltreatment there were.

Only moderate support was provided for the hypothesis that those who are most severely maltreated are most likely to offend. In order to maximise differences, the most severe third of the maltreated sample were compared to the less severe two thirds. Although, there was a trend toward greater offending for the most seriously maltreated group, the difference was not significant. There were very large differences however between the severely maltreated group and the non-maltreated group. Arrests occurred 2.8 times as often for the seriously maltreated group, 2.3 times the number of serious offences were self-reported and 1.9 times the number of violent offences as compared to the non-maltreated group. As yet however, there has been 
only a small amount of research into this aspect of maltreatment and the results are far from equivocal, a situation exacerbated by the fact that there is no universal designation of level of seriousness.

Despite differences in the types of controls used and the research questions asked, as well as differences in the eventual strength of relationship found, most studies have found that some level of relationship exists between maltreatment and delinquency as the above studies indicate. It is not only studies into maltreatment that indicate this relationship however, as studies into parenting style more generally have indicated a link between inadequate parental management styles and later delinquency. While poor parenting may not amount to maltreatment, maltreatment may be considered an extreme of poor parenting. Alternatively, Wolfe, Wekerle and McGee (1992, p. 32) contend, “maltreatment can be considered as an indicator of poor socialisation practices rather than the individual cause of poor developmental outcomes.” As such, the following studies provide further evidence of the relationship between maltreatment and delinquency as well as its nature.

\subsection{Parenting and delinquency}

Data from the Cambridge Study in Delinquent Development (Farrington, 1995) highlights the importance of parenting style as a predictor of later offending. The Cambridge Study in Delinquent Development is a longitudinal study following 411 males from a South London area from the age of eight to 32 years. The study was an investigation into the causes and correlates of crime and, as such, a wide variety of data was collected from a variety of sources. At age eight to 10, there were several differences between those children who would later offend and those who would not with poor parental child-rearing behaviours 
representing one of the strongest predictors. Overall, delinquents were more likely to be rated as troublesome and dishonest by their peers, had poorer families and larger families, living in poor houses with neglected interiors, supported by social agencies, physically neglected by parents, have convicted parents or older siblings, poor parental child-rearing behaviour (characterised by harsh or erratic parental discipline; cruel, passive or neglecting parental attitude; parental conflict; and poor supervision), broken homes, separation from parents for reasons other than death or hospitalisation, parents with an authoritarian attitude, and higher teacher ratings of hyperactivity and poor concentration.

In a study focusing more exclusively on the effects of parenting, Barnes and Farrell (1992) examined the constructs of parental support and control as predictors of adolescent drinking, delinquency, and related problem behaviours. Support was seen to involve factors such as nurturance, attachment, acceptance and love, while parental control included discipline, punishment, supervision and monitoring. The concept of parental control was separated into coercive and inductive control, and monitoring (knowing the whereabouts and activities of children). Data was collected from 699 randomly selected households with teenagers in the greater Buffalo area. It was found that more coercive controls (i.e. slap/hit, yell/shout/ scream, take away privileges) were related to problem behaviours. Coercive control also showed a significant negative correlation with parental support. Parental support and monitoring were found to be significant predictors of problem behaviours, displaying a negative relationship. These factors were found to be important even after taking into account demographic and family factors such as SES, age, gender, race, family structure and family history of alcohol abuse. In fact, monitoring was the best and most consistent predictor out of all control variables. 
In a longitudinal study from 1939 to 1979, McCord (1983) examined case records to investigate the link between parenting styles and later criminality. Data used in this study included teacher reports, official records and case reports from social workers who visited the families of participants twice a month for a period of five and a half years from 1939. These case records were used to code the child's experience as either abused (consistently punitive, physical punishments), neglected (infrequent interaction, no affection), rejected (did not neglect or abuse but parents were not loving), or loved (concerned for welfare, generally pleased with behaviour). Of the 232 participants, 49 were categorised as abused, 48 as neglected, 34 as rejected and 101 as loved. It should be noted that the children in this study did not necessarily meet official criteria for being abused or neglected, rather these categories represent the researchers' perception of general parenting style. Records for juvenile delinquency were higher for rejected, abused and neglected boys than for those from loving homes. Those classified as rejected had the highest percentage with such a record (50\%), approximately $20 \%$ of abused and neglected children had a record, while only $11 \%$ of the loved children had a record. It is interesting to note that across these four groups, rates of alcoholism, divorce and occupational success were similar. At the same time, approximately half of the abused or neglected boys had been convicted for serious crimes, become alcoholics or mentally ill, or had died when unusually young. Therefore family structures and characteristics alone did not seem to influence delinquency, rather this was influenced by rejecting, abusive or neglectful parenting styles, potentially in conjunction with other family systems.

Other studies have investigated the relative impact of parenting according to other correlates of delinquency. Larzelere and Patterson (1990) tested the hypothesis that the effect of socioeconomic status (SES) on delinquency in early adolescence would be mediated entirely by 
parental management skills. This hypothesis was put forward in support of Patterson's (1982, cited in Patterson, Capaldi, \& Bank, 1991) coercion theory of delinquency, which implies that SES influences delinquency indirectly, through its effect on how adequately parents manage their children. Structural equation modelling was adopted in testing this hypothesis utilising data from the Oregon Youth Study. SES was measured while the participating boys were in their fourth year of school. Parental discipline and monitoring (parental management) were assessed while the boys were in year six while self-reported delinquency was measured in year seven. The correlation between SES and delinquency was -.37 suggesting a link between low SES and higher rates of delinquency. However, the effect of SES was mediated entirely by parental management. Thus, the direct effect of SES on delinquency was not significant. The direct effect of parental management on delinquency was -.76, with the overall model accounting for $46 \%$ of the variance in delinquency.

Similarly, in an investigation of pathways leading to criminal involvement, Simons, Wu, Conger and Lorenz (1994) also found that SES was related only indirectly, through parental management skills, to later delinquency. In this study, a pathway was identified (for individuals who offend early and more chronically) from poor parenting skills to antisocial behaviour patterns to delinquency. It is argued that poor parenting leads to deficiencies in social skills that impact upon successful integration into law-abiding society. Thus it appears that parental management skills may be a more important consideration in delinquency than the traditionally focused upon SES. Although, stressors associated with low SES are probably instrumental in establishing poor parenting patterns. 


\subsection{Timing of maltreatment and delinquency}

While there is a considerable body of research that supports the link between maltreatment and offending, little attention has been directed towards examining whether the timing of the maltreatment is crucial in producing delinquent outcomes (Thornberry, Ireland \& Smith, 2001). Furthermore, although Moffitt (1993) proposed that the characteristics of the child and negative experiences in childhood lead to an early onset of delinquency and long-term offending, even less research has examined whether the timing of the maltreatment affects the timing of the onset of offending. This deficit is probably largely due to the inadequacy of the data collected on maltreatment and offence characteristics. Nevertheless, an important concept in pathways literature is the timing of the onset of risk factors and whether the individual is developmentally equipped to deal with adversity (Developmental Crime Prevention Consortium, 1999). Most research on maltreatment and delinquency uses reports of maltreatment that occurred in childhood, thus little is known of the effect of maltreatment that occurs in adolescence (Thornberry et al, 2001).

Thornberry et al (2001) used data from the Rochester Youth Development Study (RYDS) to examine whether the timing of maltreatment has a differential impact on adolescent outcomes. Maltreatment comprised all substantiated incidents recorded by child protective services for participants up until the age of 18. Participants were then placed into one of four categories according to the age of participants at the time of maltreatment: (1) Early childhood-only maltreatment (birth through age 5 years; $\mathrm{N}=35$ ); (2) Late childhood-only maltreatment (ages 6 - 11years; $\mathrm{N}=61$ ); (3) Adolescence-only maltreatment (ages 12 - 17 years; $\mathrm{N}$ = 78); and (4) Persistent maltreatment (maltreatment occurred in both childhood and adolescence; $\mathrm{N}=28$ ). A fifth group included children who had received no substantiated 
maltreatment notifications ( $\mathrm{N}=787$ ). Delinquency was measured according to self-reports of having committed an offence, the frequency of the behaviour and the nature of the most serious offence.

Using logistic regression, Thornberry et al (2001) found that participants who had been maltreated in childhood only were no more likely to have committed a delinquent act than children for whom there was no evidence of maltreatment. In contrast, those children who had been maltreated in late childhood had an increased risk of delinquency. Children who were maltreated in adolescence were almost five times more likely to engage in a delinquent act than children who were not maltreated. Those who were persistently maltreated (both childhood and adolescence) were not significantly more likely to be delinquent than children who had not been maltreated. The adolescence-only and persistent groups were also more likely to experience other negative outcomes, such as drug use, alcohol related problems, and internalising and externalising problems than children who were not maltreated. The authors concluded, "it is maltreatment that occurs in adolescence that is most developmentally problematic for adolescent outcomes” (Thornberry et al, 2001, p. 970).

In order to examine the effect that type of maltreatment had on adolescent outcomes, Thornberry et al (2001) combined the early- and late-childhood groups into one group (childhood-only) and the adolescent-only and persistent groups into a second group (any adolescent maltreatment). They found that physical abuse and neglect in childhood-only increases the risk by almost three times for general delinquency in early adolescence, whereas only physical abuse in adolescence increased the risk of early adolescent delinquency. What is notable about physical abuse in adolescence is that it increased the risk of general delinquency by 15 times. Physical abuse, sexual abuse and neglect in adolescence all 
increased the risk for early adolescent adjustment problems. Children who experience physical abuse and neglect in childhood-only were not significant more at risk of general delinquency in late adolescence than children who were not maltreated. In contrast, those who experienced physical abuse and neglect in adolescence were at greater risk for delinquency in late adolescence than children who were not maltreated.

While the findings of Thornberry et al (2001) are based on small sample sizes and need to be replicated using other samples of maltreated children, the results raise some interesting questions about the timing of maltreatment and its affect on adolescent outcomes. For example, why was maltreatment in childhood-only less detrimental in terms of adolescent outcomes than maltreatment in adolescence? It would be interesting to examine whether children received interventions following the maltreatment or whether other protective factors were present that might have mediated the effect. That the persistent maltreatment group was at a significantly higher risk for delinquency and other negative outcomes than children who were not maltreated and children who were maltreated in childhood-only provides evidence for the impact of repeated victimisation.

While not examining delinquency directly, Manly and associates examined children's adjustment and dimensions of child maltreatment including developmental timing, subtype and severity (Manly, Kim, Rogosh \& Cicchetti, 2001). The sample included a maltreated group and a control group of school aged children assessed on adjustment variables including internalising and externalising symptomatology, aggressive, withdrawn, and co-operative behaviour, and personality dimensions of ego resiliency and ego control. It was found that chronic maltreatment (especially with onset during infancy) was linked with more maladaptive outcomes. More specifically it was found that externalising behaviour and 
aggression were linked with the severity of emotional maltreatment in infancy and toddlerhood and with physical abuse during the pre-school period. Alternatively, internalising symptomatology and withdrawn behaviour was linked with the severity of physical neglect particularly in pre-school. While these specific effects of early maltreatment were evident, it is important to note that maltreatment during the school age period contributed significant variance for the adjustment variables after earlier maltreatment was controlled. Clearly more research examining the affect of the timing of maltreatment needs to be conducted, and may provide an empirical base on which interventions can be developed and improved.

\subsection{Severing the link: Evidence from demonstration projects}

With the knowledge that many children who are maltreated do not become delinquent later in life, several studies have focused upon identifying protective factors that may intervene to make negative outcomes less probable. It is important to note that protective factors are generally not simply considered the absence of risk factors; they are characteristics that generate positive experiences for the person, such as the presence of an alternate caregiver or good school performance (Kruttschnitt, Ward \& Sheble, 1987). Their presence reduces the effects of risk factors.

Zingraff, Leiter, Johnsen, and Myers (1994) investigated the mediating effect of good school performance on the maltreatment-delinquency relationship. This study was based on the premise that the link between maltreatment and delinquency is not an inescapable path for many individuals and, as such the path is highly contingent on intervening experiences, particularly socialisation and integration experiences, many of which take place in the school environment. Thus, Zingraff and associates investigated the effect of maltreatment on 
delinquency in relation to school performance. A sample of maltreated children $(N=522)$ was compared to a sample of the general school population $(N=256)$ in a county of North Carolina utilising official records of maltreatment (physical abuse, sexual abuse, and neglect) and official records of complaints against juveniles. School outcomes included both performance variables (class grades and scores on the California Achievement Test) and process variables (attendance, retention in grade, respects the rights/property of others, follows directions, and obeys school and class rules).

Findings indicated that the percentage of children with at least one delinquent complaint was significantly higher for the maltreated children than the general school population sample (12\% and 5\% respectively). When considering separate types of maltreatment, the probability for those who had been neglected being involved in delinquent activity was higher than the probability for the physical abuse group, although both were significantly greater than the control group. It is interesting to note that the sexually abused group was not at a significantly higher risk for delinquency (although this finding may be somewhat limited by small numbers in this group). These patterns held once race, gender, age and family structure were taken into account. However, with the introduction of school outcome variables, physically abused children were no longer at a statistically significant higher risk for delinquency than the general school population. The co-efficient for neglect was still significant although reduced in magnitude. The authors put forward the hope that introducing policies to raise school performance may act as a protective factor in reducing the link between maltreatment and delinquency.

Kruttschnitt, Ward and Sheble (1987) examined the caregiving environments of 106 abused males in order to identify risk and protective factors for later offending behaviour. Again this 
study was an investigation of the 'cycle of violence' hypothesis and the factors that may intervene in the learning of violent behaviours. According to Bandura's (1973) social learning theory, the experience of abuse as a child acts as a model for behaviour that may later be adopted in parental or conjugal roles. Further, it has been proposed that this behaviour may be generalised and adopted as a coping or interaction style in many roles. However, not all of those children who have been abused later become abusive or violent (Kruttschniit, Ward \& Sheble, 1987), therefore, it is important to identify which factors may intervene in this relationship. Their review of previous studies identified several protective or risk factors, including the presence of one nurturing adult, the number of stressful life events, isolation or the presence of a support system, and other characteristics of the family environment. These characteristics comprised family size, presence of alternative caregivers, parental neglect, sex of the abusing parent, and parental arrest history.

In Kruttschnitt and associates’ study, data was obtained from two sources. Interview data and official records were collected for approximately 100 males, aged 18 to 25 years, who were incarcerated for crimes of violence. Similar data was collected for 65 self-selected males matched on age, race, neighbourhood of residence during childhood and adolescence, and who had no history of violent criminal conduct. Information collected involved family stability, strength of family attachments, exposure to violence in the home and through media, feelings of relative deprivation, academic schooling, dating experiences, and early experiences with the criminal justice system and other social service agencies. Six variables were significant in differentiating those who participated in violent crime and those who did not. The two strongest variables were the outcome of parental conflict (physical or verbal), and family criminality. Other significant variables included having the same sex parent as abuser (father), the emotional neglect scale, whether close to siblings or not, as well as the 
number of team sports participated in. Thus, results indicate that the presence or absence of emotional neglect, family criminality, and a support system within and outside of the home, as well as the sex of the abusing parent and how parents resolve conflicts are all important for understanding the relationship between child abuse and subsequent violent criminal behaviour.

In their review of early intervention projects, the Developmental Crime Prevention Consortium (1999) separated programs into those beginning in infancy, those beginning in the pre-school years, and those beginning in early primary school. While not all programs have been aimed at reducing criminal behaviour nor have been systematically evaluated, many of those that have been evaluated have reported a reduction in areas such as child maltreatment, behaviour problems, delinquency and offending. For example, the Elmira Prenatal/Early Infancy Project (Olds, 1988) was aimed at reducing developmental problems in children. A nurse biweekly visited first time mothers in their homes. Some mothers were identified with risk factors including being young, single or poor. All mothers were provided with advice on prenatal care, baby health care and information on other relevant services.

Evaluations were conducted when children were aged four years. Evaluations were positive with a reduction in incidences of abuse and neglect, emergency room visits, accidents and rapid successive pregnancies, and an increase in use of services and social supports and a better home environment. Of those mothers who were young, single and poor, there was a $75 \%$ reduction in the incidence of abuse and neglect compared with those in a non-home visitation control group. The program provided the best benefits for the more disadvantaged families (Olds, 1988). If Weatherburn and Lind (1997) are correct in their calculations of the incidence of juvenile offending in relation to earlier child abuse and neglect, then a $75 \%$ 
reduction in maltreatment is potentially a significant step in long-term crime prevention. In fact, in a long-term follow-up of the Elmira study, at age 15 the children of the mothers who participated in the study were found to have fewer arrests and convictions, smoked and drank less and had fewer sexual partners than those in the control group (Olds, Henderson et al., 1999).

An example of an intervention program targeted at the pre-school years is the Perry Preschool Program (Weikart \& Shweinhart, 1992). This program aimed to provide cognitive enrichment and had unintended consequences on later criminal behaviour. The program targeted three and four year old children living in poverty and involved a daily pre-school program with weekly home visits by their teachers. Initial evaluations revealed cognitive improvements for children in the program between the ages of four and seven, although these were not maintained (compared with a control group matched on intelligence and SES with the same boy/girl ratio). However, there were several long-term benefits of the program. Compared with the control group, children in the program were more likely to graduate from high school and continue further education, have higher employment rates and higher incomes, become home owners, and had lower self-reported offending at age 19 and fewer arrests at age 27 (half as many as the control group). By introducing protective factors such as bonds between the school and home, and teaching children skills such as decision making and self-discipline, this may have buffered some other risk factors in the children's lives to reduce the probability of travelling a pathway to offending.

The Seattle Social Development Project (Hawkins, Catalano et al., 1992) was aimed at establishing bonds between children, their families, schools and communities. Although it targeted Grade 1 children and provided training in social and emotional problem solving 
skills, it also included teacher training and supervision, parent behaviour management training and peer group sessions. Children were placed into either the full intervention group (receiving all program components in Grades 1-4, and 5-6 where possible), a late intervention group (receiving intervention in Grades 5 and 6 only) and a control group (no intervention). Immediate results on completion of the program revealed that only white children were rated by teachers as less aggressive. In Grade 5, children who participated in the program reported more attachment to school and less alcohol use or delinquent behaviour than the control group, while the parent training also appeared to be effective. In a follow-up study at age 18, the control group had committed significantly more delinquent acts than the full-intervention group (Hawkins, Catalano, Kosterman, Abbott \& Hill, 1999). Although not significant, patterns were similar for self-reported arrests, non-violent delinquency, and official juvenile court delinquency records as they were for violent delinquent acts. Positive effects for the full intervention group were found in relation to violence, frequent drinking and sexual behaviour, with these differences being apparent years after intervention ceased. Outcomes for the late intervention group fell somewhere between those of the full intervention group and the control group.

Recently, McGloin and Widom (2001) examined resilience among abused and neglected children grown up. While this study did not involve a specific intervention program, it may be that studies into resilience and protective factors will better inform the design of such programs in the future. Resilience was defined as success in six out of eight criteria including employment, homelessness, education, social activity, psychiatric disorder, substance abuse, official arrest (adult and juvenile), and self-reports of violence. While this criteria for resilience is quite stringent and may restrict the number of participants defined as such, it also increases the likelihood of a substantive difference between resilient and non-resilient groups. 
There was a significant difference between maltreated and control groups for success levels in six out of the eight criteria (all except substance abuse and social activity). In the maltreatment group the percentage achieving success across the various criteria ranged from $19.3 \%$ for employment success to $75 \%$ successful on the homelessness domain. While the maltreated group was not as successful on the whole as the control group, it is worth noting that almost one quarter of the maltreated group did meet the criteria for resilience. Further research into the protective factors that allow a substantial proportion of at-risk individuals to meet these stringent criteria for resilience may help in the design and effectiveness of future intervention programs. In regard to the current research, it again points to the fact that the link between maltreatment and maladaptive outcomes is not an inevitable one.

While not all of these studies deal specifically with child abuse or neglect, they do include children who are deemed to be disadvantaged. The programs have demonstrated that with appropriately designed intervention programs, outcomes for disadvantaged children can be improved, which may lead either directly or indirectly to a reduction in juvenile and adult offending. Such research also provides further support for the link between child maltreatment and offending. More importantly, the findings of these studies reinforce the position that the 'cycle of violence' and general maltreatment cycles are not inevitable.

\subsection{Summary}

There is a growing body of research that links child maltreatment with delinquent or offending outcomes. While it is not yet clear by which process maltreated children move along a pathway to criminal behaviour, certain characteristics of the child at an individual, familial and more broader societal level appear to increase the risk of offending. These 
characteristics include socio-economic stress, family structure and parenting practices, academic achievement, lack of social support, and type and frequency of maltreatment. More recently the timing of the maltreatment has also been identified as an important consideration in examining trajectories from childhood maltreatment to negative adolescent outcomes. This is particularly relevant in light of the development of crime prevention programs that aim to reduce risk factors and enhance protective factors in childhood and adolescence. Although some developmental criminologists would argue that it is never to late to intervene, in terms of the effect of repeated victimisation there is a strong case that intervening early in the pathway may be critical for optimal program success.

Although there is an expanding body of knowledge on offending trajectories, there are still questions that need to be addressed and research that requires replication. Two of the main questions to be examined is how all the above mentioned factors interact together to produce delinquent outcomes and whether there are different types of delinquent outcomes depending on the type, frequency and timing of maltreatment. While the inclusion of risk factors such as family structure and academic success are beyond the scope of this research, the present study aims to address these two key issues in relation to the experience of maltreatment. The following chapter provides a discussion of the theoretical approaches that may be used to explain the relationship between maltreatment and offending that has been identified in empirical work. 


\section{CHAPTER 3: THEORETICAL EXPLANATIONS OF THE MALTREATMENT - DELINQUENCY LINK}

There are various theoretical approaches to explaining the apparent link between maltreatment and delinquency. Psychological, criminological and developmental theories based on specific research all attempt to answer the question of: why are maltreated children at greater risk of becoming delinquent?

\subsection{Psychological perspectives}

Some of the most prominent psychological perspectives in this area include social learning theory, the psychodynamic perspective, and theories within developmental psychology. According to Bandura's (1973) social learning theory, children learn through observation, modelling and reinforcement. Particularly as the family represents a child's primary support group, much early learning occurs through the family in the home environment. Thus, families who maltreat their children are likely to model and reinforce poor interpersonal skills and coping behaviour (Bandura, 1973). This behaviour is learned and subsequently adopted by children, limiting appropriate future development. Social learning theory particularly applies to more specific behaviours. Thus, it would be posited that those who are exposed to violence as children are more likely to become violent as adults. As the reviewed research suggests however, the evidence for such a position is somewhat limited as many abused children do not become violent as adults (Smith \& Thornberry, 1995; Widom, 1994). Thus, while some behaviour patterns may be learned from maltreating parents, there are many intervening factors to be considered including the fact that the family, while extremely important, is not the only learning environment children are exposed to. Furthermore, while 
one adult in the family may be abusive or neglecting, it does not necessarily mean that other adults in the family does not model appropriate behaviours.

According to psychodynamic theory, maltreatment may affect the later behaviour of children by exposing them to adverse object relations and encouraging the formation of insecure attachments. In support of this contention was the finding by Cicchetti, Toth and Bush (1988) that the vast majority of maltreated infants form insecure attachments (70 - 100\% across studies). Insecure attachments are claimed to be related to a later negative view of self, low social competence, poor adaptive ability, and long term problems in relationship formation (Paterson \& Moran, 1989). Thus, while the link is not direct, psychodynamic theories propose that maltreatment leads to delinquency through general disruptions in functioning caused by poor object-relations and attachments. The proposed mechanism by which this occurs is that working models of the self develop in parallel with models of attachment figures. That is, when caregivers are sensitive to the needs of the child, the child views themselves as worthy of care and develops the beginning of a healthy self image (Wolfe, Wekerle \& McGee, 1992). However, when the opposite occurs a child is more likely to experience a poor self-image and difficulties with attributional bias, social sensitivity, peer relations, and empathy.

Alternatively, developmental psychology does not propose a specific pathway between maltreatment and later problem behaviours and delinquency. Instead it provides a framework through which to view the potential effects of maltreatment. According to developmental psychology, the age at which a given incident occurs will effect what impact it has on the subsequent development of the child (Wolfe, et. al, 1992; Crouch \& Milner, 1993). Age effects how events are perceived, interpreted and remembered by children. Furthermore, 
different ages involve different developmental requirements and milestones that may not be met due to maltreatment. Therefore, it is argued that the effect of maltreatment is not singular, as factors such as age and developmental progress must be considered when assessing what impact is likely for a given child (Crouch \& Milner, 1993; Wolfe et al, 1992). For example, child neglect during the first years of life may lead to a low intelligence rating because of lack of stimulation in the environment during a crucial learning period. From a developmental perspective, this will then impact in different ways throughout the child's life and may, depending on surrounding conditions, lead to criminality. In a related study of abusive early child rearing and early childhood aggression, Herrenkohl and Jean-Russo (2001) found differences in the developmental stage at which different features of harsh child rearing exert their influence.

\subsection{Criminological perspectives}

Because of their broad, sociological nature, many general criminological theories do not specifically refer to the impact of maltreatment in their explanations of why individuals become, or do not become, involved in crime. A number of these theories focus on other correlates of crime such as socio-economic status and peer association and how these factors may lead to criminality (Larzelere \& Patterson, 1990). There are however some theories which identify maltreatment specifically, or parenting styles more generally, as potentially causal factors in promoting delinquency. The three primary theories in this area are: general strain theory, social control theory (and the subsequent general theory of crime), and coercion theory. 
Strain theory, initially developed by Merton (1938) posits that offending behaviour is a “normal reaction by normal people to abnormal conditions” (p 672). Originally strain theory proposed that harsh environmental conditions such as economic and social deprivation lead to strain. Strained individuals experience negative affect and, as such, are motivated to take action that will alleviate either the strain or the associated negative affect. Criminal behaviour is one option for achieving this. More recently, Agnew (1992, 1993) has developed this theory to encompass broader conceptualisations of strain and the factors that may cause it in his 'general strain theory'. In general strain theory, factors that may cause strain include those that may prevent the individual from obtaining their goals, the introduction of negative stimuli, or the removal of something valued (Agnew, 1993; Paternoster \& Mazerolle, 1994). Specifically, maltreatment is considered to be a negative stimulus that produces negative affect such as depression, anger, resentment and anxiety. Offending behaviour may alleviate this through providing escape or avoidance, retaliation, or compensation.

According to social control theory (Hirschi, 1969), individuals do not offend because they have social bonds to which they are committed and which serve to control their behaviour internally (as opposed to official controls operating externally). Social controls include attachments to others, commitment or involvement in activities such as schooling or sporting teams, and the development of beliefs in line with social norms. When such social controls are absent offending may occur. Parenting style plays a large part in this explanation of offending behaviour as parenting establishes patterns for attachment and often represents the most significant attachment for a child. Parents are also key figures in the socialisation process and the establishment of beliefs in line with the social norm. Thus incompetent parenting including maltreatment, may lead to a lack of effective social controls on behaviour, leaving the individual somewhat free to behave as they please. 
Patterson's coercion theory (1982, cited in Patterson, Capaldi \& Bank, 1991) is similar to social control theory although the focus is more exclusively on the family and is based on social learning principles. According to this theory, inconsistent parental discipline and monitoring leaves the child with unclear boundaries and models for behaviour and with a likelihood of developing antisocial behaviour patterns. Such behaviour patterns then have ramifications for performance at school and other places. Thus, the coercion model predicts that improving parental discipline and monitoring practices would produce reductions in antisocial behaviour. It also suggests that there may be two different pathways to crime for those who are involved in delinquency relatively early and those who become involved later. Those who experience inappropriate parenting from an early age are likely to develop antisocial tendencies and may become involved in crime at a younger age and with greater chronicity. However, those who do not experience such parenting may not develop antisocial behaviour patterns. Instead they may become more influenced by peers during adolescence when searching for independence or if there is a breakdown in the parenting relationship such as divorce. These individuals are likely to be involved in criminality at a later age and do not offend as chronically. This perspective is supported by path analysis in the previously mentioned study conducted by Simons, Wu, Conger \& Lorenz (1994) and corresponds with the life-course persistent versus adolescent limited pathways subsequently put forward by Moffitt (1993).

\subsection{Developmental criminology: Integrated perspectives}

There are several competing and varied theories as to why maltreated children are at a greater risk of adolescent offending, most of which can be supported by some level of empirical evidence. Given the variety of problem behaviours and difficulties that are potentially linked 
to childhood maltreatment, it is probable that instead of a singular causal pathway between maltreatment and delinquency, there are multiple pathways, via which early experiences of stress and abuse may influence subsequent behaviour and increase the risk for problem behaviours such as criminality. The pathways model outlined at the beginning of this report reflects this emphasis on the importance of taking a life-course perspective of offending.

Sampson and Laub (1993) drew together many of the variables that have been associated with delinquency and offending (i.e., SES, parental structure and practices, school bonds, abuse and neglect) and developed a longitudinal theory of the development of delinquency and crime. This theory grew out of a secondary analysis of data collected from the 1930's to 1970 's on one thousand delinquents and non-delinquents, a study originally conducted by Sheldon and Eleanor Glueck. The theory looks at life experiences and circumstances from childhood into adolescence and then into adulthood.

According to Sampson and Laub (1993), the development of juvenile delinquency occurs primarily because of informal social control processes, occurring mainly in the family context. They propose that erratic and harsh discipline, lack of supervision, parental rejection of the child and the child's emotional rejection of their parents leaves children more vulnerable to transitions along negative pathways. A lack of bonds with school and the influence of delinquent peers also increase the likelihood of delinquency and juvenile offending. In relation to characteristics such as low SES, a crowded household, parental criminality and family disruption, the authors argue that the effect of these structural background factors is indirect, as they are mediated by the informal social control processes. For example, low family SES may create increased stress in the family home, leading to poor parenting practices. 
Whether or not juvenile offenders then go on to offend in adulthood is dependent upon the accumulation of early experiences and the interaction of these. Having a criminal record as a juvenile may limit the opportunity to make positive transitions in life. An absence of adult social bonding, the likelihood of which is increased by childhood delinquency, also influences the pathway to adult criminal behaviour. Importantly, Sampson and Laub (1993) also suggest that the likelihood of criminal behaviour is reduced with positive social ties such as attachment to spouse and job stability. This age-graded theory of informal social control put forward by Sampson and Laub provides a comprehensive, and to some extent empirically supported, account of how structural and social control factors interact and accumulate to produce trajectories to offending.

Building upon the work of Rutter (1983) and based upon the premise that there are multiple pathways from stress and abuse to delinquent and criminal behaviour, Widom (1994, p. 141143), developed a model specifically linking maltreatment to offending. She identified six possible pathways between maltreatment and problem behaviours. These six pathways are largely supported by research into the correlates of maltreatment and delinquency.

The first pathway occurs when childhood victimisation leads to "immediate sequelae that have an irremediable effect on the subsequent development of the child”. Physical abuse or neglect may lead to several problems such as dehydration or failure to thrive which may cause further problems such as developmental retardation and school difficulties. For example, Galler, Ramsey, Solinano and Lowell (1983) found that malnourished children aged 5 - 11 years old had significantly lower IQ than a matched control group. The malnourished group also exhibited more attention deficits, poorer social skills, and less emotional stability. 
A second pathway may exist where "experiences of early childhood victimisation may lead to bodily changes that influence a child's vulnerability to certain adolescent problem behaviours". One possible route for this proposed pathway is that experiences of maltreatment lead to desensitisation that decreases the child's emotional and physiological responsiveness. For example, Eichelman (1990) found that stress at critical developmental points was associated with abnormal brain chemistry and aggressive behaviour. Further studies altering the nurturing environment of animals have found that rearing conditions affect reactivity (Higley, Melman \& Taub, 1991) and are associated with varied levels of norepinephrine and serotonin. More recently, Cicchetti and Rogosch (2001) investigated cortisol levels in maltreated and control groups in conjunction with clinical level externalising and internalising problems. While the capacity to elevate cortisol in response to acute trauma is a necessary function, chronic hyperactivity may impact adversely on the functioning of the neuroendocrine system. Cicchetti and Rogosch found those maltreated children with comorbid internalising and externalising problems were more likely not to show the expected diurnal decreased in cortisol. Further, those maltreated children with internalising problems displayed higher morning, afternoon, and average daily cortisol levels.

A third pathway occurs if abuse and/or neglect "encourage the development of certain styles of coping that may be maladaptive”. Children may cope with maltreatment by tuning out or dissociating, a strategy which is not well suited to the demands of other social situations. Furthermore, the child may learn to be impulsive or conversely, inflexible.

A fourth pathway is where "early childhood victimisation may alter the child's self-concept, attitudes or attributional styles that, in turn, may influence the adolescent's response to later situations”. In a study by Dodge, Bates and Pettit (1990), physically harmed four years olds 
showed deviant patterns of processing social information at age five and were more aggressive. They were also significantly less attentive to relevant social cues, more biased toward attributing hostile intent, and were less likely to generate competent solutions to personal problems. While this finding is in application to younger children, it is possible that difficulties in processing social information continue into adolescence. It is also the case that adolescents who have been maltreated in the past often have low self-esteem.

A fifth pathway may involve childhood abuse or neglect leading to "changed environments or family conditions that...increase risk for delinquency or other problem behaviours”. This suggestion is somewhat contentious and there are conflicting research findings as to whether environmental changes such as placement in foster care are positive or negative in relation to the child's experience and later outcomes.

A final pathway involves a function of the juvenile justice system where practices may “disproportionately label and adjudicate maltreatment victims as juvenile offenders”. There are several ways in which this pathway may operate. Firstly, a bias toward policing those of low socio-economic status may come into effect. Alternatively, once authorities know a family they may be watched more closely and police bias may assume that those with problematic childhoods become problem children. However there is little evidence for these contentions, which at present, are largely speculative. More likely to account for at least some of the maltreatment - delinquency relationship are observations that some options for coping or escaping from a maltreating environment (such as running away or drug taking) bring adolescents into contact with the law (Halstead, 1992; Widom, 1994). 
Similarly, further research findings into the effects of maltreatment and their implications from a developmental perspective are described by Crounch and Milner (1993) and Wolfe and associates (1992). Detrimental effects of maltreatment have been observed in regard to children's physical development, intellectual development and social development, the precise nature of which varies depending on the developmental stage at which maltreatment occurs. Difficulties in early development may cause cumulative problems eventually leading to criminal behaviour at a later stage. Overall this perspective proposes a number of pathways from maltreatment to later delinquency, rather than a single path or effect common to all maltreated children.

\subsection{Summary}

There are a number of theories from both the psychology, sociology and general criminology disciplines that can be used to attempt to explain the development of delinquency and offending. It is likely that no theory that draws on a singular causal relationship between childhood experience and adolescent offending can adequately explain the development of criminality. Rather, those integrated perspectives such as Sampson and Laub’s (1993) sociogenic model and Widom's (1994) maltreatment pathways model have greater explanatory value by taking into account the interaction and accumulation of multiple early childhood and adolescent experiences. Thus research that investigates the impact of a wide range of possible influential factors that fit within a pathways model, acknowledging the importance of experiences across the life-course, is likely to contribute increased understanding of the potential for criminality which may then feed into the development of appropriate policies and practices for intervention. While the following research is looking specifically at the impact of maltreatment on subsequent offending, it adopts the life-course 
perspective put forward in developmental criminology by examining the timing, type and accumulation of maltreatment and how this impacts on offending trajectories. 


\section{CHAPTER 4: AIMS, HYPOTHESES AND METHOD}

\subsection{Aims and Hypotheses}

As outlined at the beginning of the report, this study has three aims. The first aim is to examine the nature and frequency of individual children's experiences with the child protection and juvenile justice systems. There are no specific hypotheses generated in relation to this aim. However, it is of particular interest to examine the extent of repeat victimisation and repeat offending.

The second aim is to look at the relationship between child maltreatment and juvenile offending. Based on previous research it is hypothesised that children who have been maltreated are more likely to offend in adolescence than children for whom there is no evidence of maltreatment. Within this aim we are also interested in examining if child's experience of maltreatment impacts on later offending behaviour. To do this, we will examine the prospective route from child maltreatment to offending by comparing maltreated children who went on to offend with maltreated children who did not offend. In this respect it is hypothesised that children who have been maltreated more often are more likely to have a criminal offence than children who have experienced one occurrence of maltreatment. Furthermore, Thornberry et al (2001) found that maltreatment in adolescence was more likely to be associated with offending outcomes that maltreatment that occurred in childhood only. Following this finding, it is hypothesised that the older the children are at age of the final maltreatment incident the more likely children are to commit offences in adolescence.

In relation to the second aim, we were also interested in comparing the offending patterns of children who had experienced maltreatment with the offending patterns of children who had not 
experienced maltreatment. It is hypothesised that children with child protection histories will have more serious offending careers than children with no child protection history.

The third aim is to examine pathways from child maltreatment to juvenile offending to address the question: What is the relationship between a child's maltreatment experience and their later offending behaviour? Specifically, we will focus on the timing, frequency and type of maltreatment and subsequent outcomes for children. This is an exploratory question and of interest is whether clusters of children with similar maltreatment experiences follow the same trajectories into adolescence.

\subsection{Method}

\subsubsection{Birth Cohort}

The children in this study included all members of the Queensland population who were born in 1983 and who had recorded contact with the child protection system and/or the juvenile justice system. Data was supplied by the Department of Families who are involved with, and record information regarding both notifications of child maltreatment and the appearance of children in court. Such recorded information includes a unique child identification number used on both child protection and juvenile justice databases. Consequently, children may be matched between databases and comparisons made without the need for identifying information to be released.

Data for this birth cohort was collected from 1983 to the end of 2000. As such, all children in the study would have turned 17 by the end of data collection. At 17 they would no longer be under the jurisdiction of the Department of Families and would no longer be considered to be ‘children' by the courts after this time. Thus, the 1983 birth cohort was chosen to provide a complete data-set 
allowing analysis of the relationship between childhood maltreatment and juvenile offending and, vice-versa, between juvenile offending and earlier maltreatment.

The characteristics of these children (those who had recorded contact with either the child protection or juvenile justice systems) may be compared with the characteristics of the overall 1983 birth cohort in Queensland. In 1983 there was approximately 41,700 births in Queensland (21,542 [52\%] males and 20,181 [48\%] females; Australian Bureau of Statistics, 1984a). With the effect of immigration from other countries and migration from other states, this population increased steadily until 2000 when it contained approximately 53,700 people (27,546 [51\%] males and 26,210 [49\%] females; Australian Bureau of Statistics, 2001a). Calculations based on 1996 census data indicate that approximately 2.6\% of this cohort is Indigenous Australians (2.1\% Aboriginal Australian, 0.5\% Torres Strait Islander; Australian Bureau of Statistics, 1998d). Also of interest, the death rate for the cohort as a whole represents a ' $U$ ' shape with a dramatic decrease in the rate from the baby years to middle childhood, increasing somewhat during the teenage years (Australian Bureau of Statistics, 1984b - 2001b; Australian Bureau of Statistics, 1984c - 2001c).

\subsubsection{Child Protection System}

For this birth cohort, two primary legislative Acts have determined the functioning of the child protection system, these being the Children's Services Act (1965) and the Child Protection Act (1999) which superseded the earlier Act. Although the two pieces of legislation are quite different, for the purposes of this study, the differences are minimal. Under the provision of both Acts, the Department of Families evaluates notifications of child maltreatment, finding them to be either substantiated or unsubstantiated, and organises for the protection of children (individuals aged 17 years and under) according to these findings. 
Under the Child Protection Act (1999) after a report of suspected harm (notification) has been made to the Department, one of two main responses may occur. When the level of harm or risk is not judged to be significant (and an initial assessment is not warranted), protective advice may be provided. Protective advice includes information, resources, referral and advice (Note that protective advice was not an official response category under the $1965 \mathrm{Act})$. The alternative response is an initial assessment that occurs when a notification indicates significant harm or risk of significant harm to the child. During the assessment stage it is decided whether there is sufficient evidence to substantiate the notification (i.e. the child has suffered harm, is suffering harm, or is at unacceptable risk of suffering harm). According to the Child Protection Act (1999, s9[1]) 'harm' to a child is any detrimental effect of a significant nature on the child's physical, psychological, or emotional wellbeing. It is immaterial how the harm is caused (s9[2]) and harm can be caused by;

(a) physical, psychological or emotional abuse or neglect; or

(b) sexual abuse or exploitation (s9[3]).

The definition of a 'child in need of protection' in the 1965 Act encompasses similar concepts, also outlining more specific illegal acts that are subsumed in the above definition.

Cases with an initial assessment outcome of 'substantiated' or 'at risk' are those where there is 'reasonable cause to believe that the child has been harmed or is at risk of harm' (Department of Families, 2002, p. 21) as opposed to unsubstantiated cases where 'reasonable cause' is lacking. Those cases that are 'substantiated' or 'at risk' are then categorised according to the type of harm the child has experienced (physical abuse, emotional abuse, sexual abuse, or neglect). In substantiated cases action is then taken to protect the child. Depending on the severity and circumstances of the case, protection may range from supervision through to out of home placement. 
At the time of a child protection notification, the Department records various data regarding the case. Aside from identifying information, this data includes: date of birth; sex; indigenous status, country of birth, and ethnicity; the age of the child at the time of notification; and the statistical local area in which the child lives. Data regarding the nature of the notifications includes the notified harm category (physical abuse, emotional abuse, sexual abuse, neglect), and the primary source of the notification.

After assessment further data are recorded including assessment start and end dates and the outcome of the assessment. If the outcome is either 'substantiated' or 'at risk', further data includes family type, the harm inflicted (specific description of the harm) and the assessed harm category (physical abuse, emotional abuse, sexual abuse, neglect) as well as outcomes of the assessments (such as placement action). For the purpose of clarity throughout the report, children who received substantiated notifications for maltreatment will be described as 'maltreated children’ and substantiated notifications will be labelled ‘maltreatment incidents'. Children who received notifications that were not substantiated will be referred to as children who were not maltreated.

\subsubsection{Child protection data}

In relation to the birth cohort, the Department of Families received 9,811 notifications of maltreatment over the 17-year period. Over the 17-year study period the absolute number of child protection notifications received by the Department have increased dramatically (Figure 4.1). Although these numbers are not presented as rates, the small changes in the relevant population figures can not account for the dramatic increase in numbers. Rather these numbers reflect changes in the child protection policies and strategies of the Department of Families. In 1997 a new child protection information system was implemented. Associated with this implementation were changes to definitions and the introduction of new terminology in relations to outcomes for child 
protection cases (Families, Youth and Community Care Queensland, 2000). Furthermore, the Department of Families notes that the increase in the number of notifications received 2000-2001 and attributes this to increased community awareness following the Forde Inquiry and other child protection initiatives (Department of Families, 2002).

\section{Figure 4.1}

Number of children who were subject to notifications in Queensland (1983-2000)



Approximately $54 \%$ of the notifications received were in relation to female children (46\% male) and approximately 15\% were in relation to indigenous Australian children. Figure 4.2 shows the number of notifications of maltreatment by age of the child. While the age of the children notified has changed over time this is more likely to reflect changes in departmental practices over the years rather than changes in maltreatment risk. The small numbers of children under the age of two years is indicative of the relatively small numbers of notifications in 1993 and 1994. 


\section{Figure 4.2}

Child protection records: Age of the birth cohort at notification of maltreatment

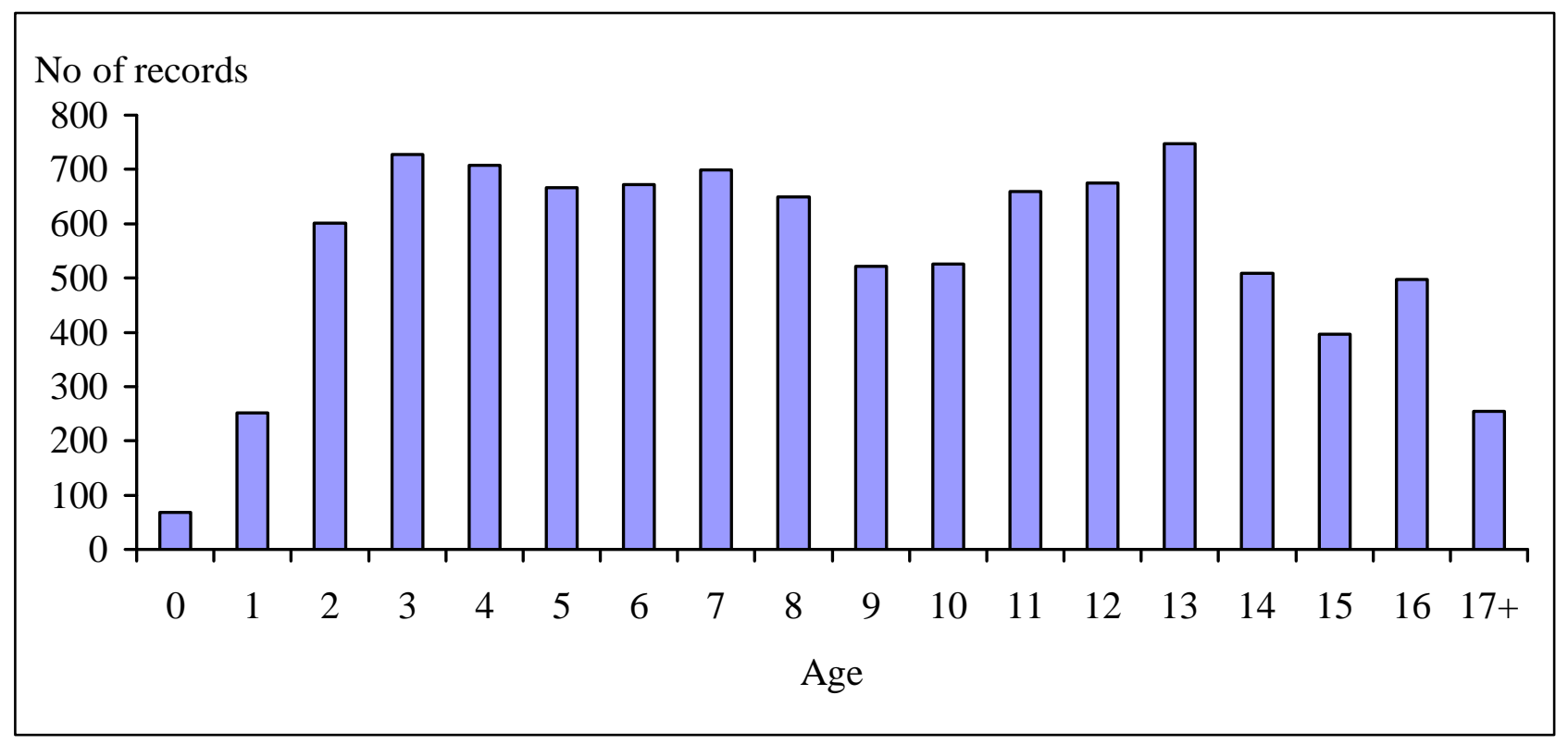

Of the 9,811 notifications of maltreatment, $51 \%(5,053)$ received an assessment of substantiated harm or at risk of harm. The substantiated / at risk cases were categorised according to the most serious maltreatment identified; 37\% neglect, 30\% physical abuse, 18\% emotional abuse, and 15\% sexual abuse. Fifty-five percent of substantiated maltreatment were in relation to female children and $17 \%$ were in relation to indigenous children.

While the notification based data provides an understanding of the functioning of the child protection system, it provides little information about the experiences of individual children. For the 1983 birth cohort, 4,656 distinct children accounted for the 9,811 notifications of maltreatment and 5,053 substantiated notifications of maltreatment. Close on $10 \%$ of all children born in Queensland in 1983 came into contact with the Department of Families over a child protection matter. Of the 4,656 children 53\% were female (accounting for 54\% of notifications) and 14\% were indigenous children (accounting for $15 \%$ of notifications). 


\subsubsection{Juvenile Justice System}

Youths come into contact with the juvenile justice system according to the regulations set out in the Juvenile Justice Act (1992). Under Queensland jurisdiction, children are only deemed to be offenders after the age of 10, before which they are not held criminally responsible although they may be involved in offending behaviour. Further, under section 5 of the Act, a 'child' is defined as “ a person who has not yet turned 17 years". Therefore the data related to offending behaviour applies only to such behaviour that occurred while the 1983 birth cohort was between and including 10 and 16 years of age.

Under section 22 (1(b)) of the Act “ a person who arrests a child must promptly advise of the arrest and whereabouts of the child the chief executive or a person who holds an office within the department nominated by the chief executive for the purpose”. Section 28 (1[b]) deals similarly with the issuing of attendance notices as an alternative to arrest. It is in this way that the Department of Families is notified of the commencement of a court proceeding against a child. Data is then recorded for each court appearance that the child is involved in and requires a departmental response. It is important to note therefore that the data obtained from the Department of Families is not a complete summary of offending behaviour. Rather the data only represents that behaviour for which the child has come to the attention of the police and for which the police have initiated court proceedings. Further, it must be considered that according to the principles of juvenile justice (section 4 [d]) "if a child commits an offence - the child should be treated in a way that diverts the child from the courts criminal justice system, unless the nature of the offence and the child's criminal history indicate that a proceeding for the offence should be started”. As such, law enforcement officers are encouraged to utilise alternatives such as cautioning or community conferencing unless a court appearance is deemed necessary. Therefore, data on court appearances probably represents the more serious offences and/or more serious offenders. Table 4.1 contains the 
types of action taken by the Queensland Police for juvenile crimes during the 1999 - 2000 financial year (Queensland Police Service, 2000 pp. 72-73). These figures reinforce the above assumption that court appearances will not be representative of all offending behaviour.

\section{Table 4.1}

Police responses to juvenile offending (1999 - 2000)

\begin{tabular}{lcccccrr}
\hline & Arrest & Caution & $\begin{array}{c}\text { Confer- } \\
\text { encing }\end{array}$ & $\begin{array}{c}\text { Notice to } \\
\text { attend }\end{array}$ & $\begin{array}{c}\text { Summon } \\
\text { s }\end{array}$ & Warrant & Other \\
\hline Person & 796 & 866 & 18 & 643 & 16 & 1 & 32 \\
Property & 5,513 & 10,091 & 173 & 6912 & 156 & 13 & 242 \\
Other & 1,806 & 3,303 & 34 & 2907 & 36 & 0 & 51 \\
\hline
\end{tabular}

Source: Queensland Police Service Annual Statistical Report

For each appearance in court, data is recorded pertaining to: the child, to the matter about which the child is appearing, and to procedural issues in the justice system. Information recorded about the child includes: the date of birth of the child, the child's birth place (Queensland, other States of Australia, outside Australia), the sex of the child, their indigenous status (Aboriginal Australian, Torres Strait Islander, both Aborigine and Torres Strait Islander, non-indigenous, unknown), the language the child speaks (English, indigenous Australian, other, unknown), the ethnicity or cultural background of the child (Anglo-Australian, indigenous Australian, other, unknown), the date of birth of the mother and date of birth of the father, and the statistical local area, suburb and post-code in which the child lives.

For each court appearance more than one matter may be dealt with. As such, data is recorded for each matter at each appearance. A matter number is recorded so that each particular matter may be followed across appearances (as more than one appearance is often required to finalise a matter). However, data are not collected on every appearance a child makes, only appearances where a Department of Families response is required (e.g., the child is held in custody). Department of 
Families provided flags on the data that identified when an offence matter was finalised, what the most serious offence type was that was finalised at this appearance and what the most serious outcome was at this appearance. Only these data were included in these analyses. Final outcome category includes: no case to be heard, not guilty, order made, divert from formal order, non supervised order, community supervision, immediate release, or detention served.

Matters are also recorded as being one of approximately 277 offence types. As this represents such a large number of offence types, analysis according to these categories would not be meaningful or reliable. As such the offence types were categorised according to the 16 broad classifications utilised by the Australian Bureau of Statistics known as the Australian Standard Offence Classification (ASOC) (Australian Bureau of Statistics, 1997d). These 16 offence classifications and the occurrence of such offences in the sample under study are outlined in Table 4.2.

\subsubsection{Juvenile Justice data}

Over the six-year period the birth cohort, was responsible for a total of 7,494 finalised appearances. Over the corresponding six-year period (1993 - 2000) there appears to be a slight increase in the absolute numbers of children offending (Figure 4.3). However, as these numbers are not presented as rates this may reflect an increase in the population numbers rather than an increase in offending behaviour or the official response to this behaviour. It is important to note that the 1999 and 2000 figures exclude court appearances resulting in a committal and are therefore not compatible with similar published statistics prior to this period (Department of Families 2001). 
Figure 4.3

Number of juvenile appearances for an offence matter in Queensland (1993-2000)

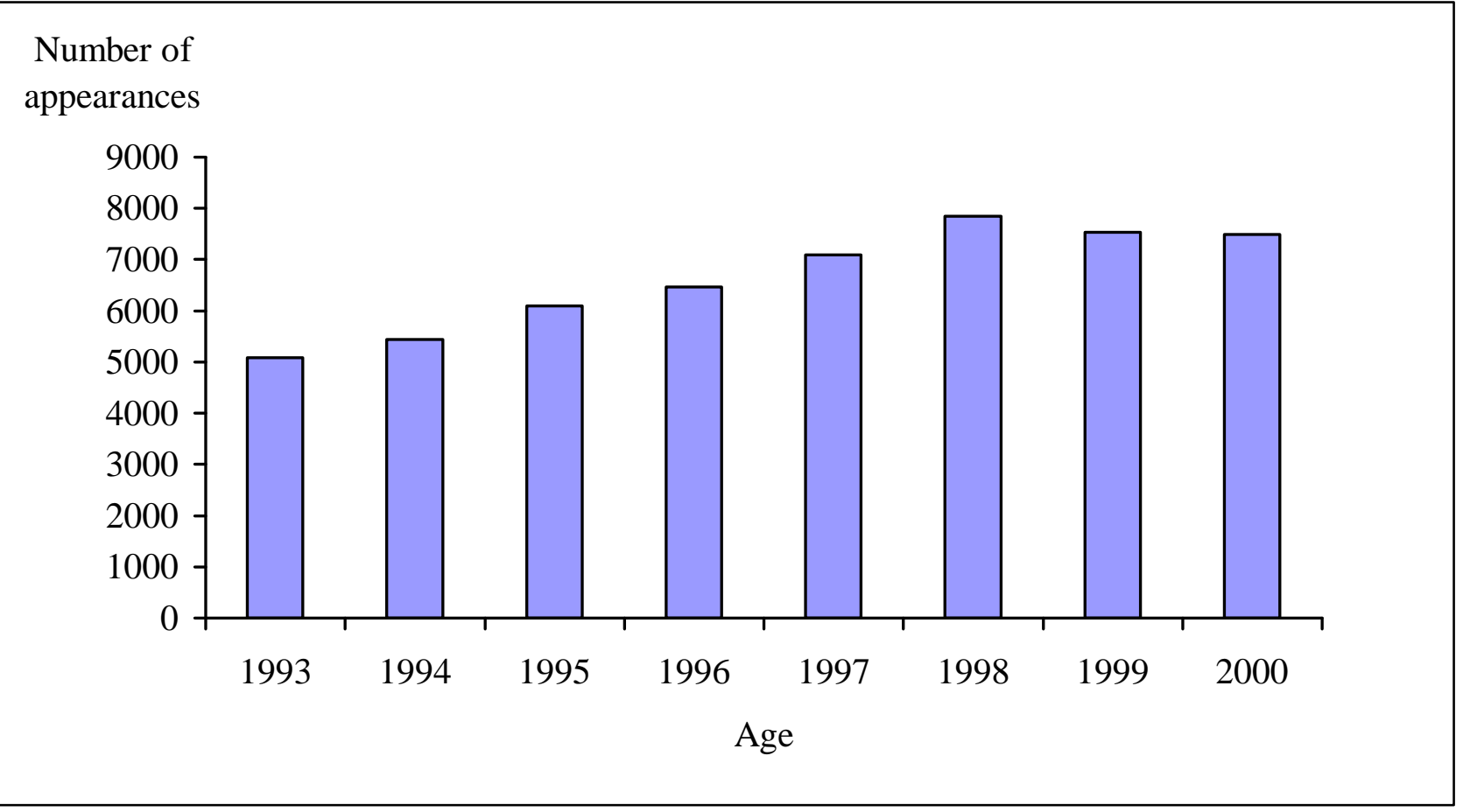

Of the 7,494 finalised appearances for this cohort, 38\% involved indigenous Australian young people, reflecting a substantial over-representation of the indigenous population that is consistent with the literature in this area (Wundersitz, 1996). Also consistent with general offending patterns, males accounted for the majority of appearances (82\%). Figure 4.4 displays the number of finalised court appearances by age. Again this data displays the expected pattern of increase in offending behaviour during adolescence, decreasing slightly in later adolescence. 


\section{Figure 4.4}

Finalised appearances for the birth cohort by age of the child



The most serious offence for each appearance was also recorded and this information is displayed in Table 4.2 according to the frequency of each of the 16 ASOC (Australian Standard Offence Classification; Australian Bureau of Statistics, 1997) offence categories. These were further collapsed into five categories.

Very few of the appearances heard before the children's courts resulted in a finding of not guilty (see Table 4.3). However, over 6\% resulted in a finding of no case to be heard. Finalised appearances in which the most serious outcome was not an order (e.g. there was no case to be heard or a finding of not guitly) were excluded from further analyses leaving 6,993 finalised appearances for an offence where an order was made. The majority of appearances resulted in a non-supervised order. 
Table 4.2

Number of finalised appearances for an offence by most serious offence

\begin{tabular}{llrr}
\hline & \multicolumn{1}{c}{ ASOC code } & $\mathrm{n}$ & $\%$ \\
\hline personal & Homicide and related offences & 7 & 0.1 \\
personal & Acts intended to cause injury & 511 & 6.8 \\
personal & Sexual assault and related offences & 51 & 0.7 \\
personal & Dangerous or negligent acts endangering persons & 66 & 0.9 \\
personal & Abduction and related offences & 6 & 0.1 \\
personal & Robbery, extortion and related offences & 166 & 2.2 \\
property & Unlawful entry with intent/burglary, break and enter & 1351 & 18.0 \\
property & Theft and related offences & 1926 & 25.7 \\
property & Deception and related offences & 195 & 2.6 \\
drug & Illicit drug offences & 742 & 9.9 \\
good order & Weapons and explosives offences & 57 & 0.8 \\
property & Property damage and environmental pollution & 357 & 4.8 \\
good order & Public order offences & 662 & 8.8 \\
traffic & Road traffic and motor vehicle regulatory offences & 567 & 7.6 \\
good order & Offences against justice procedures, government security & 766 & 10.2 \\
& and government operations & & \\
good order & Miscellaneous offences & 64 & 0.9 \\
\hline & Total & 7494 & 100 \\
\hline
\end{tabular}

Table 4.3

Number of finalised appearances for an offence by most serious outcome

\begin{tabular}{lrr}
\hline & Frequency & Percent \\
\hline No case to be heard & 496 & 6.6 \\
Not guilty & 3 & 0.0 \\
Divert from formal order & 66 & 0.9 \\
Non supervised order & 3815 & 50.9 \\
Community supervision & 2705 & 36.1 \\
Immediate release & 213 & 2.8 \\
Detention served & 193 & 2.6 \\
\hline Total & 7491 & 100.0 \\
\hline
\end{tabular}

Note. Missing = 3

Again, while the above information gives a general overview of contacts with the juvenile justice system, for the purpose of this study the offending behaviour of individual children is more 
pertinent than individual appearances. In the 1983 birth cohort there were 2,687 distinct children with finalised court appearances. This accounts for just over 5\% of all children in Queensland. Of these children 94 (3.5\%) received only an outcome of no case to be heard or they were found not guilty. These children were excluded from further analyses. This left 2,593 children who had at least one finalised appearance for an offence where an order was made. Of these children, 22\% were indigenous (accounting for 38\% of all appearances) and $79 \%$ of the children were male (accounting for $82 \%$ of all appearances). 


\section{CHAPTER 5: RESULTS}

We have presented the results in four sections. In the first two sections we address the first aim of the research by describing children's experiences with the Department of Family Services. While acknowledging that many children who are maltreated and offend do not come to the attention of the Department, these results include only those children who came to the attention of the Department because of maltreatment (through a notification) or offending (through the children's courts). In the first section, we examine the children with a child protection notification to investigate their experiences of maltreatment. In the second section, we examine children's offending behaviour over the period that they are under the jurisdiction of the children's courts (10 years to 16 years).

In the third section we address the second aim of the research, which is to look at the relationship between child maltreatment and juvenile offending. We merge the two databases, selecting children with at least one child protection notification and children with a finalised juvenile justice appearance for a least one offence. To attend to the first hypothesis, that children who have been maltreated are more likely to offend than children for whom there is no maltreatment, we compare children with only unsubstantiated notifications for maltreatment with children with substantiated notifications. We establish that child maltreatment is a risk factor for later offending. To answer the second research question of whether a child's experience of maltreatment impacts on the likelihood of them offending, we examine the prospective route from child maltreatment to offending by comparing maltreated children who offended with maltreated children who did not offend. We found support for the second hypothesis that children with more maltreatment incidents are more likely to offend than children with a single maltreatment incident. The third hypothesis that maltreatment in adolescence was more likely to lead to offending that maltreatment in childhood 
alone was also supported, with the age of last maltreatment incident significantly affecting the likelihood of offending. To answer the final research question of whether a child's maltreatment impacted on their offending patterns, we examine, retrospectively, the offending careers of children with a child maltreatment history with the careers of those children with no child maltreatment history. These two analyses are performed using direct logistic regression, with dichotomised outcome measures of, offending or not offending, and maltreated or not maltreated.

In the final section we address the third aim of the research, which is to examine the pathways from maltreatment to offending. The question we are addressing here is: What is the relationship between a child's maltreatment experience and their later offending behaviour? The aim of these analyses is to examine if particular maltreatment experiences in childhood (e.g., timing, frequency, and type) are related to offending patterns. Only children who had been maltreated and later offended were included in these analyses. To examine the relationship between child maltreatment and offending behaviour a canonical correlation was performed.

\subsection{Children with a Child Protection Notification}

\subsubsection{Substantiated and unsubstantiated notifications}

In the 1983 birth cohort there were 4,656 distinct children with a child protection notification. These children counted for 9,811 notifications and 5,053 substantiated notifications of maltreatment. The maximum number of notifications a child had was $23(M=2.1, S D=2.6)$, and the maximum number of maltreatment episodes was $17(M=1.8, S D=1.5)$.

A small number of the 1983 birth cohort accounted for large number of notifications of maltreatment received by the Department (Table 5.1). Whereas $57 \%$ of children had only one 
notification, the notifications these children received accounted for $27 \%$ of all notifications. However, 9\% of children had five or more notifications (up to a maximum of 23) and the notifications these children received over their childhood accounted for 32\% of all notifications. Similarly, $40 \%$ of maltreated children had only one substantiated notification for maltreatment and accounted for $37 \%$ of all maltreatment records. However, $4 \%$ of the maltreated children had five or more substantiated notifications (up to a maximum of 17) and these children accounted for $22 \%$ of all maltreated children.

\section{Table 5.1}

Distinct children (1983 birth cohort) by number of notifications and number of substantiated maltreatment episodes

\begin{tabular}{ccccc}
\hline $\begin{array}{c}\text { Number of } \\
\text { notifications }\end{array}$ & $\begin{array}{c}\text { Total number of } \\
\text { children }\end{array}$ & $\begin{array}{c}\text { \% of } \\
\text { children }\end{array}$ & $\begin{array}{c}\text { Total number of } \\
\text { notifications }\end{array}$ & $\begin{array}{c}\text { \% of } \\
\text { notifications }\end{array}$ \\
\hline 1 & 2636 & 56.6 & 2636 & 26.9 \\
2 & 942 & 20.2 & 1884 & 19.2 \\
3 & 446 & 9.6 & 1338 & 13.6 \\
4 & 213 & 4.6 & 852 & 8.7 \\
$5+$ & 419 & 9.0 & 3101 & 31.6 \\
\hline Total & 4656 & 100 & 9811 & 100 \\
\hline Number of & Total number of & $\%$ of & Total number of & $\%$ of \\
substantiated & children & children & substantiated & substantiated \\
maltreatment & & & maltreatment & maltreatment \\
\hline 0 & 1771 & 38.0 & & \\
1 & 1895 & 40.7 & 1895 & 37.5 \\
2 & 520 & 11.2 & 1040 & 20.6 \\
3 & 203 & 4.4 & 609 & 12.0 \\
4 & 96 & 2.1 & 384 & 7.6 \\
$5+$ & 171 & 3.7 & 1125 & 22.3 \\
\hline Total & 4656 & 100 & 5053 & 100 \\
\hline
\end{tabular}

Note. $\mathrm{N}=4,656$ children

Children's experiences of notifications and maltreatment are examined in Table 5.2. Thirty eight percent of children had only unsubstantiated notifications of maltreatment. That is, after the Department had investigated, it was determined that the child was not at risk or, or being 
maltreated. The majority of these children with only unsubstantiated notifications had only one notification (76\%), however, four children had seven notifications all of which, when investigated, were unsubstantiated. Cross sectional analysis of the substantiation rates of child protection notifications indicated that about $49 \%$ of notifications were unsubstantiated (Section 4.2.3). However, over childhood, the majority of children (62\%) who came to the notice of the Department of Families for a child protection matter ended up with at least one substantiated notification of maltreatment. Over a quarter of the children had both had both substantiated and unsubstantiated notifications and these children accounted for over $50 \%$ of all notifications.

\section{Table 5.2}

Individual children's experience with notifications by number of substantiated and unsubstantiated notifications.

\begin{tabular}{|c|c|c|c|c|c|c|c|}
\hline \multirow[b]{2}{*}{ Outcomes } & \multicolumn{2}{|c|}{ Children } & \multicolumn{2}{|c|}{$\begin{array}{l}\text { Children with } \\
\text { one notification }\end{array}$} & \multirow[t]{2}{*}{$\begin{array}{l}\text { Max. no. of } \\
\text { notifications }\end{array}$} & \multicolumn{2}{|c|}{$\begin{array}{c}\text { Total no of } \\
\text { notifications }\end{array}$} \\
\hline & $\mathrm{n}$ & $\%$ & $\mathrm{n}$ & $\%$ & & $\mathrm{n}$ & $\%$ \\
\hline $\begin{array}{l}\text { Only unsubstantiated } \\
\text { notifications }\end{array}$ & 1771 & 38.0 & 1349 & 52.2 & 7 & 2372 & 24.2 \\
\hline $\begin{array}{l}\text { Only substantiated } \\
\text { notifications }\end{array}$ & 1645 & 35.3 & 1287 & 48.8 & 12 & 2236 & 22.8 \\
\hline $\begin{array}{l}\text { Both substantiated and } \\
\text { unsubstantiated notifications }\end{array}$ & 1240 & 26.6 & & & 23 & 5203 & 53.0 \\
\hline Totals & 4656 & 100 & 2636 & 100 & & 9811 & \\
\hline
\end{tabular}

Note. $\mathrm{N}=4,656$ children

\subsubsection{Biographical details: Sex, Indigenous status and Age at First and Final Maltreatment Incident}

Of the 4,656 children 53\% were female. When these figures are compared with the Queensland population figures (see section 4.2.1) for this age group it appears that girls are more likely than boys to be notified for maltreatment. Eight percent $(N=394)$ of children had missing data for indigenous status. Of the remaining children, $12 \%(N=514)$ were aboriginal Australian and less 
than 1\% (27) were Torres Strait Islanders. Both groups of indigenous children are over-represented in child protection notifications. Estimates indicate that only 2.1\% of the 1983 birth cohort is aboriginal Australian and 0.5\% are Torres Strait Islanders (see Section 4.2.1). While acknowledging that the overrepresentation appears much higher for Aboriginal Australians than for Torres Strait Islanders, these two groups of children were categorised under indigenous Australian for further analyses.

When the substantiation rates for notifications are examined by sex and indigenous status, girls were no more likely than boys to have at least one substantiated notification $\left(\chi^{2}(1, N=4,656)=\right.$ $0.01, p=.51$ ). Furthermore, of the 2,885 maltreated children, boys and girls had equal numbers of substantiated maltreatment incidents $(t(2,883)=0.99, p=0.80)$. The mean number of substantiated notifications children had was $1.71(S D=1.52)$.

Of children with substantiated notifications, 160 had missing data for indigenous status. Indigenous children (72\%) were more likely than non-indigenous children (63\%) to have at least one substantiated notification $\left(\chi^{2}(1, N=4,262)=18.67, p<.001\right)$. For the 2,725 children with substantiated notifications, indigenous children had significantly higher numbers of substantiated notifications $(t(2,723)=4.50, p<.001)$. The mean number of substantiated notifications for indigenous children was $2.08(S D=1.75)$ and non-indigenous children was $1.70(S D=1.49)$.

The mean age for first maltreatment incident was $7.56(S D=4.45)$ and for the final maltreatment incident was $8.95(S D=4.42)$. Figure 5.1 shows the distribution of age at the first incident and age at the final incident across the years. Unfortunately, these figures are more reflective of the systems response to maltreatment over the 17-year period than of the experiences of the children. 


\section{Figure 5.1}

Age of child at first maltreatment incident and final maltreatment incident



Boys were significantly younger than girls both at the first incident $(t(2883)=3.57, p<.001)$ and the final incident $(t(2883)=4.48, p<.001$; see Table 5.3). Indigenous children were the same age as non-indigenous children at the first maltreatment incident $(t(2723)=-1.39, \mathrm{p}=.17)$ but were significantly older than non-indigenous children at the final incident $(t(2723)=-2.12, p<.05)$.

Table 5.3

Mean age of children at first and final maltreatment incident by sex and indigenous status

\begin{tabular}{|c|c|c|c|c|c|c|}
\hline & & & \multicolumn{2}{|c|}{ Age at first incident } & \multicolumn{2}{|c|}{ Age at final incident } \\
\hline & & & $M$ & $S D$ & $M$ & $S D$ \\
\hline \multirow[t]{2}{*}{ Sex } & Male & 1330 & 7.24 & 4.29 & 8.55 & 4.31 \\
\hline & Female & 1555 & 7.84 & 4.61 & 9.29 & 4.48 \\
\hline \multirow{2}{*}{$\begin{array}{l}\text { Indigenous } \\
\text { status }\end{array}$} & Indigenous & 391 & 7.14 & 4.13 & 9.24 & 4.21 \\
\hline & Non-indigenous & 2334 & 7.47 & 4.45 & 8.73 & 4.42 \\
\hline Total & & 2885 & 7.56 & 4.48 & 8.95 & 4.42 \\
\hline
\end{tabular}

Using the age at the first maltreatment incident and the age at the final incident children (who had at least one substantiated notification) were categorised into the four categories identified by 
Thornberry et al (2001): (1) Early childhood-only maltreatment (birth through to age 5 years); (2) Late childhood only maltreatment (ages 6 - 11 years); (3) Adolescence-only maltreatment (ages 12 17 years); and (4) Persistent maltreatment (maltreatment occurred in both childhood and adolescence). Children were reasonably evenly split across the four categories with $25 \%$ of maltreated children in the early childhood-only maltreatment, $34 \%$ of children in the late childhoodonly maltreatment, $26 \%$ of children in the adolescence only maltreatment and $15 \%$ in the persistent maltreatment.

Using these categories, girls had different timing of maltreatment to boys $\left(\chi^{2}(3, N=2,885)=\right.$ 20.77, $p<.001$ ). Female were more likely to be in the adolescent only (29\%) and persistent maltreatment (16\%) groups than males (23\% vs 13\%). Indigenous children had different timing to non-indigenous children $\left(\chi^{2}(3, N=2,725)=21.39, p<.001\right)$. Indigenous children $(22 \%)$ were far more likely than non-indigenous children (13\%) to be in the persistent maltreatment group (Table

\section{Table 5.4}

Timing of maltreatment by sex and indigenous status.

\begin{tabular}{lcccccccc}
\hline & \multicolumn{4}{c}{ Sex } & \multicolumn{3}{c}{ Indigenous status } \\
\cline { 2 - 9 } & \multicolumn{2}{c}{ Male } & \multicolumn{2}{c}{ Female } & \multicolumn{2}{c}{ Indigenous } & $\begin{array}{c}\text { Non- } \\
\text { indigenous }\end{array}$ \\
\cline { 2 - 9 } & $\mathrm{n}$ & $\%$ & $\mathrm{n}$ & $\%$ & $\mathrm{n}$ & $\%$ & $\mathrm{n}$ & $\%$ \\
\hline $\begin{array}{l}\text { Early childhood only } \\
\text { maltreatment (0-5) }\end{array}$ & 367 & 27.6 & 350 & 22.5 & 86 & 22.0 & 613 & 26.3 \\
$\begin{array}{l}\text { Late childhood only } \\
\text { maltreatment (6-11) }\end{array}$ & 475 & 35.8 & 511 & 32.8 & 126 & 32.2 & 819 & 35.1 \\
$\begin{array}{l}\text { Adolescent only } \\
\text { maltreatment (12+) }\end{array}$ & 310 & 23.3 & 451 & 29.0 & 92 & 23.5 & 589 & 25.2 \\
$\begin{array}{l}\text { Persistent } \\
\text { maltreatment }\end{array}$ & 177 & 13.3 & 244 & 15.7 & 87 & 22.3 & 313 & 13.4 \\
\hline Total & 1329 & 100 & 1556 & 100 & 382 & 100 & 2334 & 100 \\
\hline
\end{tabular}




\subsubsection{Type and Frequency of Maltreatment Incidents}

Of the 2,885 maltreated children, 1,895 had only one substantiated notification for maltreatment. Of the children with multiple maltreatment incidents, 380 had been victims of only one type of maltreatment and 610 had been victims of multiple types of maltreatment.

Children with only one substantiated notification, children with multiple incidents but only one maltreatment type, and children with multiple maltreatment types were compared on sex, indigenous status, age at the first maltreatment incident, age at the last maltreatment incident and timing of maltreatment. Girls and boys were equally represented in the three groups $\left(\chi^{2}(2, N=\right.$ $2,885)=1.92, p=.38$ ). There were significant differences between the indigenous and nonindigenous children in their experience of maltreatment $\left(\chi^{2}(2, N=2,725)=24.31, p<.001\right)$ (Figure 5.2). Non-indigenous children were more likely (67\%) to have only one experience of substantiated maltreatment than indigenous children (56\%). However, 29\% of indigenous children experienced multiple types of maltreatment compared with $20 \%$ of non-indigenous children.

\section{Figure 5.2}

Maltreatment experience by indigenous status.

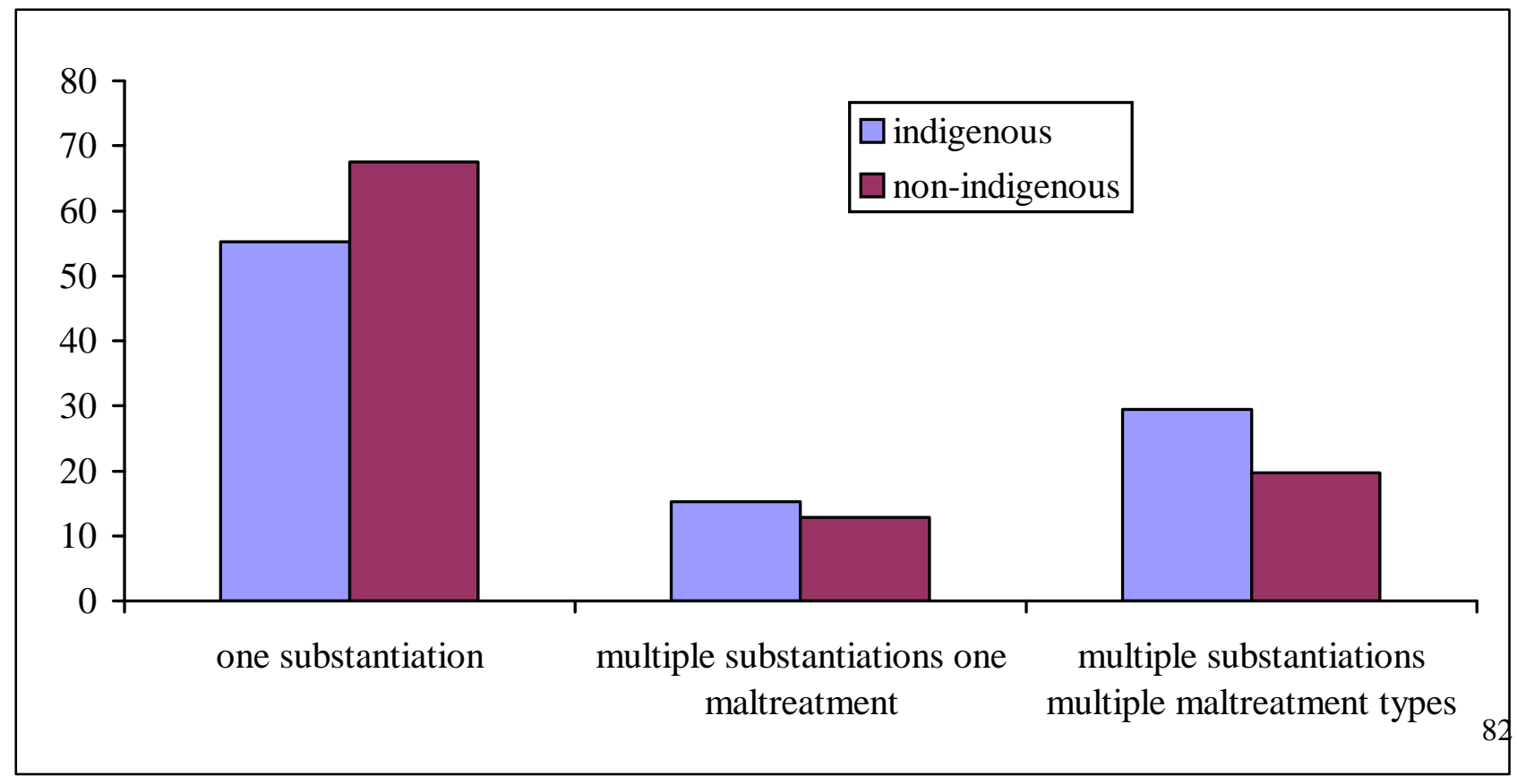


Significant differences were found among the three groups for both age of the first maltreatment incident $(F(2,2882)=94.20, p<.001)$ and age of the final maltreatment incident $(F(2,2882)=76.69$, $p<.001$ ). Table 5.5 presents the means and standard deviations for each of the groups. Post hoc analysis revealed significant age differences among the three groups. At the age of the first maltreatment incident children with only one incident were older than children who had multiple incidents of only one type of maltreatment. Furthermore, children who were the victim of multiple maltreatment types were the youngest at the age of the first incident. The reverse pattern was apparent at the age of the final maltreatment incident. Children who were the victims of multiple types of maltreatment were the oldest at the age of the final maltreatment incident. Maltreated children who had multiple incidents of one type of maltreatment were younger at the final maltreatment incident. Children with multiple types of maltreatment were young at their first maltreatment incident and old at their last maltreatment incident.

\section{Table 5.5}

Mean age at the first maltreatment incident and at the final maltreatment incident by maltreatment experience

\begin{tabular}{|c|c|c|c|c|}
\hline \multirow[b]{2}{*}{ Maltreatment experience } & \multicolumn{2}{|c|}{ Age at first incident } & \multicolumn{2}{|c|}{ Age at final incident } \\
\hline & $\mathrm{M}$ & $S D$ & M & $S D$ \\
\hline $\begin{array}{l}\text { One substantiated incident } \\
\text { Multiple substantiated incidents }\end{array}$ & 8.34 & 4.51 & 8.34 & 4.51 \\
\hline one maltreatment type & 6.63 & 4.16 & 8.97 & 4.16 \\
\hline $\begin{array}{l}\text { Multiple substantiated incidents } \\
\text { multiple maltreatment types }\end{array}$ & 5.73 & 3.88 & 10.83 & 3.71 \\
\hline Total & 7.56 & 4.47 & 8.95 & 4.42 \\
\hline
\end{tabular}

When the four groups as defined by Thornberry et al (2001); early childhood only maltreatment, late childhood only maltreatment, adolescent only maltreatment and persistent maltreatment are compared with the child's maltreatment experience, significant differences were found $\left(\chi^{2}(6, N=\right.$ $2,885)=768.07, p<.001$; see Table 5.6). Again, children who were the victims of multiple 
maltreatment types were more likely to be in the persistent group (54\%) than in the other three groups. That is, the maltreatment started when they were young, took various forms and continued into adolescent.

\section{Table 5.6}

Children's experience of maltreatment by timing of maltreatment.

\begin{tabular}{|c|c|c|c|c|c|c|c|}
\hline & \multicolumn{2}{|c|}{$\begin{array}{c}\text { one substantiated } \\
\text { notification }\end{array}$} & \multicolumn{2}{|c|}{$\begin{array}{c}\text { multiple } \\
\text { substantiated } \\
\text { notifications / one } \\
\text { maltreatment type }\end{array}$} & \multicolumn{2}{|c|}{$\begin{array}{c}\text { multiple } \\
\text { substantiated } \\
\text { notifications / } \\
\text { multiple } \\
\text { maltreatment types }\end{array}$} & \multirow[b]{2}{*}{ totals } \\
\hline & $\mathrm{n}$ & $\%$ & $\mathrm{n}$ & $\%$ & $\mathrm{n}$ & $\%$ & \\
\hline $\begin{array}{l}\text { early childhood only } \\
\text { maltreatment }(0-5)\end{array}$ & 550 & 29.0 & 99 & 26.1 & 68 & 11.1 & 717 \\
\hline $\begin{array}{l}\text { late childhood only } \\
\text { maltreatment }(6-11)\end{array}$ & 738 & 38.9 & 116 & 30.5 & 132 & 21.6 & 986 \\
\hline $\begin{array}{l}\text { adolescent only } \\
\text { maltreatment }(12+)\end{array}$ & 607 & 32.1 & 72 & 18.9 & 82 & 10.8 & 761 \\
\hline \multirow[t]{2}{*}{$\begin{array}{l}\text { persistent } \\
\text { maltreatment }\end{array}$} & & & 93 & 24.5 & 328 & 53.8 & 328 \\
\hline & 1895 & & 380 & & 610 & & 2885 \\
\hline
\end{tabular}

When children are only exposed to one type of maltreatment it is possible to categorise them into the type of maltreatment they experienced (Table 5.7). Children who had only one maltreatment incident were equally likely to be the victims of wither physical abuse or neglect. For children with multiple experiences of one type of maltreatment neglect was the most frequent form of maltreatment they experienced. Very few children had multiple maltreatment experiences for only sexual abuse. 


\section{Table 5.7}

Children only substantiated for one type of maltreatment by maltreatment type.

\begin{tabular}{lrrrrrr}
\hline & \multicolumn{2}{c}{$\begin{array}{c}\text { One substantiated } \\
\text { notification }\end{array}$} & \multicolumn{2}{c}{$\begin{array}{c}\text { Multiple substantiated } \\
\text { notifications one } \\
\text { maltreatment type }\end{array}$} & Total number of children \\
\cline { 2 - 7 } & $\mathrm{n}$ & $\%$ & $\mathrm{n}$ & $\%$ & $\mathrm{n}$ & $\%$ \\
\hline Sex abuse & 421 & 22.2 & 33 & 8.7 & 454 & 20.0 \\
Physical abuse & 579 & 30.6 & 115 & 30.3 & 694 & 30.5 \\
Neglect & 578 & 30.5 & 184 & 48.4 & 762 & 33.5 \\
Emotional abuse & 317 & 16.7 & 48 & 12.6 & 365 & 16.0 \\
\hline Total & 1,895 & 100.0 & 380 & 100.0 & 2,275 & 100 \\
\hline
\end{tabular}

When children are the victims of multiple types of maltreatment it is more difficult to understand their maltreatment experiences. The 610 children (13\% of all children) with multiple types of maltreatment accounted for 2,226 substantiated notifications (44\% of all substantiations; see Table 5.8). These children were most likely to have been the victims of both physical abuse and neglect (24\%) but every type of maltreatment combination was represented. It is apparent that many children are victims of multiple types of abuse. That is, these children are living in situations where, over their childhood, they are exposed to different types of maltreatment. 


\section{Table 5.8}

Children with multiple types of abuse by number of children and total number of maltreatment incidents

\begin{tabular}{lrrrr}
\hline \multicolumn{1}{c}{ Type of abuse } & \multicolumn{2}{c}{ Distinct children } & \multicolumn{2}{c}{$\begin{array}{c}\text { Substantiated } \\
\text { notifications }\end{array}$} \\
\cline { 2 - 5 } & \multicolumn{1}{c}{$\mathrm{n}$} & \multicolumn{1}{c}{$\mathrm{n}$} & $\%$ \\
\hline sexual + physical & 51 & 8.36 & 131 & 5.88 \\
sexual + emotional & 25 & 4.10 & 69 & 3.10 \\
sexual + neglect & 51 & 8.36 & 147 & 6.60 \\
physical + emotional & 102 & 16.72 & 317 & 14.24 \\
physical + neglect & 145 & 23.77 & 484 & 21.74 \\
emotional + neglect & 101 & 16.56 & 314 & 14.11 \\
sexual + physical + neglect & 31 & 5.08 & 151 & 6.78 \\
sexual + physical + emotional & 15 & 2.46 & 67 & 3.01 \\
physical + emotional + neglect & 50 & 8.20 & 289 & 12.98 \\
emotional + sexual + neglect & 18 & 2.95 & 80 & 3.59 \\
emotional + sexual + physical + neglect & 21 & 3.44 & 177 & 7.95 \\
\hline
\end{tabular}

Two classification schemes were employed to examine the maltreatment children who were the victims of a number of different types of maltreatment. In the first, children were placed into one of four maltreatment groups based on Cicchetti and Rogosh (1997) classification scheme. If a child experienced any sexual abuse they were placed in the sex abuse category, if they experienced any physical abuse but not sexual abuse they were placed in the physical abuse category. If they experienced no sexual abuse, no physical abuse but neglect and emotional abuse they were placed in the neglect category. Finally if they only experienced emotional abuse they were placed in the emotional abuse category. Using this classification scheme the 2,885 children who experienced maltreatment were placed into one of the four groups. Twenty-three percent of children were classified as sexually abused, 34\% of children were classified as physically abused, $30 \%$ of children were classified neglected and 13\% of children were classified emotionally abused (Table 5.9). 


\section{Table 5.9}

Type of maltreatment (Cicchetti and Rogosh, 1997) classification by number of substantiated notifications

\begin{tabular}{lcccccr}
\hline & \multicolumn{2}{c}{$\begin{array}{c}\text { One maltreatment } \\
\text { type }\end{array}$} & \multicolumn{2}{c}{$\begin{array}{c}\text { Multiple maltreatment } \\
\text { types }\end{array}$} & \multicolumn{2}{c}{ Total } \\
\cline { 2 - 7 } & $\mathrm{n}$ & $\%$ & $\mathrm{n}$ & $\%$ & $\mathrm{n}$ & $\%$ \\
\hline Sex abuse & 454 & 20.0 & 212 & 34.8 & 666 & 23.1 \\
Physical abuse & 694 & 30.5 & 297 & 48.7 & 991 & 34.4 \\
Neglect & 762 & 33.5 & 101 & 16.6 & 863 & 29.9 \\
Emotional abuse & 365 & 16.0 & & & 365 & 12.7 \\
\hline Total & 2275 & 100.0 & 610 & 100.0 & 2885 & 100.0 \\
\hline
\end{tabular}

Children who had only been the victim of one type of maltreatment were most likely to be victims of physical abuse or neglect. However, of children with multiple incidents for multiple types of maltreatment over a third of children had been the victim of sexual abuse as well as other abuse types, and half the children had been the victim of physical abuse but not sexual abuse. Children who were the victims of multiple types of maltreatment had substantiated maltreatment for 483 incidents of emotional abuse. However, all these children also had been victims of other types of maltreatment.

The differential impact of each type of maltreatment was also examined by separate comparisons of maltreated children who had experienced each type of maltreatment with children who had not experienced that type of maltreatment. Table 5.10 shows that neglect and physical abuse were the most common form of maltreatment. 
Table 5.10

Maltreated children's experience of each type of maltreatment

\begin{tabular}{lcccccccc}
\hline & \multicolumn{2}{c}{ Sexual abuse } & \multicolumn{2}{c}{ Physical abuse } & Neglect & \multicolumn{2}{c}{$\begin{array}{c}\text { Emotional } \\
\text { abuse }\end{array}$} \\
\hline $\begin{array}{l}\text { Children with one } \\
\text { maltreatment type }\end{array}$ & 454 & 68.2 & 694 & 62.6 & 762 & 64.6 & 365 & 52.4 \\
$\begin{array}{l}\text { Children with multiple } \\
\text { maltreatment types }\end{array}$ & 212 & 31.8 & 415 & 37.4 & 417 & 35.4 & 332 & 47.6 \\
\hline & 666 & $23.1^{*}$ & 1109 & $38.4^{*}$ & 1179 & $40.9^{*}$ & 697 & $24.2^{*}$ \\
\hline
\end{tabular}

Note. * Percentages do not add to 100 as children could experience more than one type of maltreatment.

Using Cicchetti and Rogosh (1997) classification scheme for maltreatment, maltreated children were compared across the maltreatment categories (sexual, physical, neglect and emotional) for differences in sex, indigenous status, age at the first maltreatment incident, age at the final maltreatment incident and timing of maltreatment. Maltreated boys and girls displayed different patterns of maltreatment $\left(\chi^{2}(3, N=2,885)=141.71, p<.001\right)$. Girls were more likely than boys to be victims of sexual abuse (32\% of girls and $13 \%$ of boys). However, boys were more likely than girls to be categorised as physically abused (40\% of boys compared with $30 \%$ of girls) and neglected (33\% of boys compared with $26 \%$ of girls). Maltreated boys and girls were equally likely to be categorised as emotional abused (13\%; see Figure 5.3). 
Figure 5.3

Children's experience of maltreatment (Cicchetti \& Rogosh, 1997) by sex

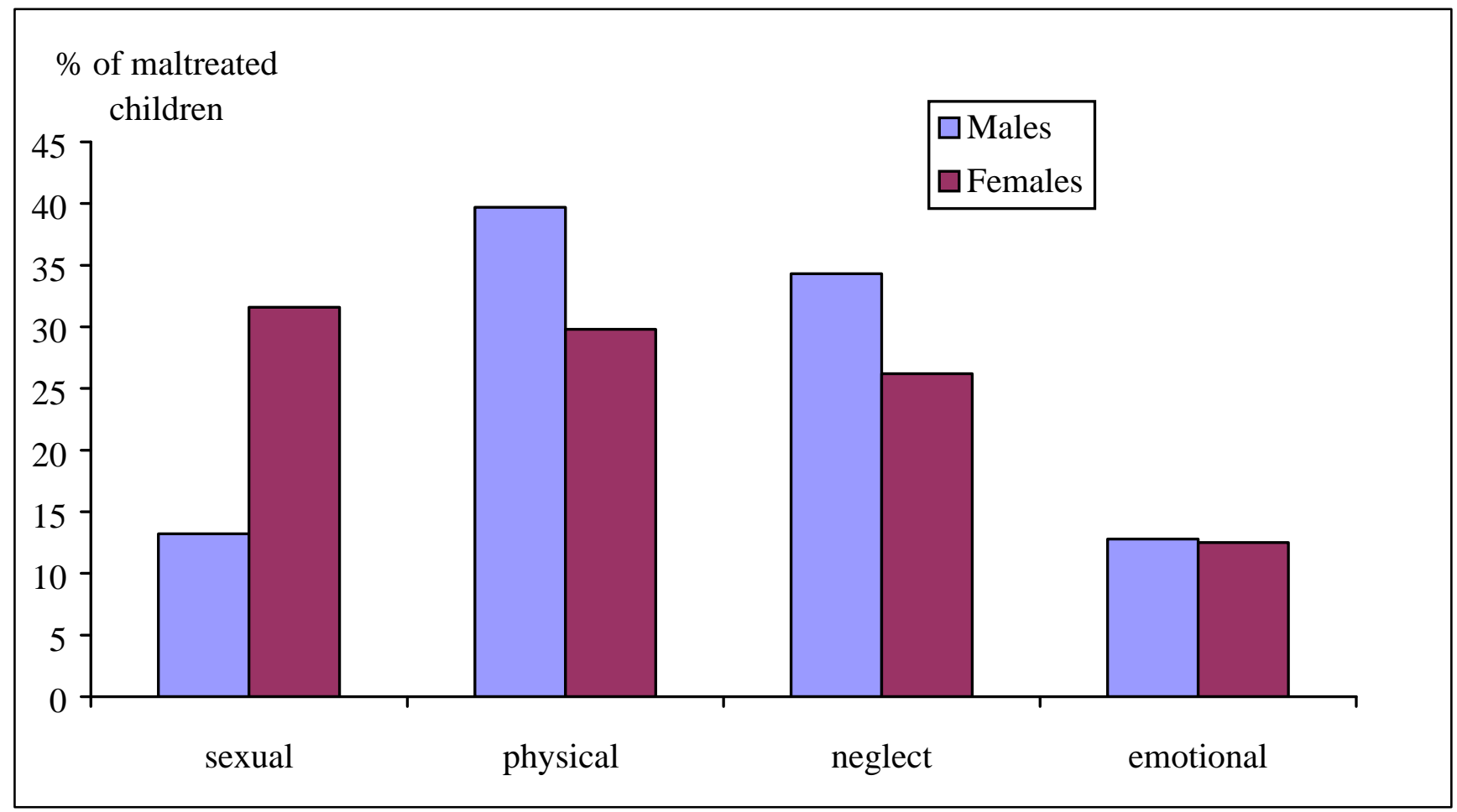

Indigenous children had different experiences of maltreatment from non-indigenous children $\left(\chi^{2}(3\right.$, $N=2,725)=43.59, p<.001)$. Maltreated indigenous children were less likely than non-indigenous children to be the victims of emotional abuse (7\% compared with 13\%) and sexual abuse (17\% compared with 25\%). In contrast, indigenous children were more likely than non-indigenous children to be the victims of neglect (43\% compared with 28\%). Indigenous children were no more likely than non-indigenous children to be the victim of physical abuse (34\%; see Figure 5.4) 


\section{Figure 5.4:}

Children's experience of maltreatment (Cicchetti \& Rogosh, 1997) by indigenous status

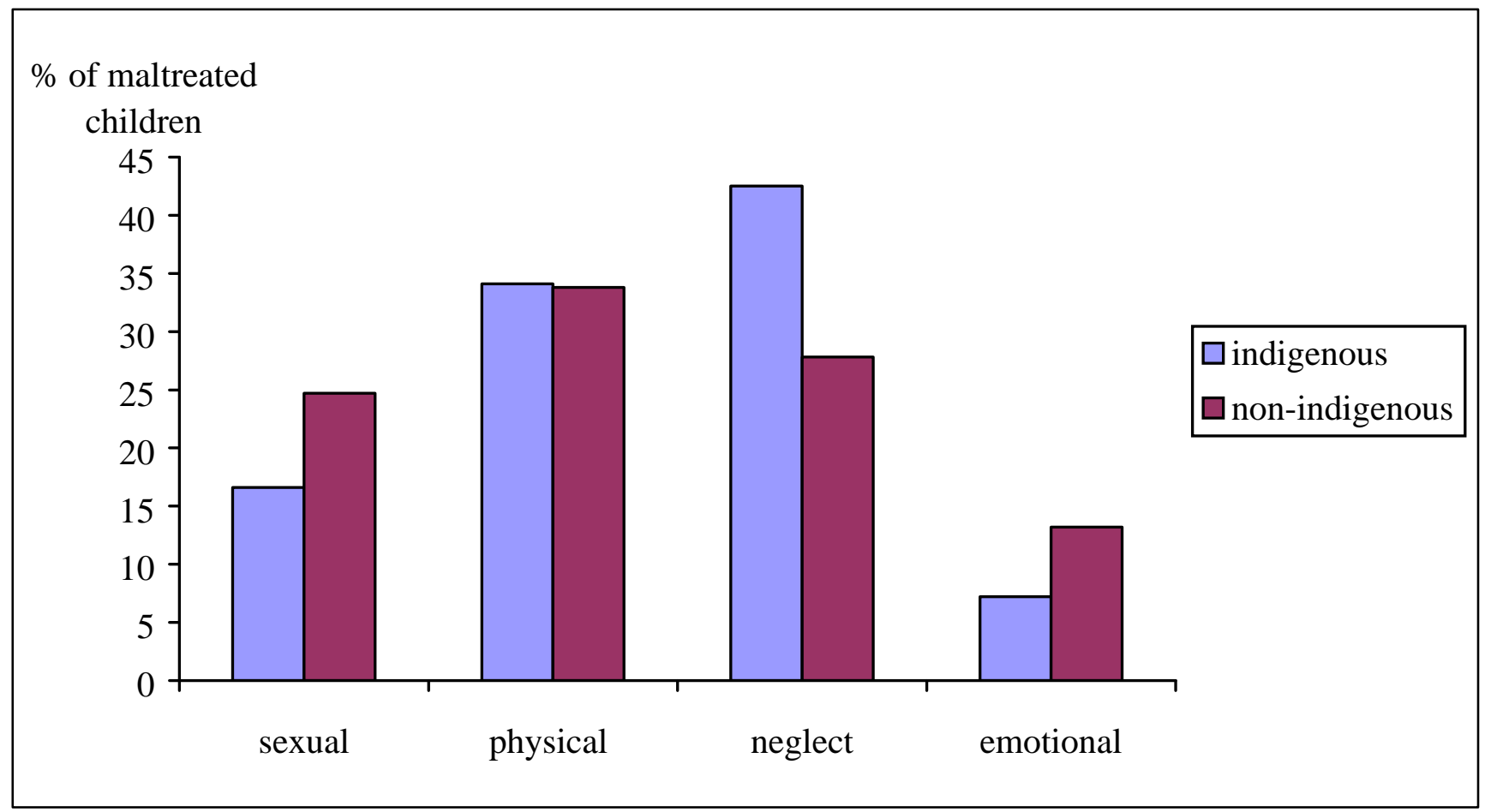

Significant differences across the four maltreatment categories were found for the age of the child at the first $(F(3,2881)=39.94, p<.001)$ and the final incident $(F(3,2881)=43.33, p<.001)$ (Figure 5.5). At the first maltreatment incident, children categorised as emotionally abused were older $(M=$ 9.42 years, $S D=3.89$ ) than children who were categorised into the other three age groups. Children who were physically abused were older $(M=8.00$ years, $S D=4.75)$ than children who were sexually abused or neglected. There were no differences in age between children who were classified as sexually abused $(M=7.05$ years, $S D=3.89)$ or neglected $(M=6.67$ years, $S D=4.21)$.

At the final maltreatment incident, children categorised as physically $(M=9.88$ years, $S D=4.46)$ or emotionally abused $(M=9.54$ years, $S D=4.61)$ were significantly older than children who were sexually abused or neglected. Children who were sexually abused $(M=8.92$ years, $S D=4.02)$ were significantly older at the final maltreatment incident than children who were neglected $(M=7.65$ 
years, $S D=4.67)$. There were no age differences between physically and emotionally abused children.

Figure 5.5

Children's experience of maltreatment (Cicchetti and Rogosh, 1997) by mean age at the first and final maltreatment incident



Using Thornberry et al's (2001) classification, children's timing of maltreatment was significantly different between children who had experienced each type of maltreatment $\left(\chi^{2}(9, N=2,885)=\right.$ 252.54, $p<$.001) (Table 5.11). Children who experienced early childhood only maltreatment were most likely to experience neglect (41\%) than the other three classifications of abuse. Children who experienced late childhood only maltreatment were equally likely to experience sexual, physical and neglect. Children in adolescent only group were most likely to experience physical abuse (42\%) as with children in the persistent group (47\%). 
Table 5.11

Children's timing of maltreatment by type of maltreatment experienced.

\begin{tabular}{lrrrrrrrr}
\hline & $\begin{array}{c}\text { Early childhood } \\
\text { only maltreatment } \\
(0-5)\end{array}$ & $\begin{array}{c}\text { Late childhood only } \\
\text { maltreatment } \\
(6-11)\end{array}$ & $\begin{array}{c}\text { Adolescent only } \\
\text { maltreatment } \\
(12+)\end{array}$ & \multicolumn{2}{c}{$\begin{array}{c}\text { Persistent } \\
\text { maltreatment }\end{array}$} \\
\cline { 2 - 9 } & $\mathrm{n}$ & $\%$ & $\mathrm{n}$ & $\%$ & $\mathrm{n}$ & $\%$ & $\mathrm{n}$ & $\%$ \\
\hline Sexual & 135 & 18.9 & 285 & 29.0 & 108 & 14.3 & 133 & 31.7 \\
Physical & 207 & 28.9 & 272 & 27.7 & 315 & 41.7 & 196 & 46.6 \\
Neglect & 291 & 40.6 & 306 & 31.2 & 174 & 23.0 & 89 & 21.2 \\
Emotional & 83 & 11.6 & 119 & 12.1 & 159 & 21.0 & 2 & 0.5 \\
\hline Total & 716 & 100 & 982 & 100 & 756 & 100 & 420 & 100 \\
\hline
\end{tabular}

\subsubsection{Outcomes of maltreatment: Out of home placement}

Unfortunately there was no indication on the database of the severity of the maltreatment a child experiences. However, information was provided as to whether the child was placed outside the home. Of children who were the victims of maltreatment, $37 \%(1,083)$ were placed outside the home at least once. The maximum number of out of home placements a child had in 17 years was seven.

Girls were no more likely than boys to be placed outside the home $\left(\chi^{2}(1, N=2,885)=1.39, p=\right.$ .24). Indigenous children were more likely to be placed outside the home than non-indigenous children $\left(\chi^{2}(1, N=2,722)=35.96, p<.001\right)$. Just over half of the indigenous children $(50 \%)$ in the sample were placed outside the home compared with 35\% of non-indigenous children. Interestingly, children who were placed outside the home were significantly older at their first maltreatment incident $(M=8.17, S D=4.86)$ than children who were not placed outside the home $(M=7.20, S D$ = 4.19) $(\mathrm{t}(2885)=-5.68, p<.001)$. Furthermore, children placed outside the home were significantly $(\mathrm{t}(2885=-16.61, \mathrm{p}<.001)$ older at their final maltreatment incident $(M=10.63, S D=$ 4.30) than children not placed outside the home $(M=7.94, S D=4.77)$. 
Children who had experienced out of home placement had significantly different timing of maltreatment $\left(\chi^{2}(3, N=2,885)=307.38, p<.001\right)$. Of children who had early childhood only maltreatment, 26\% experienced an out of home placement. Of children who had late childhood only maltreatment, 24\% experienced an out of home placement. However, for adolescent only maltreatment and persistent maltreatment the proportion was significantly higher (50\% and 66\% respectively).

Children with out of home placement had significantly more substantiated notifications $(M=2.37$, $S D=2.07)$ than children with no out of home placements $(M=1.38, S D=.87)(t(1315.56)=$ 15.03, $p<.001)$. Almost two thirds of children (64\%) who had experienced multiple types of maltreatment had at least one out of home placement compared with $27 \%$ of children who had only one experience of abuse.

Children who were classified as physically abused were more likely (41\%) to be placed out side the home than children who where classified as neglected (37\%) or either sexually (35\%) or emotionally abused $(35 \%)\left(\chi^{2}(3, N=2,885)=11.33, p<.01\right)$.

\subsection{Children with a finalised juvenile justice appearance}

\subsubsection{Biographical details: Sex, indigenous status, and age at first offence}

The 1983 birth cohort contained 2,687 distinct children with finalised juvenile justice appearances. These children accounted for 7,494 finalised appearances. Of these children 94 (4\%) received an outcome of no case to be heard or they were found not guilty. As these children had never been found guilty of an offence they were excluded from further analyses. This left 2,593 children who had at least one finalised appearance for an offence where an order was made. 
Of these children, $22 \%$ were indigenous and $21 \%$ of the children were female. There were significant sex differences between indigenous and non-indigenous children $\left(\chi^{2}(1, N=2,384)=\right.$ 10.86, $p<.001)$.

\section{Table 5.12}

Young offenders by sex and indigenous status

\begin{tabular}{|c|c|c|c|c|c|c|}
\hline \multirow[b]{3}{*}{ Indigenous status } & \multicolumn{4}{|c|}{ Sex } & \multirow{2}{*}{\multicolumn{2}{|c|}{ Total }} \\
\hline & \multicolumn{2}{|c|}{ Males } & \multicolumn{2}{|c|}{ Females } & & \\
\hline & $n$ & $\%$ & $n$ & $\%$ & $n$ & $\%$ \\
\hline Non-indigenous & 1431 & 77.1 & 349 & 70.1 & 1780 & 75.6 \\
\hline Indigenous & 425 & 22.9 & 149 & 29.9 & 574 & 24.4 \\
\hline & 1856 & & 498 & & 2354 & \\
\hline
\end{tabular}

The age at first finalised appearance climbed steadily from age 10 to 16 (Figure 5.5). The children over the age of 16 years were children who had committed their offence at age 16 but the case was not finalised until after the child had turned 17. Under Queensland legislation, young people who offended after the age of 16 are treated as adults. Thirteen percent of children had their first finalised appearance before the age of 14 . 
Figure 5.6

Age of children at first finalised appearance

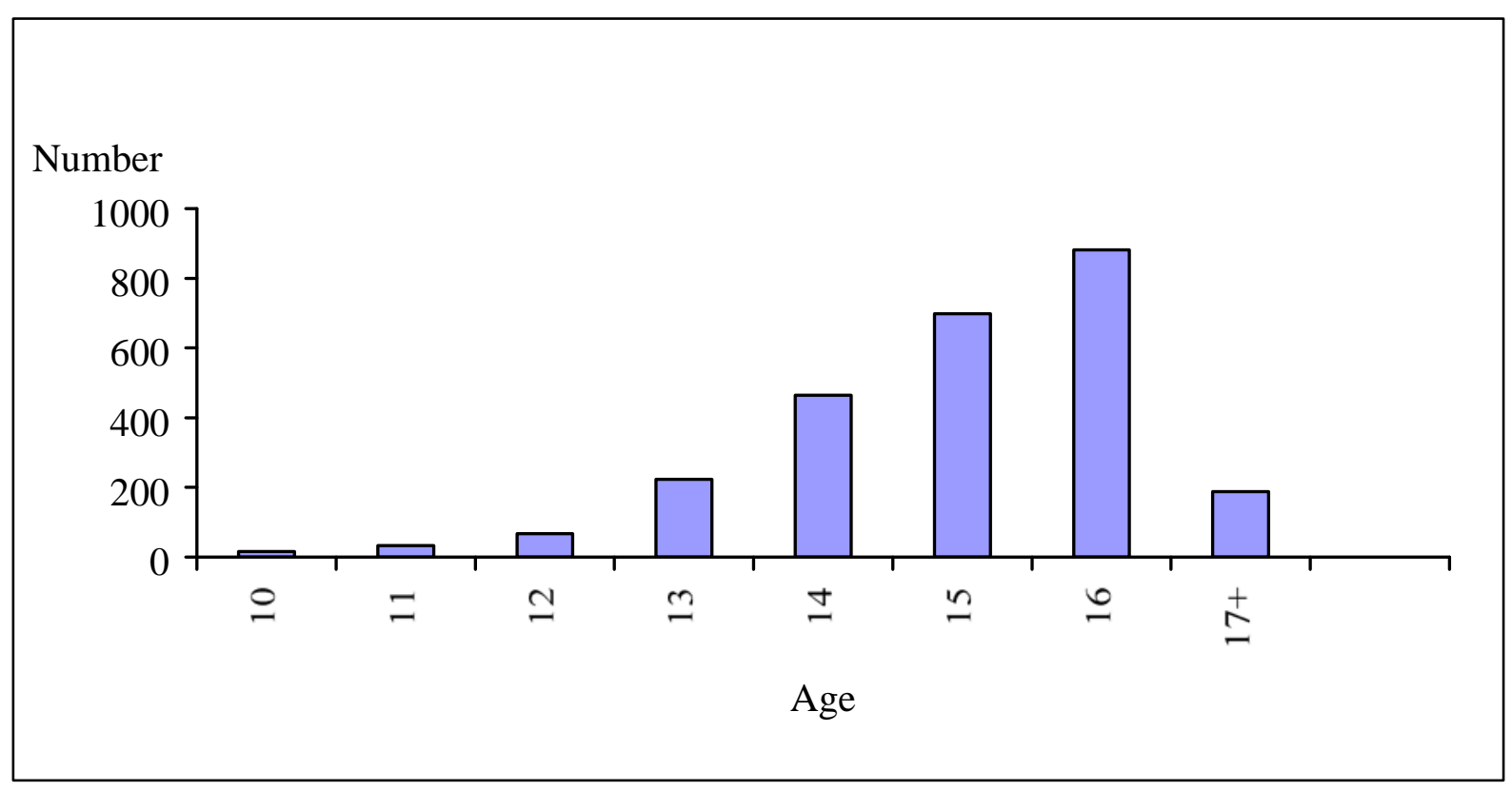

\subsubsection{Repeat offending}

Just over $50 \%$ of children had only one finalised appearance. The maximum number of finalised appearances were an order was made was 22 (Table 5.13). Only 9\% of children had more than six finalised appearances and these children accounted for 34\% of all finalised appearances. The 17\% of children with more than four appearances accounted for almost half (49\%) of all finalised appearances. In line with findings on repeat offending (Wundersitz, 1996) a small number of children account for a large percentage of the juvenile offending behaviour. 
Table 5.13

Multiple finalised appearances where an order was made by number of children

\begin{tabular}{crccc}
\hline No. of appearances & No. of children & \% of children & $\begin{array}{c}\text { No. of } \\
\text { appearances }\end{array}$ & $\begin{array}{c}\text { \% of } \\
\text { appearances }\end{array}$ \\
\hline 1 & 1,315 & 50.7 & 1,315 & 18.8 \\
2 & 456 & 17.6 & 912 & 13 \\
3 & 228 & 8.8 & 684 & 9.8 \\
4 & 160 & 6.2 & 640 & 9.1 \\
5 & 100 & 3.9 & 500 & 7.1 \\
$6+$ & 334 & 12.8 & 2,944 & 42.2 \\
\hline Total & 2,593 & 100 & 6,995 & 100 \\
\hline
\end{tabular}

To examine if the number of appearances varied by age at first appearance category, sex or indigenous status and $2 \times 2 \times 2$ ANOVA was performed. Significant main effects were found for all three variables age $(F(1,2462)=272.28, p<.001)$, sex $(F(1,2462)=73.88, p<.001)$ and indigenous status $(F(1,2462)=118.00, p<.001)$. Interaction effects were found for age at first appearance and sex $(F(1,2462)=45.02, p<.001)$ and for age at first appearance and indigenous status $(F(1,2462)=27.11, p<.001)$. All children who had their first finalised appearance before the age of 14 , regardless of age and sex, had more extensive offending histories $(M=5.99, S D=$ 4.68) than children whom had their first offence after the age of $14(M=2.20, S D=2.07)$. However, when the means for age are examined by indigenous status it is apparent that the indigenous children who first offend before the age of 14 have substantially more finalised juvenile appearances than non-indigenous children who first offend before the age of 14 . This disparity is not as evident in children who have their first offence after the age of 14 . A similar pattern is apparent when the sex of the child is examined with boys whose first offences is before the age of 14 having more finalised offences than girls who first offend before the age of 14. Again, after the age of 14, girls and boys have similar number of finalised appearances. 
Table 5.14

Mean number of finalised appearances by age of first offence, indigenous status and sex.

\begin{tabular}{|c|c|c|c|c|c|c|c|}
\hline & & \multicolumn{4}{|c|}{ Age } & & \\
\hline & & \multicolumn{2}{|c|}{$<14$} & \multicolumn{2}{|c|}{$14+$} & \multicolumn{2}{|c|}{ Total } \\
\hline & & $M$ & $S D$ & $M$ & $S D$ & $M$ & $S D$ \\
\hline \multirow{2}{*}{$\begin{array}{l}\text { Indigenous } \\
\text { status }\end{array}$} & Indigenous & 7.48 & 4.70 & 2.97 & 2.65 & 4.17 & 3.87 \\
\hline & Non-indigenous & 4.65 & 4.24 & 1.99 & 1.85 & 2.25 & 2.32 \\
\hline \multirow[t]{2}{*}{ Sex } & Female & 4.02 & 3.63 & 1.92 & 1.90 & 2.30 & 2.41 \\
\hline & Male & 6.38 & 4.81 & 2.18 & 2.05 & 2.82 & 3.00 \\
\hline Total & & 5.99 & 4.68 & 2.20 & 2.07 & 2.71 & 2.86 \\
\hline
\end{tabular}

\subsubsection{Type of offending: Most serious finalised offence}

The analyses examining the type of offending a child had a finalised appearance for is based on the most serious offence finalised at any one appearance. A child could have multiple offences finalised at any one appearance. In these analyses those other offences are not taken into account. Just over half of all children had only one finalised appearance $(N=1,315)$. These children were more likely to have a property offence (42\%) as their most serious finalised offence than any other type of offence (Table 5.15). Almost a quarter of children (24\%) with more than one offence had multiple offences for the same type of offence. The majority of these children had property offences. As the majority of offending was classified as property offences this result is not surprising. It could be with finer categorisation of the property offence type (e.g. shop lifting, break and enter, graffiti) a more informative picture of children's offending behaviour may emerge. As is stands it is difficult to draw any conclusions concerning offence specialisation among young offenders. Whereas the data were available to perform these analyses it was beyond the scope of this report. 
Table 5.15

Children with only one type of finalised offence by most serious finalised offence

\begin{tabular}{lcccc}
\hline & \multicolumn{2}{c}{ Only one finalised offence } & \multicolumn{2}{c}{$\begin{array}{c}\text { Multiple finalised offences } \\
\text { only one offence type }\end{array}$} \\
\hline \multicolumn{1}{c}{ Offence type } & n children & $\%$ & n children & $\%$ \\
\hline Personal offences & 138 & 10.5 & 7 & 75.5 \\
Property offences & 556 & 42.3 & 228 & 4.0 \\
Drug offences & 152 & 11.6 & 12 & 10.9 \\
Good order offences & 290 & 22.0 & 33 & 7.3 \\
Traffic offences & 179 & 13.6 & 22 & 100 \\
\hline Total & 1,315 & 100 & 302 & \\
\hline
\end{tabular}

To examine if their was any evidence that children with multiple appearances changed their offending patterns over time, the offence types were examined by the appearance number (Table 5.16). This analysis is an appearance based not child based analysis. However, it appears that children with multiple appearances are most likely to commit a property offence as their first offence. There appears to be a gradual increase in the likelihood that a young person will commit a personal offence or a good order offence with increasing number of offences. Again, without more detail about individual offences it is difficult to conclude that young people's offending becomes more serious or changes over time. 


\section{Table 5.16}

Offence type by number of offences by appearance number

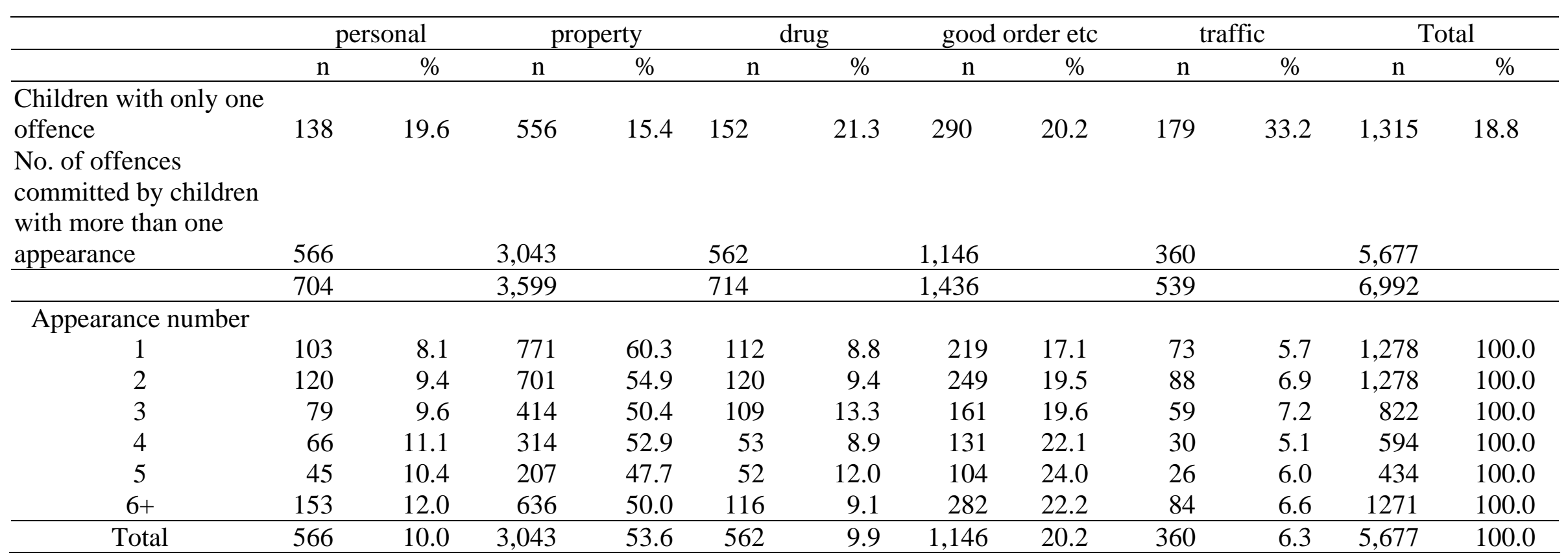




\subsubsection{Outcome of offending: Most serious finalised outcome}

Table 5.17 provides the most serious outcome for an appearance by the number of previous appearances for a child. Children get increasingly severe outcome as they progress through the system with the majority of children receiving a non supervised order on their first appearance. Very few children received a detention sentence on their first appearance in the courts. However, the majority of detention sentences were delivered to children on their 10 appearance in the court.

Table 5.17

Most serious outcome from the court by court appearance number

\begin{tabular}{|c|c|c|c|c|c|c|c|c|c|c|c|}
\hline \multicolumn{12}{|c|}{ Most serious outcome } \\
\hline & \multicolumn{2}{|c|}{$\begin{array}{l}\text { Divert from } \\
\text { formal order }\end{array}$} & \multicolumn{2}{|c|}{$\begin{array}{c}\text { Non } \\
\text { Supervised } \\
\text { order } \\
\end{array}$} & \multicolumn{2}{|c|}{$\begin{array}{l}\text { Community } \\
\text { Supervision }\end{array}$} & \multicolumn{2}{|c|}{$\begin{array}{c}\text { Immediate } \\
\text { Release }\end{array}$} & \multicolumn{2}{|c|}{$\begin{array}{l}\text { Detention } \\
\text { Served }\end{array}$} & \\
\hline & $n$ & $\%$ & $n$ & $\%$ & $n$ & $\%$ & $n$ & $\%$ & $n$ & $\%$ & Total \\
\hline 1 & 30 & 45.5 & 1,927 & 50.5 & 618 & 22.8 & 12 & 5.6 & 6 & 3.1 & 2,593 \\
\hline 2 & 10 & 15.2 & 709 & 18.6 & 536 & 19.8 & 17 & 8.0 & 6 & 3.1 & 1,278 \\
\hline 3 & 1 & 1.5 & 363 & 9.5 & 440 & 16.3 & 11 & 5.2 & 7 & 3.6 & 822 \\
\hline 4 & 2 & 3.0 & 234 & 6.1 & 315 & 11.6 & 28 & 13.1 & 15 & 7.8 & 594 \\
\hline 5 & 3 & 4.5 & 162 & 4.2 & 224 & 8.3 & 22 & 10.3 & 23 & 11.9 & 434 \\
\hline 6 & 1 & 1.5 & 122 & 3.2 & 174 & 6.4 & 22 & 10.3 & 15 & 7.8 & 334 \\
\hline 7 & 5 & 7.6 & 87 & 2.3 & 116 & 4.3 & 19 & 8.9 & 16 & 8.3 & 243 \\
\hline 8 & 1 & 1.5 & 62 & 1.6 & 90 & 3.3 & 21 & 9.9 & 10 & 5.2 & 184 \\
\hline 9 & 2 & 3.0 & 44 & 1.2 & 58 & 2.1 & 14 & 6.6 & 13 & 6.7 & 131 \\
\hline $10+$ & 11 & 16.7 & 105 & 2.8 & 134 & 5.0 & 47 & 22.1 & 82 & 42.5 & 379 \\
\hline & 66 & & 3,813 & & 2,707 & & 213 & & 193 & & 6,992 \\
\hline
\end{tabular}

The most serious outcome a child received over their juvenile offending history was determined. The majority of children received an unsupervised order. Only 105 of the children served a period of detention, although a further 100 of children were sentenced and then an immediate release order was imposed. There was a significant difference in the mean number of finalised offences by the type of most serious outcome $(F(4,2587)=606.84, p<$ .001). These means are presented in Table 5.18. Post hoc analysis indicated that sentences 
became more serious as a child's offending history grew. Children with a community supervision order had significantly more appearances than children with a non-supervised order or diversion. Similarly, children with a custodial sentence had significantly more finalised offences than children on immediate release who had significantly more than children on supervised orders.

Table 5.18

Most serious outcome for a child by mean number of finalised appearances.

\begin{tabular}{lrrrrr}
\hline \multicolumn{1}{c}{ Most serious outcome } & $N$ & $\%$ & $M$ & $S D$ & Max. \\
\hline Divert from formal order & 16 & 0.6 & 1.00 & 0.00 & 1 \\
Non supervised order & 1,375 & 53.1 & 1.35 & 0.73 & 7 \\
Community supervision & 996 & 38.4 & 3.42 & 2.44 & 14 \\
Immediate release & 100 & 3.9 & 7.25 & 3.98 & 21 \\
Detention served & 105 & 4.0 & 9.50 & 4.83 & 22 \\
\hline Total & 2,592 & 100 & 2.70 & 2.83 & 22 \\
\hline
\end{tabular}

Indigenous children were more likely than non-indigenous children to have a serious sentence as their most serious outcome $\left(\chi^{2}(1, N=2,383)=151.30, p<.001\right)$. Over half of nonindigenous children received a non-supervised order as their most serious outcome (Table 5.19). Only $2 \%$ of non-indigenous children served a period of detention compared with $10 \%$ of indigenous children.

Table 5.19

Most serious court outcome for a child by indigenous status

\begin{tabular}{lrrrrr}
\hline & \multicolumn{2}{c}{$\begin{array}{c}\text { Indigenous } \\
\text { children }\end{array}$} & \multicolumn{2}{c}{$\begin{array}{c}\text { Non-indigenous } \\
\text { children }\end{array}$} \\
\cline { 2 - 6 } \multicolumn{1}{c}{ Most serious outcome } & $N$ & $\%$ & $N$ & $\%$ & Total \\
\hline Divert from formal order & 1 & 0.2 & 13 & 0.7 & 14 \\
Non supervised order & 193 & 33.2 & 1,009 & 56.0 & 1,202 \\
Community supervision & 279 & 48.0 & 684 & 38.0 & 963 \\
Immediate release & 48 & 8.3 & 52 & 2.9 & 100 \\
Detention served & 60 & 10.3 & 44 & 2.4 & 104 \\
\hline Total & 581 & 100 & 1,802 & 100 & 2,383 \\
\hline
\end{tabular}


Boys received more serious outcomes than girls $\left(\chi^{2}(1, N=2,591)=21.78, p<.001\right.$; see Table 5.20). Girls were more likely than boys to have a non-supervised order as their most serious outcome. Almost $9 \%$ of boys were sentenced to detention, although half were on the immediate release program.

Table 5.20

Most serious court outcome for a child by sex

\begin{tabular}{lrrrrr}
\hline \multirow{2}{*}{\multicolumn{1}{c}{ Most serious outcome }} & $N$ & $\%$ & $N$ & $\%$ & Total \\
\cline { 2 - 6 } & 2 & 0.4 & 14 & 0.7 & 16 \\
\hline Divert from formal order & 337 & 60.9 & 1,037 & 50.9 & 1,374 \\
Non supervised order & 186 & 33.6 & 810 & 39.7 & 996 \\
Community supervision & 17 & 3.1 & 83 & 4.1 & 100 \\
Immediate release & 11 & 2.0 & 94 & 4.6 & 105 \\
Detention served & 553 & 100 & 2,038 & 100 & 2,591 \\
\hline Total & & & &
\end{tabular}

Children whose first offence was under the age of 14 were more likely to end up with a custodial sentence $\left(\chi^{2}(1, N=2,592)=268.32, p<.001\right.$; see Table 4.21). Over a quarter of children who had their first appearance under the age of either served a period of detention or received an immediate release order.

Table 5.21

Most serious order the child received by age of child at first appearance

\begin{tabular}{|c|c|c|c|c|c|}
\hline & \multicolumn{2}{|c|}{ Less than 14 years } & \multicolumn{2}{|c|}{14 years or older } & \\
\hline Most serious outcome & $N$ & $\%$ & $N$ & $\%$ & Total \\
\hline Divert from formal order & 1 & 0.3 & 15 & 0.7 & 16 \\
\hline Non supervised order & 90 & 26.6 & 1,285 & 57.0 & 1,375 \\
\hline Community supervision & 153 & 45.1 & 843 & 37.4 & 996 \\
\hline Immediate release & 38 & 11.2 & 62 & 2.8 & 100 \\
\hline Detention served & 57 & 16.8 & 48 & 2.1 & 105 \\
\hline & 339 & 100 & 2,253 & 100 & 2,592 \\
\hline
\end{tabular}




\subsection{Links between Child Protection and Juvenile Justice}

The second aim of the research was to examine the relationship between maltreatment and juvenile offending. The total number of children in the merged data was 6,649 (Table 5.22). The child protection data included both children with substantiated notifications and those with no substantiated notifications.

Table 5.22

Children in the 1983 birth cohort with a child protection notification and/or a finalised juvenile justice appearance for an offence.

\begin{tabular}{cccrc}
\hline & & \multicolumn{2}{c}{$\begin{array}{c}\text { Children with a finalised } \\
\text { juvenile justice appearance }\end{array}$} & \\
\cline { 2 - 4 } & & Yes & No & \\
\hline Children with a child & Yes & 694 & 3,962 & 4,656 \\
\cline { 2 - 4 } protection notification & No & 1,993 & 0 & \\
\hline & & 2,687 & & 6,649 \\
\hline
\end{tabular}

Of the 94 children who had a finalised appearance in the juvenile court but had either no case to answer or were found not guilty, 17 had a previous child protection notification. These 17 children were placed in the child protection only category. The remaining 77 children were removed from the juvenile justice data. Thirty-one of the remaining 677 children who appeared in both databases had their first maltreatment incident before their first finalised appearance in the juvenile justice court. While it is possible to speculate that these children came to the attention of the child protection authorities because of their offending behaviour, there is no way of confirming this with the current data. Consequently, these children were excluded from further analyses leaving 6,541 children, of whom 3,978 (60.8\%) children with 
only a child protection record, 647 (9.9\%) children with both a child protection record and an offending record, and 1,916 (29.3\%) children with only a juvenile justice record.

These data were examined both prospectively (child protection to juvenile justice) and retrospectively (juvenile justice to child protection).

\subsubsection{Prospective designs}

When the 4,625 children who had a child protection notification are examined, $14 \%$ of children had a subsequent finalised appearance for a juvenile justice matter. This was significantly higher $\left(\chi^{2}(1, N=4,626)=42.53, p<.001\right)$ for children with at least one notification that is substantiated (17\%) than for children with no substantiated notifications (10\%; see Table 5.23). Therefore the first hypothesis, that children who have been maltreated are more likely to offend than children for whom there is no evidence of maltreatment, is supported.

Table 5.23

Number of children notified by outcome of notification and juvenile justice appearance

\begin{tabular}{|c|c|c|c|c|c|c|}
\hline & \multicolumn{4}{|c|}{ Substantiated notifications } & \multirow{2}{*}{\multicolumn{2}{|c|}{ Total }} \\
\hline & \multicolumn{2}{|c|}{ no } & \multicolumn{2}{|c|}{ yes } & & \\
\hline & $n$ & $\%$ & $n$ & $\%$ & $n$ & $\%$ \\
\hline Only child protection records & 1,598 & 90.2 & 2,380 & 83.4 & 3,978 & 86.0 \\
\hline Both child protection and juvenile justice & 173 & 9.8 & 474 & 16.6 & 647 & 14.0 \\
\hline Total & 1,771 & & 2,854 & & 4,625 & \\
\hline
\end{tabular}

This indicates that it is not just the child's contact with the Department of Families but children's maltreatment experience that impacts on their later offending behaviour. Unfortunately, very little information is available on the Department of Families database on the children who only have an unsubstantiated maltreatment notification. Earlier analyses 
have indicated that the age of the child at first notification and the child's indigenous status both impact significantly on the child's likelihood of the notification being substantiated (Section 5.1.2). No further analyses were performed examining children who only had unsubstantiated notifications.

To examine if the likelihood of a child's offending could be predicted from their substantiated child protection history a direct logistic regression was performed. One hundred and sixty children had missing data on indigenous status leaving 2,694 children available for analysis. Of these children 474 (17\%) went on to offend and 2,380 (83\%) did not offend. The 11 predictor variables included sex of the child (male/female), indigenous status of the child (indigenous/non-indigenous), age of the child at first notification, age at first maltreatment incident, age at final maltreatment incident, number of notifications, number of maltreatment incidents, substantiated incidents for emotional, physical, sexual abuse and neglect (yes/no), and out of home placement (yes/no). Two additional variables were examined, these being the age category of the child (Thornberry et al, 2001) and the classification of the child's most serious maltreatment (Cicchetti \& Rogosh, 1997). Neither of these variables was significant in the multivariate analysis. As ages at final substantiation and the presence or absence of each maltreatment type are more precise measures of the child's maltreatment experience, these variables will be interpreted instead.

A test of the full model with all 11 predictors against a constant only model was statistically reliable, $\left.\chi^{2}(11, N=2,694)=394.47, p<.001\right)$ indicating that all the predictors, as a set, distinguished between offenders and non-offenders. However, the variance in offending account for was small (Cox and Snell $R^{2}=.14$ ) and classification accuracy was $84 \%$. 
Table 5.24 shows the regression coefficients, Wald statistics, odds ratios and 95\% confidence limits for each of the 11 predictors. According to the Wald criterion, sex of the child, indigenous status, timing of maltreatment, number of notifications, experience of neglect and physical abuse and out of home placement all significantly contributed to predicting offending status.

Table 5.24

Logistic regression analysis of offending status as a function of child protection notifications.

\begin{tabular}{|c|c|c|c|c|c|c|c|}
\hline & \multirow[t]{2}{*}{$\mathrm{B}$} & \multirow[t]{2}{*}{ S.E. } & \multirow[t]{2}{*}{ Wald } & \multirow[t]{2}{*}{$\mathrm{df}$} & \multirow[t]{2}{*}{$\begin{array}{l}\text { odds } \\
\text { ratio }\end{array}$} & \multicolumn{2}{|c|}{$\begin{array}{l}95 \% \text { CI for odds } \\
\text { ratio }\end{array}$} \\
\hline & & & & & & Lower & Upper \\
\hline sex & 1.14 & .12 & $87.70 * * *$ & 1 & 3.13 & 2.46 & 3.97 \\
\hline indigenous status & 1.44 & .13 & $114.33^{* * *}$ & 1 & 4.21 & 3.23 & 5.47 \\
\hline age at first incident & -.01 & .02 & .14 & 1 & .99 & .94 & 1.04 \\
\hline age at last incident & -.07 & .02 & $11.69 * * *$ & 1 & .92 & .87 & .96 \\
\hline emotional abuse & .07 & .17 & .18 & 1 & 1.07 & .77 & 1.50 \\
\hline neglect & .38 & .17 & $4.77 *$ & 1 & 1.46 & 1.04 & 2.06 \\
\hline physical abuse & .53 & .16 & $10.26 * * *$ & 1 & 1.70 & 1.23 & 2.35 \\
\hline sexual abuse & -.14 & .18 & .61 & 1 & .87 & .60 & 1.24 \\
\hline number of notifications & -.15 & .04 & $13.98 * * *$ & 1 & .86 & .80 & .93 \\
\hline out of home placement & .40 & .12 & $10.51 * * *$ & 1 & 1.49 & 1.17 & 1.89 \\
\hline number of incidents & .13 & .07 & 3.15 & 1 & 1.14 & .99 & 1.31 \\
\hline Constant & .34 & .47 & .51 & 1 & 1.40 & & \\
\hline
\end{tabular}

Using the Wald criteria indigenous status among the maltreated children was the most significant in determining whether or not a maltreated child would offend. Maltreated indigenous children were 4.3 times more likely to subsequently offend than non-indigenous children with $42 \%$ of indigenous children offending compared with $14 \%$ of non-indigenous maltreated children. Of male maltreated children, 25\% subsequently offended whereas only $11 \%$ of the female maltreated children offended. When the age of the maltreated child was examined only the age of the final substantiated maltreatment was significant in determining whether the maltreated child would subsequently offend. At the final maltreatment incident 
the mean age of children who offended was 10.6 years $(S D=4.0)$ compared to 8.6 years $(S D$ $=4.4)$ for maltreated children who did not offend. Therefore those children whose maltreatment extended into or occurred in adolescence were more likely to offend than children whose maltreatment was confined to childhood. This finding conforms with Thornberry et al (2001) findings that children who were only maltreated in childhood were less likely to offend than children who were only maltreated in adolescence or had maltreatment that continued into adolescence. Additionally, maltreated children who offended had more notifications ( $M=5.5$ notifications, $S D=3.0$ ), but not necessarily more substantiated notifications, than maltreated children who did not subsequently offend $(M=$ 2.4 notification, $S D=2.3$ ).

The type of maltreatment a child was victim of also was significantly related to the likelihood of the child offending. Children who were the victims of either physical abuse or neglect were more likely to offend than children who had not been the victims of these types of maltreatment. Twenty three percent of children who were the victims of physical abuse subsequently offended compared with $15 \%$ of children who were not the victims of physical abuse. Similarly, 23\% of maltreated children who were the victims of neglect subsequently offended compared with $14 \%$ of maltreated children who were not the victims of neglect.

Placement of the child outside his or her home influenced the likelihood of a child subsequently offending. Twenty six percent of maltreated children who were placed outside the home subsequently offended at least once, compared with $13 \%$ of children who were never placed outside the home. Whether the child was placed outside the home as a consequence of the maltreatment is likely to be indicative of the seriousness of the maltreatment. In the absence of a better measure of severity of maltreatment, the present 
finding suggests that the greater the severity of the maltreatment that greater the likelihood of subsequently committing a criminal offence.

\subsubsection{Retrospective question}

The previous analysis examined the experiences of maltreated children for information that would predict their likelihood of offending. This analysis examines offending children for differences in their offending behaviour between those who had been the victim of maltreatment and those children that had no recorded maltreatment experience. Of the 2,563 children who had a finalised juvenile justice appearance where an order was made 474 (18\%) had a substantiated child protection notification. A further 173 children had unsubstantiated notifications. After the 209 children who had missing data for indigenous status was removed the offending histories of children who were victims of child maltreatment $(\mathrm{N}=458)$ were compared with the histories of children who had not previous victimisation $(\mathrm{N}=1896)$.

To examine if the likelihood of a child being a victim of maltreatment could be predicted from their offending history a direct logistic regression was performed. The ten predictor variables included were sex of the child (male/female), indigenous status of the child (indigenous/non-indigenous), age of the child at first appearance for a finalised offence (< $14 / 14+$ ), number of appearances, appearances for personal property drug, good order, traffic offences, most serious outcome ever (detention/no detention).

A test of the full model with all ten predictors against a constant only model was statistically reliable, $\left.\chi^{2}(10, N=2,354)=211.54, p<.001\right)$ indicating that all the predictors, as a set, distinguish between children who had experienced maltreatment victims and children who 
had not reported maltreatment experience. The variance in maltreatment accounted for was small (Cox and Snell $R^{2}=.9$ ) and 81.6\% classification accuracy.

Table 5.25 shows the regression coefficients, Wald statistics, odds ratios and 95\% confidence limits for each of the ten predictors. Child protection victimisation was successfully predicted for sex, age of first appearance, property offending, traffic offending and number of finalised appearances.

Table 5.25

Logistic regression analysis of child protection status as a function of offending appearances.

\begin{tabular}{|c|c|c|c|c|c|c|}
\hline & \multirow[t]{2}{*}{ B } & \multirow[t]{2}{*}{ S.E. } & \multirow[t]{2}{*}{ Wald } & \multirow[t]{2}{*}{$\begin{array}{l}\text { odds } \\
\text { ratio }\end{array}$} & \multicolumn{2}{|c|}{$\begin{array}{l}\text { 95\% C.I. for odds } \\
\text { ratio }\end{array}$} \\
\hline & & & & & Lower & Upper \\
\hline$\overline{\operatorname{sex}}$ & 1.01 & 0.12 & $66.63 * * *$ & 2.75 & 2.16 & 3.50 \\
\hline age at first appearance & 0.43 & 0.16 & $7.25 * *$ & 1.53 & 1.12 & 2.09 \\
\hline indigenous status & 0.01 & 0.13 & 0.01 & 1.01 & 0.78 & 1.31 \\
\hline number of finalised offences & 0.12 & 0.03 & $13.44^{* * *}$ & 1.12 & 1.06 & 1.20 \\
\hline personal offending & 0.17 & 0.14 & 1.34 & 1.18 & 0.89 & 1.57 \\
\hline property offending & 0.51 & 0.15 & $11.07 * * *$ & 1.67 & 1.23 & 2.25 \\
\hline drug offending & 0.13 & 0.14 & 0.82 & 1.14 & 0.86 & 1.51 \\
\hline good order offences & 0.11 & 0.14 & 0.68 & 1.12 & 0.86 & 1.46 \\
\hline traffic offences & 0.44 & 0.19 & $5.39 *$ & 1.55 & 1.07 & 2.24 \\
\hline child sentenced to detention & 0.06 & 0.22 & 0.07 & 1.06 & 0.69 & 1.62 \\
\hline Constant & -2.97 & 0.47 & 4.32 & 0.05 & & \\
\hline
\end{tabular}

$* * * p<.001, * * p<.01 * p<05$

Girls who offend are more likely to have a child protection history (30\%) than boys who offend (15\%). The pathway from child maltreatment to offending appears to be more characteristic of girls' behaviour than boys' behaviour. Children who appear in the juvenile courts under the age of 14 are more likely (36\%) to have a child protection history than children who have their first appearance over the age of 14 (16\%). Offending children who have child protection histories have more appearances $(M=3.99, S D=3.91)$ than offending 
children who do not have child protection histories $(M=2.34, S D=2.34)$. Children with child protection histories are more likely to commit property offences (77\%) than children who had no child protection history (59\%). Conversely, children a child protection history are less likely to commit traffic offences (11\%) than children with no child protection history $(17 \%)$.

\subsection{The pathways from child maltreatment to offending}

The final analysis was conducted to examine the links between type of maltreatment, severity of maltreatment, frequency of maltreatment and type of offending, severity of offending and frequency of offending. Only children who had both a child protection history and finalised juvenile justice appearances could be included in these analyses $(N=486$ children). A further 16 children were excluded because of missing data on the indigenous status variable. The sex and the indigenous status of the remaining 470 children are presented in Table 5.26.

\section{Table 5.26}

Children who offended and had a child protection history by sex and indigenous status

\begin{tabular}{lrrrrrr}
\hline & \multicolumn{9}{c}{ Indigenous status } & \multicolumn{3}{c}{ Total } \\
\cline { 2 - 7 } & \multicolumn{2}{c}{ Non-indigenous } & \multicolumn{2}{c}{ Indigenous } & \multicolumn{1}{c}{$\%$} \\
\cline { 2 - 7 } & $n$ & $\%$ & $n$ & $\%$ & $n$ & 65.5 \\
Sale & 224 & 70.2 & 84 & 55.6 & 308 & 34.5 \\
Female & 95 & 29.8 & 67 & 44.4 & 162 & 100.0 \\
\hline Total & 319 & 100.0 & 151 & 100.0 & 470 & \\
\hline
\end{tabular}

A canonical correlation was performed between the set of child protection variables and the set of offending variables. Canonical Correlation is a statistical techniques used to analyse the correlation between a set of independent variables and a set of dependent variables. It is a descriptive rather than a hypothesis-testing procedure. The independent variables included 
the child protection variables; age at first maltreatment incident, age at final maltreatment incident, number of notifications, number of sexual, physical, emotional abuse, and neglect incidents, and number of out of home placements. The dependent variables included the offending variables; age of first appearance, number of appearances for personal, property, drug, good order traffic, number of time child served a period of detention. Data relating to the number of maltreatment incidents and number of offending appearances were severely positively skewed and were consequently transformed using an inverse transformation.

Sex and indigenous status were known to be powerful predictors of both the type of maltreatment victimisation and the offending behaviour of young people. It was anticipated that the relationships between child maltreatment victimisation and offending behaviour would be different for each of the four sex/indigenous status groups. Consequently four separate analyses were carried out for each of the four groups of children (male/nonindigenous, male /indigenous female/non-indigenous female/indigenous).

All four analyses were non-significant. For children who were maltreated and went on to offend there was no relationship between the type of and severity of the maltreatment and the type and severity of later offending behaviour. As shown in earlier sections the type and severity of the maltreatment does predict the likelihood of the child offending. Furthermore, offending behaviour differs between children who have been maltreated and children who have not been maltreated. However, the type and severity of the maltreatment victimisation experienced by the child does not predict the type of or severity of the offending behaviour. 


\section{CHAPTER 6: DISCUSSION}

The purpose of this research was to examine the risk factor of child maltreatment and the effect maltreatment has on juvenile offending activity. This research extends what is known about the association between maltreatment and juvenile offending by examining the effect of the timing, accumulation and type of maltreatment on the onset and persistence of offending. Some important findings emerged from the data. The hypothesis that maltreated children would be more likely to have finalised court appearances than children who were not maltreated was supported. The hypothesis that repeated victimisation increases the likelihood of juvenile offending was also supported, as was the hypothesis that the later the age of final maltreatment incident the more likely the child was to engage in juvenile offending. Furthermore, we found that maltreatment appeared to accelerate the age at which offending began. The hypothesis that children with child protection histories would have more serious offending careers than children with no child protection histories was also supported. The gender of the child, indigenous status and type of maltreatment and offending also played an important role in the links between maltreatment and juvenile offending. The results are discussed below in relation to young people's experiences with maltreatment, engagement in juvenile offending, and possible pathways from maltreatment to offending.

\subsection{Experiences of maltreatment}

An aim of the research was to examine the nature and frequency of individual children's experiences with the child protection and juvenile justice systems. Although many studies have examined the link between child maltreatment and juvenile offending, few studies have 
reported in any depth the actual maltreatment experiences of children. Of particular interest was determining who the children are that experience maltreatment, children's experiences of a single account of maltreatment versus repeat victimisation, and children's experiences with various types of maltreatment. We were also interested in whether the type of maltreatment and frequency of maltreatment was related to the age period in which the maltreatment took place.

\subsubsection{Single versus repeat victimisation}

Of all children born in Queensland in 1983, almost 10\% received child protection notifications. Only a small number of children had five or more maltreatment incidents (4\%) and yet these children accounted for a relatively large proportion of all maltreatment incidents (22\%). This means that almost a quarter of the workload of child protection services is being taken up by a small percentage of children. This finding points to the need for effective interventions to prevent repeat victimisation but also has implications for the later adjustment of children who have been repeatedly maltreated.

Children who experienced multiple types of maltreatment were youngest at age of first maltreatment incident, compared with children with multiple maltreatment incidents but only one form of maltreatment, with both groups being younger than children with one maltreatment incidents and one maltreatment type. Therefore children who were youngest when first victims of maltreatment were more likely to be repeatedly victimised. The majority of children who were victims of persistent maltreatment (childhood and adolescence) experienced multiple forms of maltreatment. Clearly interventions that take place 
immediately after the first incident of maltreatment are necessary to prevent a continuation of maltreatment that seems likely to take place for these young individuals.

\subsubsection{Indigenous status}

Indigenous children were over-represented in maltreatment notifications. This finding is consistent with Alfaro's (1981) finding that minority groups are over-represented in terms of children with histories of abuse and neglect. Differences also existed between indigenous and non-indigenous children and adolescents according to the timing of maltreatment. Indigenous youths were more likely to receive notifications of maltreatment in both childhood and adolescence than non-indigenous youths. They were also more likely to have multiple notifications and experience multiple forms of maltreatment compared with non-indigenous children. Indigenous children were almost twice as likely as non-indigenous children to be victims of neglect, whereas they were less likely to be victims of emotional and sexual abuse and had similar occurrences of physical abuse.

Whether the above findings mean indigenous children are at greater risk of maltreatment or simply that they are more likely to come to the attention of the Department of Families is not known. Brown (1984) suggested that official data over-represents those with low SES because of bias in agency activity. Given the social inequalities that exist for many indigenous families higher maltreatment notifications may be more a function of increased attention by protective services rather than higher maltreatment levels. This finding requires further investigation such that the root causes of the problem may be addressed. Homel, Lincoln \& Herd (1999, p. 184) argue that “we cannot understand...the relevant developmental pathways in indigenous communities, unless we also appreciate the impact on 
indigenous people of such experiences as forced removals and institutionalised racism, as well as the ongoing protection provided by such features as strong social bonds to family”. 


\subsubsection{Type of maltreatment}

Across all children the most common forms of maltreatment were neglect and physical abuse. For children who experienced one type of maltreatment, this was more likely to consist of neglect or physical abuse, although sexual and emotional abuses were also represented. Children who were repeatedly maltreated were more likely to experience multiple forms of maltreatment, although for those children who experienced multiple incidents with one form of maltreatment this was more likely be neglect. Boys were more likely than girls to be victims of physical abuse and neglect, whereas girls were more likely to be victims of sexual abuse than boys. The experience of emotional neglect was similar for males and females.

Children who were victims of sexual abuse or neglect were younger at age of first notification compared with other children who were the victims of other maltreatment types. In terms of the timing of maltreatment, children who experienced maltreatment in early childhood-only were more likely to be victims of neglect. Children who experienced maltreatment in late childhood-only were almost equally likely to be victims of physical abuse, sexual abuse or neglect. Young people who experienced maltreatment in adolescenceonly were more likely to be victims of physical abuse than any other form of maltreatment. Those children who experienced persistent maltreatment (childhood and adolescence) were more likely to be victims of neglect, followed by physical abuse. This finding indicates that the type of maltreatment experienced is related to the timing in which maltreatment occurs. Therefore when examining the relationship between the timing of maltreatment and juvenile offending it is also necessary to consider the type of maltreatment that occurred. Furthermore, programs that provide support and interventions for maltreated youths may consider the type of maltreatment that is more likely to occur in various life phases. 


\subsubsection{Out of home placements}

Children with out of home placements had significantly more maltreatment incidents than children who had never been placed outside the home. Furthermore, almost two thirds of children who had experienced multiple types of maltreatment had at least one out of home placement, compared with less than a third of children who had only one experience of abuse. It is likely that out of home placements reflect more severe forms of maltreatment. Children who were placed outside the home were significantly older at age of first notification, and were more likely to have been victims of adolescent-only or persistent maltreatment than childhood-only maltreatment. There were no differences between out of home placements according to the sex of the child. However, indigenous children were more likely to be placed outside the home than non-indigenous children, a finding which is likely to be associated with evidence that indigenous children were more likely to be victims of persistent maltreatment, with a greater likelihood of receiving multiple notifications and multiple forms of maltreatment. It is important to determine the consequences of out of home placements, such as whether children had further notifications or went on to offend. It is not known whether out of home placements provide protective mechanisms for maltreated children or whether being removed from the home produces a further risk factor.

\subsection{Engagement in offending}

Another aim was to examine the juvenile offence experiences of children, in terms of who the children are with juvenile justice convictions, the age of first finalised appearance, the frequency of offending and the type of offences committed. Furthermore, some research has 
suggested that specific types of maltreatment, such as physical abuse, may be related to specific forms of offending in adolescence, such as violent offending. The analysis of finalised appearances also sought to determine whether there was any evidence of offence specialisation in this birth cohort.

\subsubsection{Frequency and Outcomes of Offending}

As well as being over-represented in maltreatment notifications, indigenous youths were also over-represented in the juvenile justice system. This finding is consistent with the literature (Wundersitz, 1996). Also not surprisingly, males accounted for the majority of appearances in court, which is consistent with general offending patterns. When taking into account both indigenous status and sex we found that there were more indigenous females with finalised appearances in court compared with non-indigenous females.

Half of the children with offence records had only one finalised appearance. Less than $20 \%$ of children had four or more finalised appearances, yet these children accounted for approximately half of all finalised appearances. This finding indicates that there is a group of adolescents who are repeat offenders. One important finding in terms of age of onset of juvenile offending and the criminal careers perspective is that children who had their first finalised appearance before the age of 14 had more extensive offending histories that children whose first offence took place after the age of 14 . This finding held true regardless of the sex of the child.

The likelihood of being placed in detention increased with the number of finalised appearances before the courts, indicating that children receive more serious court outcomes 
as they have more contact with the juvenile justice system. The age of first finalised appearance was associated with the most serious court order received by the child. Children who made their first appearance before the age of 14 were more likely to be sentenced to detention than children who made their first court appearance after the age of 14 . This pattern is probably due to the greater number of appearances before the courts for children who first appeared before the age of 14 .

Indigenous children were more likely than non-indigenous children to have a serious sentence (including detention) as their most serious outcome, which is not surprising given that indigenous children were more likely to make more finalised appearances before the courts than non-indigenous children. It appears that young offenders, both indigenous and nonindigenous, are not being adequately deterred from committing further offences. There is clearly a greater need for intervention early in the criminal career. While it is not known how far the criminal activities will extend into adulthood, if Moffitt's (1993) theory of life-course persistent offending holds true, there are likely to be a small group of offenders who continue to offend well past adolescence. Standard law and order interventions are not sufficient in addressing the aetiology of life-course persistent criminal behaviour. Programs that introduce protective factors and promote opportunities for pathways with more positive outcomes are required.

\subsubsection{Offence types}

Property offences were the most common form of the most serious finalised offence for children with one finalised appearance and children with multiple offences for the same offence. The majority of youths with multiple finalised appearances had various offence type 
combinations, with the most common combination being that of property and good order offences. There were various combinations of offence types, with no evidence that offence specialisation existed in the criminal careers of the youths.

\subsection{Links Between Maltreatment and Offending}

The second major aim was to look at the relationship between child maltreatment and juvenile offending. Based on previous research, it was hypothesised that maltreated children would be significantly more likely to have a juvenile justice record than children for whom there was no evidence of maltreatment. Using a prospective design this hypothesis was supported, with significantly more children with at least one substantiated notification offending in adolescence compared with children who had no substantiated notifications. While both these groups of children had contact with the child protection system, it was the experience of maltreatment rather than the contact itself that increased the likelihood of them committing later offences. In fact, the results were remarkably similar to that of previous research. In the present study $17 \%$ of the maltreated group went on to offend, compared with $16 \%$ in a study by Bolton et al (1977) and 19\% in Alfaro’s (1981) research. Similarly, 8\% of the non-maltreated group went on to offend in both the present study and that by Bolton et al (1977). The results for non-maltreated children are also consistent with the findings of McCord (1983), Widom (1989) and Thornberry and Smith (1995), although a greater percentage of maltreated children in the latter two studies went on to offend.

When examining what aspects of children's maltreatment experiences predicted finalised appearances in the courts, we found that the gender of the child, indigenous status, timing of maltreatment, number of notifications, experience of neglect and physical abuse, and out of 
home placements significantly contributed to predicting offence status. In particular, males were more likely to offend than females and indigenous children were more likely than nonindigenous children to offend. This finding is consistent with Widom (1989) who reported that the maltreated group with the highest risk of offending were black males.

In terms of the timing of maltreatment, the age of final maltreatment incident contributed significantly to predicting the likelihood of offending. Children whose final maltreatment incident occurred in adolescence were more likely to offend than children whose maltreatment did not extend past childhood. This supports our third hypothesis and the findings of Thornberry et al (2001) who reported that maltreatment that occurred in adolescence or both childhood and adolescence was associated with a greater likelihood of adolescent offending than children who were victims of maltreatment in childhood but not adolescence. This is an important finding as the results of Thornberry et al's (2001) were based on a very small sample size and was the first study of its kind to explore the impact of timing in this way. The results have important implications for crime prevention interventions, as there is now growing evidence that maltreatment in adolescence can be more damaging for offending outcomes than early maltreatment. Thus interventions need to focus on maltreated adolescents as well as children, and it is possible that what is required for successful interventions for adolescents will differ to that which is required for children. Clearly there is need for more focused attention on the impact that timing of maltreatment has on delinquent and offending outcomes.

A greater number of maltreatment incidents were associated with an increased likelihood of having a finalised court appearance. Therefore repeat victimisation appears to pave the way for a greater likelihood of juvenile offending. This is consistent with Marshall and Watt's (1999) suggestion that the number of risk factors a child has may be more predictive of later 
problems than any specific risk factor. Therefore with each experience of maltreatment the child is likely exposed to a number of risk factors (e.g., the maltreatment itself, poor parental discipline or supervision) that continue to accumulate over time. These risk factors may then lead to the onset of further risk factors. For example, child maltreatment may lead to withdrawal at school, leading to poor academic performance and eventually school failure, which may further increase the risk of delinquency (Developmental Crime Prevention Consortium, 1999).

Some forms of maltreatment were more closely associated with offending than others. Specifically, children who were neglected or physically abused were more likely to offend than children who had not been victims of these types of maltreatment. Weatherburn and Lind (1997) and Zingraff et al (1994) also reported a significant association between neglect and delinquency, although a link between physical abuse and delinquency has been somewhat more tenuous (e.g., Brown, 1984; Weatherburn \& Lind, 1997; Zingraff et al, 1994). Although, it should be noted that Widom and Ames (1994) found no differences between physically abused, sexual abused and neglected groups for likelihood of arrest, except for arrests for running away. Consistent with previous findings (Widom \& Ames, 1994; Zingraff et al, 1994) and in contrast to some speculations, children who were sexually abused were at no more risk of later offending than children with other forms of maltreatment.

Responses to maltreatment were also associated with offending, with children with at least one out of home placement being twice as more likely to go on to offend than children who had never been placed out of home. As stated previously, out of home placements are likely to reflect severe cases of maltreatment or a seriously inadequate home environment. It is 
therefore likely that the association between offending and out of home placements is being driven by the experiences of serious maltreatment. Therefore children who have experienced more serious forms of maltreatment appear more likely to offend in adolescence. This association needs to be further explored using a better measure of severity in order to determine the validity of this finding.

When the data was examined retrospectively, we found that of all children in the birth cohort with a finalised juvenile justice appearance, almost a quarter of them had a substantiated child protection notification. Thus the magnitude of the relationship between maltreatment and offending was higher when using the retrospective design than when using a prospective design, as noted previously by Widom (1994). Therefore the strength of the relationship may be over-estimated when using retrospective designs, meaning findings based on retrospective designs should be interpreted with caution.

When using demographic information and offence histories to predict previous child maltreatment, the sex of the child, age at first finalised appearance, property and traffic offending and the number of finalised appearances significantly contributed to predicting earlier maltreatment. Girls who offended were approximately twice as likely to have a child protection history than boys. Children with convictions for property offences were twice as likely to have a child protection history than children without property offences, whereas children with traffic offences were less likely to have been victims of maltreatment compared with children with no traffic offences. Children with child protection histories had their first finalised appearance at a younger age than children without evidence of maltreatment. This finding supports Moffitt's (1993) hypothesis that children with early negative experiences will begin offending early than other children. Children without early negative experiences 
are thought to offend in late adolescence, more due to delinquent peer influences than higher levels of anti-social behaviour (Moffitt, 1997). Children with child protection histories also had more finalised appearances than children who were not maltreated. The above findings support the final hypothesis that children with child protection histories have more serious offending careers than children with no child protection histories.

\subsection{Pathways From Maltreatment to Offending}

The third aim was to examine pathways from child maltreatment to juvenile offending. Did the timing, frequency and type of maltreatment produce different outcomes in terms of subsequent offending? The pathways from child maltreatment to juvenile offending were examined for those children with both child protection records and juvenile offence records. No significant relationship could be identified between the nature of maltreatment experiences and offence behaviour. This is not to say that no significant pathways exists between maltreatment and offending, but rather a canonical correlation may not be the best statistical procedure to identify pathways to offending. A trajectory analysis may be the most appropriate method of elucidating any significant pathways, however at the time of analysis this procedure was not available. The potential appropriateness of this procedure is described in the subsequent section.

\subsection{Limitations and Further Research}

This report compares children with substantiated maltreatment notifications with children whose maltreatment notifications were not substantiated. It is not known how these two groups of children differ from children who have never come into contact with the child 
protection system. Furthermore, maltreatment is based on notifications that came to the attention of the Department of Families and were subsequently substantiated. This is unlikely to provide a representative account of the rate of maltreatment in the general community, or the severity of that maltreatment given that more serious cases are likely to come to the attention of official agencies (Widom, 1989). Data that is based on official reports only is also likely to significantly underestimate the true level of child maltreatment and juvenile offending. The limitations of the data set should be considered when attempting to extrapolate results to the existence of maltreatment and juvenile offending in society.

The type of data collected from the Department of Families also limits our analyses. There are a number of variables that have been correlated with juvenile offending in the past, such as poor parental discipline, single parent households, teenage mothers and SES. However, none of these variables have been recorded by the Department, therefore our study cannot include all those risk factors that may be prevalent in pathways to offending. However, we can surmise that maltreatment is fairly indicative of poor parenting practices and environmental stresses, so our data may indirectly tap into these risk factors.

There were a number of significant relationships identified between maltreatment and offending. However, the patterns from one maltreatment notification to the other, along with first and subsequent offences, incorporating type of maltreatment and type of offending, as well as the impact of gender and indigenous status, need to be understood.

An issue that also needs to be addressed is the effect of protective custody on subsequent outcomes for children. In the present study children who were placed out of home had more substantiated notifications, although it was not determined how many of these took place 
after placement. For some children out of home placements may have a positive effect, for other children it may create a further risk factor for delinquency. It is important that we develop a better understanding of what works, when it works, and for what children if developmental crime prevention strategies are going to have optimal effect. In short, it is the dynamics leading to offending that we are trying to identify. Ascertaining these dynamics will help augment the future success of development crime prevention initiatives. This raises a methodological consideration regarding the statistical method used to examine pathways from maltreatment to offending in this study. A trajectory analysis would likely provide a measure of the dynamic sequence of pathways from maltreatment to offending. A semiparametric group-based approach methodology identifies whether there are distinct clusters of trajectories within a population (Nagin, 1999). For example, this methodology can determine whether particular maltreatment experiences lead to distinct developmental trajectories. In the case of the present study, we are interested in whether frequency, type and severity of maltreatment differentially impacts on later juvenile offending, such that there are distinctive offending trajectories.

The group-based approach tests the probability of group membership based on individual characteristics, such as maltreatment history, enables us to determine the optimal number of distinct trajectories that best fit the data, and also allows us to determine whether specific aspects of child maltreatment are related to early versus late onset of juvenile offending. Although this form of analysis is relatively new, it is gaining in usage in the investigation of developmental trajectories (see, for example, Brame, Nagin \& Tremblay, 2001; McDermott \& Nagin, 2001; Nagin \& Tremblay, 1999; White, Bates \& Byske, 2001) and is increasingly being viewed as a legitimate statistical procedure, even if the view is not yet widespread. The next stage of this research will apply a trajectory analysis to the data set. 


\subsection{Conclusions}

From this data, we can make some preliminary conclusions that children with more maltreatment are more likely to offend in adolescence, are more likely to offend at a younger age, and are likely to offend more often. Young people whose final maltreatment occurs in adolescence are at greater risk for offending than children whose maltreatment does not extend beyond childhood. Children with more maltreatment incidents are also more likely to receive out of home placements than those children with no evidence of maltreatment. There is also a small group of children being repeatedly victimised and a small group of children repeatedly offending. It is not known whether these are the same children in both groups. Further examination using trajectory analysis may assist in tracking these clusters of children.

The results of this research have implications for the life-course persistent versus adolescent limited theory of juvenile offending. The experience of maltreatment seems to accelerate the age at which offending first begins. Whether or not these children then go on to offend in adulthood is not known at this stage. At any rate, the data needs to be looked at more comprehensively to look at the time of maltreatment and timing and duration of offending to begin to draw any firm conclusions. The potential consequences of decisions made in the child protection and juvenile justice systems regarding protective care and detention on subsequent outcomes for the children needs to be further examined. Research may inform strategies for reducing ongoing risk factors and providing the kind of support that may buffer the child from continuing along a pathway to offending. 
Similarly, other attempts to counteract the effect that risk factors such as maltreatment or poor parental discipline may have on later offending include the introduction of protective factors in early childhood. Many of these projects have demonstrated positive results by providing, for example, better education for children and teaching child-rearing techniques to parents, particularly young single mothers. In fact, Weatherburn and Lind (2001, p.177-178) recently suggested that "investments in childcare and parental support programs...are almost certainly of greater value that investments in systems for detecting and responding to parents who maltreat or neglect their children”. This is not to say that child maltreatment should not be responded to, but rather preventing child maltreatment in the first place may produce a larger reduction in the onset and persistence of offending.

Notwithstanding these suggestions, the results from this and other studies indicates that by also directing attention to those children who are maltreated and ensuring that the maltreatment is not repeated, such initiatives will also have significant benefits in crime reduction and the outcomes for these children. However, better information on the sequence of events, the extent of abuse and neglect, as well as the type of later offending, would help direct crime prevention approaches to transition points in the child's life or clusters of risk factors such that greater success might be achieved. It is anticipated that further analysis with the present data will make a significant contribution to these important endeavours. 


\section{REFERENCES}

Agnew, R. (1992). Foundation for a general strain theory of crime and delinquency. Criminology, 5, 373-387.

Agnew, R. (1993). Why do they do it? An examination of the intervening mechanisms between "social control" variables and delinquency. Journal of Research in Crime and Delinquency, 30 (3), pp 245 - 266.

Alfaro, J. (1981). Report on the relationship between child abuse and neglect and later socially deviant behaviour. In R. Hunner., \&Y. Walker. (Eds). Exploring the Relationship between Child Abuse and Delinquency. Montclair NJ: Allanheld, Osmun \& Co. Publishers (p175 - 219).

Australian Bureau of Statistics. (1984a - 2001a). Population by age and sex (No. 3201.0). Canberra, Australian Capital Territory: Author

Australian Bureau of Statistics. (1984b - 2001b). Demography Queensland (No. 3311.3). Canberra, Australian Capital Territory: Author

Australian Bureau of Statistics. (1984c - 2001c). Deaths Australia (No. 3302.0). Canberra, Australian Capital Territory: Author

Australian Bureau of Statistics. (1997d). Australian Standard Offence Classification. Canberra, Australian Capital Territory: Author

Australian Bureau of Statistics. (1998d). Population: Special Article - Experimental estimates of the Torres Strait Islander population. Year Book Australia 1998. Canberra, Australian Capital Territory: Author

Bandura, A. (1973). Aggression: A Social Learning Analysis. New Jersey: Prentice Hall. 
Barnes, G., \& Farrell, M. (1992). Parental support and control as predictors of adolescent drinking, delinquency and related problem behaviours. Journal of Marriage and the Family, 54, 763 - 776.

Barnett, D., Manly, J., \& Cicchetti, D. (1993). Defining child maltreatment: The interface between policy and research. In D. Cicchetti \& S. Toth (eds.), Child Abuse, Child Development, and Social Policy. Norwod, NJ: Ablex.

Bolton, F., Reich, J., \& Gutierres, S. (1977). Delinquency patterns in maltreated children and siblings. Victimology, 2, 349-357.

Brame, B., Nagin, D. S., \& Tremblay, R. E. (2001). Developmental trajectories of physical aggression from school entry to late adolescence. Journal of Child Psychology and Psychiatry, 42 (4), 503 - 512.

Brown, S. (1984). Social class, child maltreatment, and delinquent behavior. Criminology, 22 (2), $259-278$.

Child Protection Act, 1999, (QLD)

Children Services Act, 1965, (QLD)

Cicchetti, D., \& Rogosch, F. (2001). The impact of child maltreatment and psychopathology on neuroendocrine functioning. Development and Psychopathology, 13, $783-804$.

Cicchetti, D., Toth, S., \& Bush, M. (1988). Developmental psychopathology and incompetence in childhood: Suggestions for intervention. In B Lahey, \& A. Kazdin (eds.), Advances in Clinical Child Psychology, 11, 1-77.

Crouch, J., \& Milner, J. (1993). Effects of child neglect on children. Criminal Justice and Behavior, 20 (1), $49-65$. 
Department of Families. (2001). Annual Report 1999 - 2000: Book 1. Brisbane, Queensland: Queensland Government Printer

Department of Families. (2002). Annual Report 2000 - 2001: Book 1. Brisbane, Queensland: Queensland Government Printer

Developmental Crime Prevention Consortium. (1999). Pathways to Prevention: Developmental and Early Intervention Approaches to Crime in Australia. Canberra: National Crime Prevention, Attorney - General’s Department.

Dodge, K., Bates, J., \& Pettit, G. (1990). Mechanisms in the cycle of violence. Science, 250, 1678-1683.

Eichelman, B. (1990). Neurochemical and pharmacologic aspects of aggressive behaviour. Annual Review of Medicine, 41, 149-158.

Families Youth and Community Care Queensland. (2000). Annual Report 1998 1999: Book 1. Brisbane, Queensland: Queensland Government Printer

Farrington, D. (1995). The development of offending and antisocial behaviour from childhood: Key findings from the Cambridge study in delinquent development. Journal of Child Psychology and Psychiatry, 36 (6), 929 - 964.

Galler, J., Ramsey, Solimano, G., \& Lowell, W. (1983). The influence of malnutrition on subsequent behavioral development. II. Classroom behavior. Journal of the American Academy of Child Psychiatry, 24, 16-22.

Garbarino, J. (1976). A preliminary study of some ecological correlates of child abuse: The impact of socio-economic stress on mothers. Child Development, $47,178-185$.

Garbarino, J., \& Guttmann, E. (1986). Characteristics of High Risk families: Parental and Adolescent Perspectives. In Garbarino, J., Schellenbach, C., \& Sebes, J. 
(Eds). Troubled Youth, Troubled Families. New York: Aldine Publishing (p121 - 150).

Garbarino, J., \& Plantz, M. (1986). Child Abuse and Juvenile delinquency: What are the links. In Garbarino, J., Schellenbach, C., \& Sebes, J. (Eds). Troubled Youth, Troubled Families. New York: Aldine Publishing (p27 - 40).

Halstead, B. (1992). Young people as victims of violence: A NYARS discussion paper. Hobart: National Clearinghouse for Youth Studies.

Hawkins, J., Catalano, R., Kosterman, R., Abbott, R., \& Hill, K. (1999). Preventing adolescent health-risk behaviors by strengthening protection during childhood. Archives of Pediatric Adolescent Medicine, 153, 226 - 234.

Hawkins, D., Catalano, R., Morrison, D., O’Donnell, J., Abbott, R., \& Day, L. (1992). The Seattle social development project: Effects of the first four years on protective factors and problem behaviours. In J. McCord, \& R. Tremblay (Eds). Preventing Antisocial Behaviour: interventions from birth through adolescence. New York: The Guilford Press.

Herrenkohl, R., \& Jean-Russo, M. (2001). Abusive early child rearing and early childhood aggression. Child Maltreatment, 6 (1), 3 - 16.

Higley, J., Melman, P., \& Taub, D. (1991). CSF monoamine and adrenal correlates of aggression in feral living rhesus monkeys. Biological Psychiatry, 29 (50A), 16.

Hirschi, T. (1969). Causes of Delinquency. Berkley: University of California Press.

Homel, R., Lincoln, R., \& Herd, B. (1999). Risk and resilience: Crime and violence prevention in aboriginal communities. The Australian and New Zealand Journal of Criminology, 32 (2), 182 - 196.

Juvenile Justice Act, 1992, (QLD) 
Kazdin, A. (1997). Conduct disorder across the lifespan. In S. Luthar, \& J. Burack, (Eds). Developmental Psychopathology: Perspectives on adjustment, risk, and disorder. New York: Cambridge University Press (p248 - 272).

Kruttschnitt, C., Ward, D., \& Sheble, M. (1987). Abuse-resistant youth: Some factors that may inhibit violent criminal behavior. Social Forces, 66 (2), 501-519.

Larzelere, R., \& Patterson, G. (1990). Parental management: mediator of the effect of socio-economic status on early delinquency. Criminology, 28 (2), pp 301 323.

Leiter, J., Myers, K., \& Zingraff, M. (1994). Substantiated and unsubstantiated cases of child maltreatment: Do their consequences differ? Social Work Research, 18, 67-82.

Loeber, R., \& Stouthamer-Loeber, M. (1996). The development of offending. Criminal Justice and Behavior, 23 (1), 12 - 24.

Manly, J. T., Kim, J., Rogosch, F., \& Cicchetti, D. (2001). Dimensions of child maltreatment and children's adjustment: Contributions of developmental timing and subtype. Development and Psychopathology, 13, 759 - 782.

Marshall, J., \& Watt, P. (1999). Child behavioural problems: A literature review of the size and nature of the problem and prevention interventions in childhood. Perth, Western Australia: The Interagency Committee on Children’s Futures, pp. $126-135$.

McGloin, J. .M., \& Widom, C. S. (2001). Resilience among abused and neglected children grown up. Development and Psychopathology. 13, 1021 - 1038.

McCord, J. (1983). A forty year perspective on effects of child abuse and neglect. Child Abuse and Neglect, 7, 265-270. 
McDermott, S., \& Nagin, D. S. (2001). Same or different? Comparing offender groups and covariates over time. Sociological methods and research, 29 (3), $282-318$.

Merton, R. (1938). Social structure and anomie. American Sociological Review, 3, 672-682.

Moffitt, T. (1993). Adolescent limited and life-course persistent antisocial behavior: A developmental taxonomy. Psychological Review, 100 (4), 674 - 701.

Moffitt, T. (1997). Adolescence-limited and life-course persistent offending: A complementary pair of developmental theories. In T. Thornberry (Ed.), Developmental Theories of Crime and Delinquency: Advances in Criminological Theory. Volume 7, pp. 11 - 54. New Jersey: Transaction Publishers.

Nagin, D. (1999). Analyzing developmental trajectories: A semiparametric, groupbased approach. Psychological Methods, 4 (2), 139 - 157.

Nagin, D. S., \& Tremblay, R. E. (1999). Trajectories of boy’s physical aggression, opposition, and hyperactivity on the path to physically violent and non-violent juvenile delinquency. Child Development, 70 (5), 1181 - 1196.

Olds, D. L. (1988). The prenatal / early infancy project. In R. Price., \& E. Cowen. (Eds). Fourteen ounces of prevention: a casebook for practitioners. Washington DC: American Psychological Association (p9 - 23).

Olds, D. L., Henderson, C. R., Kitzman, H. J., Eckenrode, J.J., Cole, R. E., \& Tatelbaum, R. C. (1999). Prenatal and infancy home visitation by nurses: Recent findings. Home Visiting: Recent Program Evaluations, 9 (1), 44 - 65.

Paternoster, R., \& Mazerolle, P. (1994). General strain theory and delinquency: A replication and extension. Journal of Research in Crime and Delinquency, 31 (3), $235-263$. 
Paterson, R., \& Moran, G. (1988). Attachment theory, personality development and psychotherapy. Clinical Psychology Review, 8, 611-636.

Patterson, G., Capaldi, D., \& Bank, L. (1991). An early starter model for predicting delinquency. In D. Pepler \& K. Rubin (eds.), The Development and Treatment of Childhood Aggression. Hillsdale, NJ: Lawrence Erlbaum.

Queensland Police Service. (2000). Annual Statistical Review 1999 - 2000. Brisbane, Queensland: Queensland Government Printer

Rutter, M. (1983). Stress, coping, and development: Some issues and some questions. In N. Garmezy \& M. Rutter (eds.), Stress, Coping and Development in Children (pp. 1-41). New York: McGraw-Hill.

Sampson, R., \& Laub, J. (1993). Crime in the making: Pathways and turning points through life. Cambridge, MA: Harvard University Press, pp. 243-257.

Schellenbach, C., \& Krejci, M. (1986). Methodological considerations in studying troubled youth and troubled families. In Garbarino, J., Schellenbach, C., \& Sebes, J. (Eds). Troubled Youth, Troubled Families. New York: Aldine Publishing (p57 - 82).

Simons, R., Wu, C., Conger, R., \& Lorenz, F. (1994). Two routes to delinquency: Differences between early and late starters in the impact of parenting and deviant peers. Criminology, 32 (2), 247 - 275.

Smith, C., \& Thornberry, T. (1995). The relationship between childhood maltreatment and adolescent involvement in delinquency. Criminology, 33 (4), 451 - 481.

Stouthamer-Loeber, M., Loeber, R., Homish, D. L., \& Wei, E. (2001). Maltreatment of boys and the development of disruptive and delinquent behavior. Development and Psychopathology, 13, 941 - 955. 
Thornberry, T., Ireland, T., \& Smith, C. (2001). The importance of timing: The varying impact of childhood and adolescent maltreatment on multiple problem outcomes. Development and Psychopathology, 13 (4), 957 - 979.

Tremblay, R., \& Craig, W. (1995). Developmental crime prevention. In M. Tonry, \& D. Farrington (Eds). Strategic approaches to crime prevention: Building a safer society. Chicago: The University of Chicago Press.

Vondra, J. (1990). Sociological and ecological facts. In R. Ammerman \& M. Hersen (eds.), Children at risk: an evaluation of factors contributing to child abuse and neglect. New York: Plenum.

Vondra, J. (1986). Socio-economic Stress and family Functioning in Adolescence. In Garbarino, J., Schellenbach, C., \& Sebes, J. (Eds). Troubled Youth, Troubled Families. New York: Aldine Publishing (p191 - 234).

Weatherburn, D., \& Lind, B. (1997). Social and Economic Stress, Child Neglect and Juvenile Delinquency. Sydney: New South Wales Bureau of Crime Statistics and Research.

Weatherburn, D., \& Lind, B. (2001). Delinquent-prone communities. Cambridge, UK: Cambridge University Press.

Weeks, R., \& Widom, C. S. (1998). Self-reports of early childhood victimisation among incarcerated adult male felons. Journal of Interpersonal Violence, 13 (3), $346-361$.

Weikart, D., \& Schweinhart, L. (1992). High/Scope pre-school program outcomes. In J. McCord, \& R. Tremblay (Eds). Preventing Antisocial Behavior; Interventions from birth through adolescence. New York: Guilford Press (pp. $67-86)$. 
Weiler, B. L., \& Widom, C. S. (1996). Psychopathy and violent behaviour in abused and neglected young adults. Criminal Behaviour and Mental Health, 6, 253 271.

White, H. R., Bates, M. E., \& Byske, S. (2001). Adolescence-limited versus persistent delinquency: Extending Moffitt's hypothesis into adulthood. Journal of Abnormal Psychology, 110 (4), 600 - 609.

Widom, C. S. (1989). Child abuse, neglect, and violent criminal behavior. Criminology, 27 (2), $251-271$.

Widom, C. S. (1994). Childhood Victimisation and Adolescent problem behaviours. In Ketterlinus, R., \& Lamb, M. (Eds). Adolescent Problem Behaviours: Issues and Research. New Jersey: Lawrence Erlbaum Associates (p127 - 164).

Widom, C. S., \& Ames, A. (1994). Criminal consequences of childhood sexual victimisation. Child Abuse and Neglect, 18 (4), 303 - 318.

Widom, C. S., \& Maxfield, M. (2001). An update on the 'Cycle of violence'. National Institute of Justice: Research in Brief, February 2001.

Wolfe, D., Wekerle, C., \& McGee, R. (1992). Developmental Disparities of abused children: Directions for prevention. In Peters, R., McMahon, R., \& Quinsey, V. (Eds). Aggression and Violence Throughout the Lifespan. Newbury Park: Sage Publications (p31 - 51).

Wundersitz, J. (1996). Juvenile justice. In K. M. Hazelhurst (Ed.). Crime and justice: An Australian textbook in criminology (pp. 113 - 149). Sydney: LBC.

Zingraff, M., Leiter, J., Johnsen, M., \& Myers, K. (1994). The mediating effect of good school performance on the maltreatment - delinquency relationship. Journal of Research in Crime and Delinquency, 31 (1), 62 - 91. 
Zingraff, M., Leiter, J., Myers, K., \& Johnsen, M. (1993). Child maltreatment and youthful problem behavior. Criminology, 31 (2), 173 - 202. 